\title{
Work outcome in musculoskeletal diseases
}

\author{
Citation for published version (APA):
}

van der Zee - Neuen, A. (2017). Work outcome in musculoskeletal diseases: the context of cross-cultural research, intervention and multimorbidity. [Doctoral Thesis, Maastricht University]. Maastricht University. https://doi.org/10.26481/dis.20170704avdzn

Document status and date:

Published: 01/01/2017

DOI:

10.26481/dis.20170704avdzn

Document Version:

Publisher's PDF, also known as Version of record

\section{Please check the document version of this publication:}

- A submitted manuscript is the version of the article upon submission and before peer-review. There can be important differences between the submitted version and the official published version of record.

People interested in the research are advised to contact the author for the final version of the publication, or visit the DOI to the publisher's website.

- The final author version and the galley proof are versions of the publication after peer review.

- The final published version features the final layout of the paper including the volume, issue and page numbers.

Link to publication

\footnotetext{
General rights rights.

- You may freely distribute the URL identifying the publication in the public portal. please follow below link for the End User Agreement:

www.umlib.nl/taverne-license

Take down policy

If you believe that this document breaches copyright please contact us at:

repository@maastrichtuniversity.nl

providing details and we will investigate your claim.
}

Copyright and moral rights for the publications made accessible in the public portal are retained by the authors and/or other copyright owners and it is a condition of accessing publications that users recognise and abide by the legal requirements associated with these

- Users may download and print one copy of any publication from the public portal for the purpose of private study or research.

- You may not further distribute the material or use it for any profit-making activity or commercial gain

If the publication is distributed under the terms of Article $25 \mathrm{fa}$ of the Dutch Copyright Act, indicated by the "Taverne" license above, 
Work outcome in musculoskeletal diseases

The context of cross-cultural research, intervention and multimorbidity 
(C) Antje van der Zee-Neuen, Maastricht 2017

No part of this book may be reproduced or transmitted in any form or by any means, without prior permission in writing by the author, or when appropriate, by the publishers of the publications.

Layout: $\quad$ Tiny Wouters

Cover design: Joop Vugs

Production: Gildeprint

ISBN: 978-94-6233-657-5 


\title{
Work outcome in musculoskeletal diseases
}

\author{
The context of cross-cultural research, \\ intervention and multimorbidity
}

\begin{abstract}
PROEFSCHRIFT
ter verkrijging van de graad van doctor aan de Universiteit Maastricht, op gezag van de Rector Magnificus, Prof. dr. Rianne M. Letschert, volgens het besluit van het College van Decanen, in het openbaar te verdedigen op dinsdag 4 juli 2017 om 14.00 uur
\end{abstract}

door

Antje van der Zee-Neuen 


\section{Promotoren}

Prof. dr. A.E.R.C.H. Boonen

Prof. dr. J.M.J.P. van der Linden

Prof. dr. R.A. de Bie

\section{Beoordelingscommissie}

Prof. dr. IJ. Kant, (voorzitter)

Dr. J.W.L. Cals

Dr. J.L. Hoving, Academisch Medisch Centrum Amsterdam - UWV -VU Medisch Centrum Amsterdam

Prof. dr. W.F. Lems VU Medisch Centrum Amsterdam

Prof. dr. G.M. Rommers 
For Martijn \& Finley,

my place for inspiration, contemplation, reflection and enrichment of the mind.

And for my parents, the fundament on which I may build. 



\section{Contents}

Chapter 1 General introduction 9

Part I Health and work outcomes of musculoskeletal diseases in the 21 context of multimorbidity

Chapter 2 Impact of chronic diseases and multimorbidity on health and

healthcare costs: the additional role of musculoskeletal disorders

Chapter 3 Work outcome in persons with musculoskeletal diseases:

comparison with other chronic diseases and the role of musculoskeletal diseases in multimorbidity

Part II Early intervention to improve work outcome of patients with musculoskeletal diseases

Chapter 4 Effects and costs of an intensive return to work program for patients with recent sick leave due to musculoskeletal disorders

Part III Influence of country of residence on work outcomes and validity of presenteeism measures in patients with rheumatoid arthritis

Chapter 5 Large country differences in work outcomes in patients with RA

- an analysis in the multinational study COMORA

Chapter 6 Content validity of global measures for at-work productivity in patients with rheumatic diseases: an international qualitative study

Chapter 7 Test-retest Reliability and Correlations of 5 Global Measures

Addressing At-work Productivity Loss in Patients with

Rheumatic Diseases

Chapter 8 Summary

Chapter 9 General discussion

Nederlandse samenvatting

Curriculum Vitae

Publications 



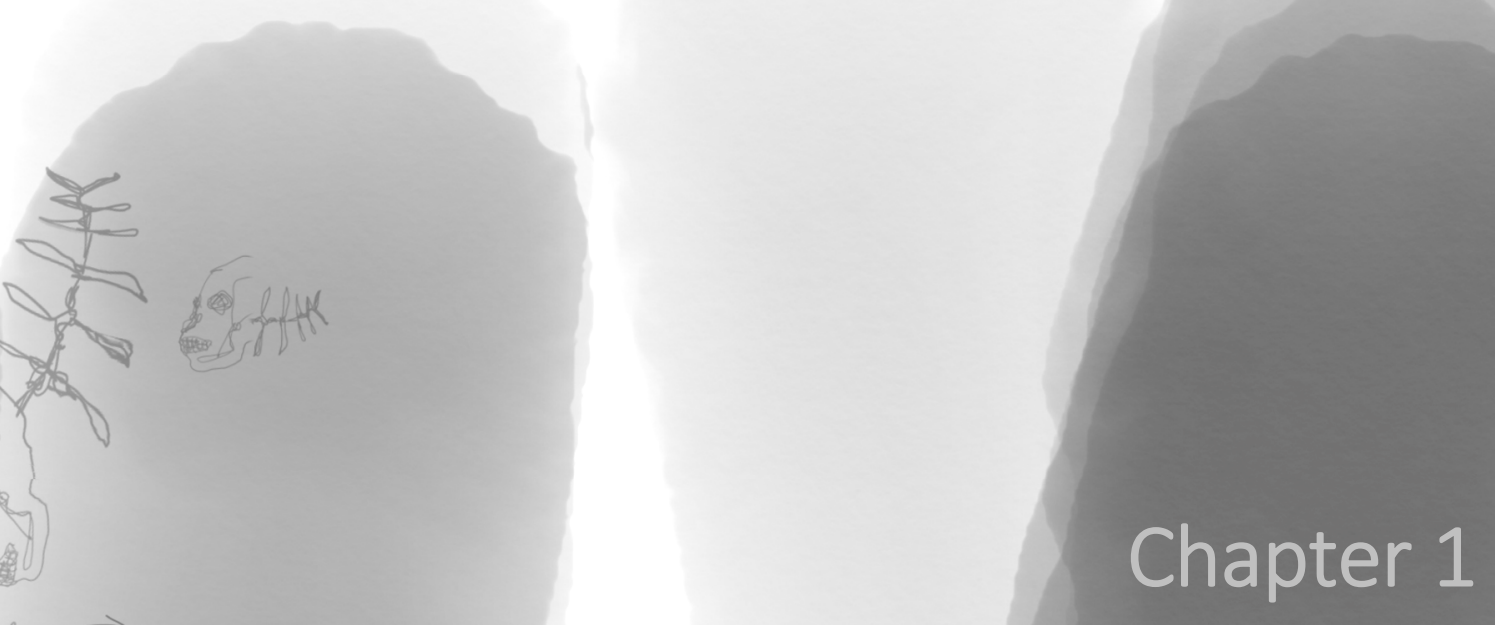

General introduction 


\section{General introduction}

'Work is the backbone of life'* from several points of view. For the individual, work contributes to purpose of life and financial autonomy, but also to long-term physical and mental health. ${ }^{1-3}$ For society, the worker's participation and resulting productivity are relevant not only from an economic perspective but also in terms of knowledge generation and societal development and progress. Persons with ill health can encounter different degrees of restrictions when participating in paid work. Work participation encompasses a continuum, ranging from normal participation, reduced workability while at work (presenteeism) or temporary sick leave (temporary absenteeism), up to withdrawal from work due to disease (permanent absenteeism, Figure 1.1). In this continuum, reduced work participation can also result in varying degrees of decrease in productivity at the workplace. The extent to which reduced worker participation results in production loss depends on the type of work, the severity of reduced work ability or length of absence, and probability that loss of production will be compensated by the ill person himself or by colleagues.

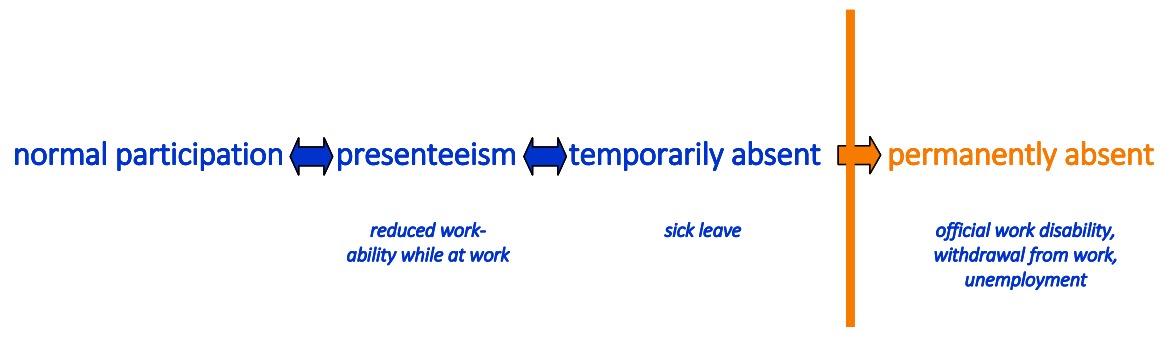

Figure 1.1 Worker participation in persons with a (chronic) disease can be depicted as a continuum, where withdrawal from work is regarded as a stage from which the chance of successful return to work is low.

The importance of work participation as an integral part of 'health' has been recognized by the World Health Organization (WHO) through the introduction of the International Classification of Functioning, Disability and Health (ICF). The ICF, a framework as well as a classification of health, was endorsed by all WHO member states in the Fifty-fourth World Health Assembly in May 2001. It emphasizes the biopsycho-social model of health and underpins the notion that work participation is a complex outcome that it is not only influenced by biological aspects, but also by socalled contextual factors (Figure 1.2). Contextual factors describe the personal and environmental characteristics of a human being. In relation to work participation,

* naar Friedrich Nietzsche 
examples of personal factors are the person's level of education (including professional education) or ability to cope with stressors. Environmental factors can include factors at the level of the workplace (amount of physical or mental demands), or the individual's home situation (tasks and duties at home), but also system factors such as the health care system or social security system available to the individual. With regard to a person's health, and thus health related participation in work, contextual factors can function either as facilitators or barriers. For example, a negative attitude of colleagues in a patient with a musculoskeletal disease (MSKD) may additionally hamper their ability to work, while a stable and supportive situation at home may enhance this ability. Similarly, the presence and level of income substitution in case of sick-leave might facilitate full recovery of the ill worker before returning to work, but might also be an incentive to withdraw early from work.

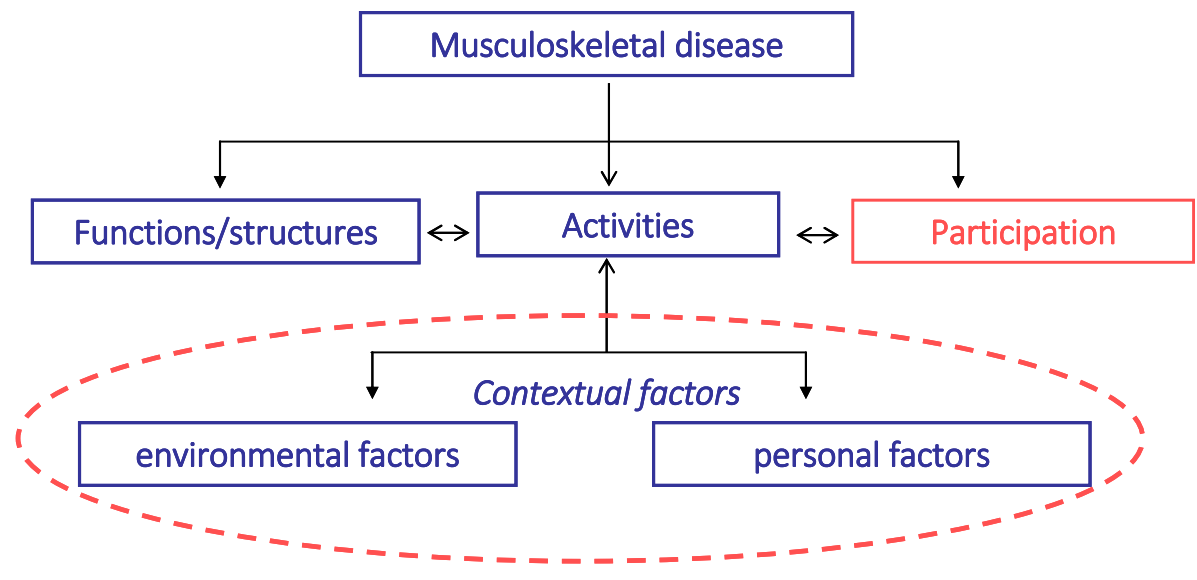

Figure 1.2 Framework of health as proposed by the WHO's International Classification of Functioning, Disability and Health (ICF).

Musculoskeletal diseases (MSKD) are worldwide responsible for a substantial health burden. In the Global Burden of Disease Study 2010 they are reported to be among the most common sequelae along with other relevant chronic diseases such as cardiovascular, respiratory, mental and gastro-intestinal diseases and diabetes. It was estimated that on a global scale MSKD were responsible for $21 \%$ of the years lived with disability (YLDs). When accounting for premature mortality in addition to disability, MSKD caused almost 7\% of total global disability-adjusted life years. Not addressed in the Global Burden of Disease project, but recognized in other literature as a major additional burden of chronic diseases is the productivity loss as a consequence of (temporary or permanent) absenteeism and presenteeism. ${ }^{4-6}$ MSKD are, together with 
mental diseases, the main reason of expenditure for work disability and sick leave in several Western countries when accounting for their prevalence.,

In view of the relevance of work participation as a component of functioning and health of persons with MSKD, much research has been done to uncover the major factors associated with or predicting (adverse) work outcomes. Such research classically focused on biomedical factors but, since the introduction of the ICF, also on the role of contextual factors. However, some aspects of the latter remain unclear and have become more important due to (economic) societal dynamics over time. This thesis explores specifically 1 ) the role of multimorbidity and MSKD in the context of multimorbidity on health and work outcome, 2) the effect of an early multidisciplinary support program on work retention and 3) the influence of socio-cultural context in relation to work participation in persons with MSKD. This introduction describes the relevance of these general study objectives and reveals the specific questions addressed in this thesis.

\section{Role of in MSKD in the context of multimorbidity in relation to health and work participation}

While the majority of studies on the burden of chronic diseases focus on the role of an index disease, little information is provided on the impact of multimorbidity and the role of MSD in the context of multimorbidity on health and work outcomes. Multimorbidity refers to the co-occurrence of two or more chronic diseases in one person without any disease being more central than the other ${ }^{9}$ ). With the aging of the population, earlier diagnosis and occurrence of lifestyle related conditions at younger age, more and more persons are likely to suffer from chronic disease and multimorbidity. ${ }^{10,11}$ In the ICF framework, which initially took a typical single disease approach, the importance of co-occurring diseases is recognized and might be considered a personal contextual factor. ${ }^{12}$ Patients with multimorbidity are not only more likely to have a poorer health status, but are also at increased risk for adverse job outcome and reduced job-opportunities, thereby posing a financial burden for their employer and eventually for society.

One previous Spanish study reported an amplified effect of multimorbidity on health when MSKD was one of the diseases ${ }^{13}$ but this observation was never replicated in other populations. Moreover, although earlier research showed that an increase in the number of different morbidities increases the adverse impact on work outcomes, ${ }^{14}$ no evidence exists on the association of multimorbidity with work participation and the specific role of MSKD in this association. In addition when addressing work outcome, it is important to address all outcomes (i.e. sick leave, presenteeism, unemployment, work disability and dependence on living allowances) as they are partly related but also comprise different information. 
It is of interest to know whether MSKDs have an invigorative effect on the association of multimorbidity in relation to both, health outcome and work participation. Such findings would plead for more interdisciplinary collaboration between rheumatologists and other medical specialists in their efforts to improve patient's health and work ability. In this line it is further relevant to research whether some chronic diseases have a more pronounced impact on health and work outcomes than others.

\section{Role of early multidisciplinary treatment directed at work retention in MSKD}

One of the most relevant contextual factors in the outcome of disease is the presence and availability of medical treatments to control or reduce the impairments and activity limitations as a consequence of the disease. However, medical treatments may be insufficient to avoid adverse impact on worker participation: For the majority of MSKD a cure does not exist and even if a cure is possible the person can experience irreversible damage. Therefore, several work-interventions have been conceptualized that aim to assimilate work-ability and work-load. An important insight from work interventions in the last decades that aimed at improvement of worker participation of persons with MSKD was the key role of prevention instead of reintegration of those already work disabled. ${ }^{15}$ (Early) work-interventions classically aim to influence the patho-biological process of the disease (consistent with the ICF framework) but also must address the personal and environmental context of the individual, in order to facilitate functioning and health despite illness. On that line, cognitive-behavioral approaches such as graded activity and self-management, which have shown to enhance the effect of physical training by accounting for patient's believes and level of motivation, have been increasingly included in multidisciplinary work interventions. ${ }^{16}$ Additionally, attention should be given to patient's individual needs emerging from the specific work or personal context. Finally, it is recognized that demands for efficiency and experienced work stress has increased over time. However, the inclusion of spaexercise elements focusing on stress-management and improvement of physical ability is as yet uncommon. In ankylosing spondylitis, one study showed beneficial effects of a combined spa-exercise programs on sickness absence and suggested part of the effect was likely due to the wellness experience. ${ }^{17,18}$ However, this study was not powered to make strong conclusions on work participation. In an era where even healthy workers experience work-stress, it would be interesting to explore the role of relaxation and wellness in work-retention programs more specifically.

As one of the aims of return to work or work-retention program is not only to improve the workers' health but also to limit he societal burden associated with productivity loss, a final element in work interventions is the cost-effectiveness of a new intervention. It would be expected that costs of the intervention would be of-set by improved worker productivity. Resources are usually limited and the cost-effectiveness 
is essential when appraising the full consequence of a new treatment program as money can only be spent once. Therefore, insight into the program cost per working day gained and overall costs per quality adjusted life year of such integrative and holistic treatment approaches may enable judgement whether such program is worthwhile.

\section{Role of socio-cultural context in relation to work participation in MSKD}

Although it has been shown that worker participation in persons with MSKD varies across countries, ${ }^{19-22}$ only limited research exists on the magnitude of the effect of country-(factors) on work participation and it is insufficiently known whether these differences can be explained by specific country characteristics that represent the social, economic and cultural context of these countries. One can imagine, for example, that richer countries, reflected by the higher Gross Domestic Product, have overall better working conditions, allowing more person with a chronic diseases to remain in labor force. Remarkably, international differences in work outcome in MSKD have almost exclusively been reported in relation to work disability and it is not known whether similar effects of the 'national contextual' also influence sick leave and presenteeism. Notwithstanding, it is relevant to extent existing knowledge on the role of country/ system characteristics on work outcome in MSKD-patients. First, summarized results on work outcomes of international studies may not provide meaningful information for individual countries, and secondly data on work outcome from one country might not be transferable to another country. Finally, such information is also essential for rheumatologists who may use this knowledge to detect shortcomings in country specific systems and to facilitate sustainable work ability in MSKD patients by addressing country specific.

When assessing work outcome, presenteeism gained interest in research and clinical practice, not only as a relevant outcome reflecting impact of disease on valued life activities but also because its potential usefulness as a predictor for sick leave. Sixteen patient reported (work) outcomes (PROs) for presenteeism are available ${ }^{23,24}$ However, so far there is no agreement on which of these questionnaires have the best validity. Moreover, no consensus exists on which measure to include in all studies in order to have a benchmark when comparing work outcomes across studies. Two main types of PROs to assess presenteeism can be distinguished, single item global measures and multi-dimensional questionnaires. Single item global measures have the advantage of easy administration and patient-acceptability in larger studies with extended questionnaires. Global PROs for presenteeism essentially vary in terms of construct, recall period, reference frame, and disease attribution. Differences in these four attributes may cause variation in interpretation and eventually lead to heterogeneity in results. So far, no attention has been given to the international validity of patient reported presenteeism questionnaires. Specifically the terms used in the single item 
global measures to describe the overall 'constructs' for presenteeism, such as productivity, work ability or performance, may not be culturally interchangeable, not only because of translation issues but also due to cultural norms, believes and attachments. Cross-cultural validation is crucial when interpreting results and transferability of presenteeism as an outcome in (multi)-national observational and interventional studies.

\section{Main aims}

This thesis aims to provide insight in the role of relevant environmental or personal contextual factors in relation to worker participation in patients with MSKD.

The specific study questions are:

1. What is the impact of MSKD (a) compared to other chronic diseases, and (b) in the context of multimorbidity on health, healthcare costs and on different work outcomes?

2. What are the effects and costs of a multidisciplinary treatment program with spaelements in persons with recent sick leave due to musculoskeletal disorders (MSKD) when compared to care as usual?

3. What is the influence of country of residence on three main work outcomes in patients with rheumatoid arthritis (RA), and which specific country characteristics can be identified that relevantly contribute to these outcomes?

4. What is the role of language and country of residence on comprehension of five single item global measures of presenteeism and what is the test-retest reliability of these measures?

\section{Outline of this thesis}

Part I: Health and work outcomes of musculoskeletal diseases in the context multimorbidity

Part I of this thesis describes the impact of MSKD on health, healthcare costs and work outcomes using data from a health survey among Dutch households. Outcomes in patients with MSKD are compared to outcomes in persons with other chronic diseases and the role of MSKD in the context of multimorbidity is explored. Chapter two addresses the impact on mental and physical health, and on healthcare utilization and costs. Chapter three focusses on the impact on work outcomes in terms of work disability, dependence on living allowances and unemployment as well as on sick leave 
in those with paid work. Data from 8904 participants of a Dutch household survey were used.

Part II: Early multidisciplinary intervention to improve work outcome of patients with MSKD

Chapter four describes the effects and societal costs of a 4-weeks in-patient multidisciplinary graded activity and mental coaching program combined with spatreatment aiming to assimilate work-ability and work-load and improve work resumption when compared to care as usual. Data of the usual care group are obtained from an occupational health service (OHS) database comprising information on age, gender, type of MSKD (inflammatory, a-specific, degenerative, other), contractual working hours and exact date of start and end of sick leave in 360,000 individuals.

Part III: Influence of country of residence on work outcomes and validity of presenteeism measures in patients with rheumatoid arthritis

In chapter five, the contribution of country of residence and of five country indices (i.e. gross domestic product, human development index, unemployment rate, social protection expenditures and world region) to three work outcome (i.e. employment, absenteeism and presenteeism) in patients with rheumatoid arthritis is described while adjusting for socio-demographic characteristics and disease state. Data from a multinational, cross-sectional study obtained from 3902 RA-patients (treated by a rheumatologist) from 17 countries across Europe, USA, Latin America, Asia and Africa is used.

Chapter six is a qualitative study that employed cognitive debriefing techniques to get insight into the conceptual interpretation of five global measures for presenteeism (2529)with emphasis on international differences in interpretability. Recruited participants from seven countries (i.e. UK, the Netherlands, France, Italy, Sweden, Romania and Canada) were either diagnosed with osteoarthritis or inflammatory arthritis. Chapter seven describes the test-retest reliability between the different global measures.

Finally in part IV (chapter eight) the main findings of the studies presented in this thesis are summarized and discussed. Furthermore, a Dutch summary is provided and the societal relevance is addressed. 


\section{References}

1. Antonovsky A. Unraveling The Mystery of Health - How People Manage Stress and Stay Well. San Francisco. 1987; Jossey-Bass Publishers.

2. Vastamaki J, Moser K, Paul KI. How stable is sense of coherence? Changes following an intervention for unemployed individuals. Scand J Psychol. 2009;50(2):161-71.

3. Waddell G, Burton AK. Is work good for your health and well-being?: The Stationery Office; 2006.

4. Woolf A. Global burden of osteoarthritis and musculoskeletal diseases. BMC Musculoskelet Disord. 2015;16 (Suppl1)(S3).

5. Vos T, Flaxman AD, Naghavi M, Lozano R, Michaud C, Ezzati M, et al. Years lived with disability (YLDs) for 1160 sequelae of 289 diseases and injuries 1990-2010: a systematic analysis for the Global Burden of Disease Study 2010. Lancet. 2012;380(9859):2163-96.

6. Murray CJL, Vos T, Lozano R, Naghavi M, Flaxman AD, Michaud C, et al. Disability-adjusted life years (DALYS) for 291 diseases and injuries in 21 regions, 1990-2010: a systematic analysis for the Global Burden of Disease Study 2010. Lancet. 2012;380(9859):2197-223.

7. Wilkie R, Pransky G. Improving work participation for adults with musculoskeletal conditions. Best practice \& research. Clin Rheumatol. 2012;26(5):733-42.

8. C. B. Working for a healthier tomorrow. London: The Stationery Office. 2008.

9. van den Akker M, Buntinx F, Knottnerus JA. Comorbidity or multimorbidity: what's in a name? A review of literature. Eur J General Pract. 1996;2(2):65-70.

10. Orueta JF, Nuno-Solinis R, Garcia-Alvarez A, Alonso-Moran E. Prevalence of multimorbidity according to the deprivation level among the elderly in the Basque Country. BMC Public Health. 2013;13:918.

11. Fortin M, Bravo G, Hudon C, Vanasse A, Lapointe L. Prevalence of multimorbidity among adults seen in family practice. Ann Fam Med. 2005;3(3):223-8.

12. Wijlhuizen GJ, Perenboom RJ, Garre FG, Heerkens YF, van Meeteren N. Impact of multimorbidity on functioning: evaluating the ICF Core Set approach in an empirical study of people with rheumatic diseases. J Rehabil Med. 2012;44(8):664-8.

13. Loza E, Jover JA, Rodriguez L, Carmona L. Multimorbidity: prevalence, effect on quality of life and daily functioning, and variation of this effect when one condition is a rheumatic disease. Semin Arthritis Rheum. 2009;38(4):312-9.

14. Kessler RC, Greenberg PE, Mickelson KD, Meneades LM, Wang PS. The effects of chronic medical conditions on work loss and work cutback. J Occup Environ Med. 2001;43(3):218-25.

15. Hoefsmit N, Houkes I, Nijhuis FJN. Intervention Characteristics that Facilitate Return to Work After Sickness Absence: A Systematic Literature Review. J Occup Rehabil. 2012;22(4):462-77.

16. Marhold C, Linton SJ, Melin L. A cognitive-behavioral return-to-work program: effects on pain patients with a history of long-term versus short-term sick leave. Pain. 2001;91(1-2):155-63.

17. van Tubergen A, Boonen A, Landewe R, Rutten-Van Molken M, Van Der Heijde D, Hidding A, et al. Cost effectiveness of combined spa-exercise therapy in ankylosing spondylitis: a randomized controlled trial. Arthritis Rheum. 2002;47(5):459-67.

18. van Tubergen A, Landewe R, van der Heijde D, Hidding A, Wolter N, Asscher M, et al. Combined spaexercise therapy is effective in patients with ankylosing spondylitis: a randomized controlled trial. Arthritis Rheum. 2001;45(5):430-8.

19. Dadoniene J, Uhlig T, Stropuviene S, Venalis A, Boonen A, Kvien TK. Disease activity and health status in rheumatoid arthritis: a case-control comparison between Norway and Lithuania. Ann Rheum Dis. 2003;62(3):231-5.

20. Mau W, Listing J, Huscher D, Zeidler H, Zink A. Employment across chronic inflammatory rheumatic diseases and comparison with the general population. J Rheumatol. 2005;32(4):721-8.

21. Chung CP, Sokka T, Arbogast PG, Pincus T. Work disability in early rheumatoid arthritis: higher rates but better clinical status in Finland compared with the US. Ann Rheum Dis. 2006;65(12):1653-7.

22. Sokka T, Kautiainen H, Pincus T, Verstappen SMM, Aggarwal A, Alten R, et al. Work disability remains a major problem in rheumatoid arthritis in the 2000s: data from 32 countries in the QUEST-RA Study. Arthritis Res Ther. 2010;12(2). 
23. Beaton DE, Dyer S, Boonen A, Verstappen SM, Escorpizo R, Lacaille DV, et al. OMERACT Filter Evidence Supporting the Measurement of At-work Productivity Loss as an Outcome Measure in Rheumatology Research. J Rheumatol. 2016;43(1):214-22.

24. Escorpizo R, Bombardier C, Boonen A, Hazes JM, Lacaille D, Strand V, et al. Worker productivity outcome measures in arthritis. J Rheumatol. 2007;34(6):1372-80.

25. Reilly MC ZA, Dukes EM. The validity and reproducibility of a work productivity and activity impairment instrument. Pharmacoeconomics. 1993;4:35365.

26. Osterhaus JT PO, Richard L. Discriminant validity, responsiveness and reliability of the rheumatoid arthritisspecific Work Productivity Survey (WPS-RA). Arthritis Res Ther. 2009;11(R73).

27. Tuomi K IJ, Jahkola A, Katajarinne L, Tulkki A. Work ability index. Helsinki: Finnish Institute of Occupational Health. 1998;30.

28. Brouwer WB KM, Rutten FF. Productivity losses without absence: measurement validation and empirical evidence. Health Policy. 1999;48:13-27.

29. Kessler RC, Barber C, Beck A, Berglund P, Cleary PD, McKenas D, et al. The World Health Organization Health and Work Performance Questionnaire (HPQ). J Occup Environ Med. 2003;45(2):156-74. 



\section{Part I}

Health and work outcomes of musculoskeletal diseases in the context of multimorbidity 



\section{Chapter 2}

\section{Impact of chronic diseases and multimorbidity on health and healthcare costs: the additional role of musculoskeletal disorders}

Antje van der Zee-Neuen, Polina Putrik, Sofia Ramiro, Andras Keszei, Rob de Bie, Astrid Chorus, Annelies Boonen 


\section{Abstract}

\section{Objective}

Chronic diseases are increasingly prevalent and often occur as multimorbidity. This study compares the impact of musculoskeletal disorders (MSKDs) on health and health care costs with other chronic diseases, and assesses the additional impact of MSKDs on these outcomes when occurring as part of multimorbidity.

\section{Methods}

A household survey in a random Dutch population sample $(\mathrm{N}=8,904)$ yielded information on sociodemographics, presence of 9 physician-confirmed chronic diseases (i.e.,musculoskeletal, migraine, diabetes mellitus, cardiovascular, cancer, respiratory, skin, mental, and gastrointestinal), physical component summary (PCS) and mental component summary (MCS) scores of the Short Form 12 health survey, and health care utilization. The independent influence of different diseases and the role of MSKDs with increasing number of morbidities on PCS/MCS and 3-month societal health care costs were explored through multivariable linear and zero-inflated negative binomial regressions, respectively.

\section{Results}

Twenty percent of all subjects and $56 \%$ of those with multimorbidity had an MSKD. MSKDs had the largest impact on PCS ( $\beta=-8.37$ [95\% confidence interval $(95 \% \mathrm{Cl})-8.84 ;-7.89]$ ) but no significant impact on MCS. When MSKDs occurred as part of multimorbidity; , an amplification of the adverse effect on PCS but not on MCS was seen, irrespective of the number of comorbidities. MSKDs were responsible for a 2-fold increase in costs ( $\operatorname{Exp}[\beta]=2.27[95 \% \mathrm{Cl} 2.08 ; 2.51])$, which was the second highest cost increase of all diseases (after cancer). Significant amplification of costs was seen when MSKDs co-occurred with mental diseases.

\section{Conclusions}

MSKDs often co-occur with other chronic diseases. In the context of multimorbidity, presence of an MSKD amplifies the impact on physical health, and to a lesser extent on health care costs, but not on mental health. 


\section{Introduction}

Chronic diseases are increasingly prevalent. Explanations may be found in the aging of the population but also in earlier and more accurate diagnoses, as well as an actual increase in occurrence of some chronic diseases related to lifestyle and environmental factors. ${ }^{1,2}$ Different studies acknowledge that musculoskeletal disorders (MSKDs) are among the most prevalent chronic diseases. ${ }^{3,4}$ While it is known that MSKDs have a large impact on health-related quality of life (HRQoL) $)^{5,6}$ and health care resource utilization $(\mathrm{HRU})^{7}$ it is insufficiently explored whether this impact differs from other chronic conditions.

Chronic diseases often occur as part of multimorbidity, i.e., the co-occurrence of 2 or more diseases in 1 person. ${ }^{8,9}$ While a comorbidity refers to any distinct additional disease that occurs in a patient who has the index (or primary) disease, the concept of multimorbidity assumes that none of the co-occurring diseases is more central than the other. ${ }^{10}$ With an increasing prevalence of chronic diseases, it is likely that their cooccurrence increases simultaneously by chance, due to pathophysiologic-related diseases, as a consequence of treatments, or due to alterations in lifestyle or social roles. So far, only a limited number of studies investigated HRQoL ${ }^{11,12}$ and costs of health care utilization ${ }^{13-17}$ in the context of multimorbidity, but the common finding is that an increasing number of diseases strongly affect $\mathrm{HRQOL}$ and health care utilization. MSKDs are frequently part of multimorbidity. ${ }^{18-20}$ A Spanish cross-sectional study reported that the HRQoL in patients with multimorbidity decreases when an MSKD is one of the diseases. ${ }^{20}$ However, the additional impact of MSKDs in combination with other specific diseases has not been explored explicitly, and to our knowledge no study explored the association of MSKDs in the context of multimorbidity with health care costs.

Insight into the impact of chronic diseases and multimorbidity (either as the number of diseases or as specific combinations of diseases) on health and health care costs is important, as it may reveal the need for adaptations in organizational structures of health care facilities aiming at improvement of patient-centred care, rather than disease-centred care. The latter might be relevant in efforts to decrease health care costs and improve patients' health as well as satisfaction with care.

The aim of the current study was therefore to assess the prevalence of MSKDs in the context of multimorbidity in the general Dutch population, to explore the impact of MSKDs compared to other common chronic conditions on health and health care costs, and to understand the additional impact of MSKDs on health and health care costs when co-occurring with other diseases. We hypothesized first that MSKDs had a more pronounced impact on health and health care costs than other diseases, and second that the presence of an MSKD in the context of comorbidity would amplify the impact of disease on health and costs. 


\section{Subjects and methods}

\section{Study design}

The National Monitor on Musculoskeletal System 2010 was a household survey study conducted by the Netherlands Organisation for Applied Scientific Research Dutch on behalf of the Dutch Arthritis Foundation in the period of early March 2010 to April 15, 2010. The aim of this survey was to assess the prevalence of rheumatic diseases in the noninstitutionalized Dutch adult population. ${ }^{21}$ The study was approved by the Medical Ethical Committee of the Leiden University Medical Centre.

\section{Sample and data collection}

Forty thousand Dutch households were randomly selected from an address registry, of a subsidiary undertaking of the Dutch Thomas Nationwide Transport post, and were invited for participation by letter, accompanied by the questionnaire and a selfaddressed envelope. To achieve arbitrary selection of participants within a household, the letter asked for participation of the member of the household age $>18$ years who was the next to have his/her birthday.

\section{Sociodemographics, lifestyle and morbidities}

Participants indicated sex, date of birth, and the 4-digit postal code of place of residence. The level of education was determined as the highest-level diploma achieved across 5 levels, i.e., primary or no education, lower professional, middle professional, general secondary (high school), and university or higher professional education. The body mass index (BMI) was calculated from self-reported weight and height $\left(\mathrm{kg} / \mathrm{m}^{2}\right)$ and categorized into 4 categories (underweight $<18.5$, normal 18.5 to $<25.0$, pre-obese 25.0 to $<30.0$, and obese $\geq 30.0){ }^{21}$ Smoking status distinguished current, former, and never smokers. From the country of birth of the participants and their parents, a new variable to reflect origin was built comprising Western, firstgeneration non-Western (i.e., not born in The Netherlands or another country in the Western world), and second-generation non-Western (i.e., mother and/or father not born in The Netherlands or another country in the Western world). ${ }^{22}$

Information on the presence of 13 common chronic diseases in the past 12 months was queried, with 3 possible answer categories (no; yes, not diagnosed by a physician; and yes, diagnosed by a physician). After combining some disease categories according to the organ system involved, 9 self-reported, physician-diagnosed diseases were considered for further analyses: MSKD (severe or persistent symptoms in or around joints [pain, stiffness, and/or swelling]), cancer, diabetes mellitus, mental diseases, respiratory diseases, cardiovascular diseases (CVD; hypertension, cerebral 
hemorrhage/stroke, myocardial infarction, other heart diseases and peripheral vascular disease), skin diseases, bowel diseases (i.e., gastrointestinal diseases), and migraine (or recurring headache). The presence of 2 or more diseases in 1 person will be referred to as multimorbidity. Further, "index disease" refers to the presence of a specific chronic condition, and patients with an index disease can (but do not have to) experience other comorbidities. "Single disease" refers to the occurrence of only 1 chronic disease, and patients with a single disease have no comorbidity.

\section{Health, health resource utilization and costs}

Selfreported health was assessed using the validated Dutch version of the 12-item Short Form health status survey (SF-12). From the 12 questions, the physical (PCS) and mental component summary (MCS) scores were computed, each ranging from 0 to 100 (where 0 indicates worst possible health and 100 indicates best possible health). ${ }^{24,25}$ HRU was assessed by asking about 1) the number of contacts with a general practitioner (GP), specialist (i.e., rheumatologist, orthopedic surgeon, other specialist), psychologist, and physiotherapist during the last 12 months, 2) the number of days of hospitalization in a nursing home, or regular or academic hospital during the past 3 months, and 3) the weekly hours of received home care or professional assistance for medical reasons during the past 3 months.

Societal costs of HRU per patient over the past 3 months were calculated by multiplying the frequency of HRU over 3 months by the unit costs of the specific health care resource, as provided by the Dutch guideline for pharmaco-economic research. ${ }^{26}$ These costs represent the true cost (or shadow price in the case of informal care) and not the tariffs. The national consumer price index was used to adjust to the unit costs for the level of $2012 .^{27}$

\section{Statistical analysis}

Descriptive statistics were used to compare sociodemographics, lifestyle factors, quality of life, and health care costs in the past 3 months across index diseases and persons reporting no disease, and we used models to explore the association of index diseases, number of diseases, and combinations including and excluding MSKD with health and health care costs.

When PCS/MCS or health care costs were the outcome, linear or zero-inflated negative binomial (ZINB) regressions were performed, respectively. ZINB models account for overrepresentation of zero values (which was the case for health care costs) and consist of 2 parts: a zero-inflated part (logistic) predicting excessive zeros (i.e., certainly no costs) and an expected count part (negative binomial, predicting the factor increase in costs while including both zeros and non-zeros). In the current article we refer to the count part of the model. 
For each of the morbidity groups the 3-month costs $(€)$ for a man and a woman with typical characteristics of the study sample were predicted. The association of 1 ) each index disease (reference: persons without the index disease) while adjusting for the presence of other diseases, 2) the number of diseases (reference: persons reporting no disease), and 3) MSKD alone or in combination with (an increasing number of) other diseases (reference: persons reporting no disease) with each of the abovementioned outcome was explored while adjusting for relevant covariates.

Manual forward selection was chosen to develop fully adjusted models. Variables remained in the model when they were either significantly associated with the outcome in the univariable assessment ( $P$ less than or equal to 0.05 ) or confounded the association of diseases with the outcome (i.e., change in $\beta$ coefficient of the morbidity $\geq 10 \%$ ).

In the models with PCS/MCS, two-way interactions between the diseases (and disease combinations) with age, sex, education, smoking status, and BMI were explored. When the $P$ value of the interaction term was less than or equal to 0.01 , the models were repeated after stratification for the covariates. The minimum important difference for PCS and MCS of $\geq 5.0$ and $\geq 2.5$, respectively, ${ }^{24,28}$ was used to decide upon clinical relevance of significant interactions. Finally, to assess possible associations of place of residence with PCS/MCS, multivariable, multilevel linear regression models with individuals nested within place of residence (based on postal code) were computed. The change in the likelihood ratio was used to assess improvement in model fit (P less than or equal to 0.05 ). Finally, the $\mathrm{R}^{2}$ of the fully adjusted models were compared to explore whether all index diseases or the number of diseases better explained PCS/MCS.

Missing values in PCS, MCS, age, sex, education, origin, smoking status, BMI and, in a separate data set, frequencies of visits to a GP, rheumatologist, orthopedist, other specialist, physiotherapist, academic and regular hospital, and home care and housekeeping were imputed using multiple imputation (imputed data sets, $n=20$ ). Chained imputations using regression-based methods were used. Predictive mean matching was used for continuous variables, logistic regression for binary variables, and multinomial logistic regression for nominal variables. Imputation was based on the abovementioned variables and, in addition, on the explanatory variables reflecting the 9 index diseases. To assess the robustness of imputation methods, the analyses with PCS and MCS as outcome were repeated on unimputed data. All analyses were performed using Stata, version $12 .^{29}$ 


\section{Results}

Characteristics of the sample and prevalence of (multi)morbidity. The questionnaire was completed and returned by $22.4 \%$ of the contacted persons, resulting in a study sample of 8,904 subjects with a mean \pm SD age of $54 \pm 16$ years, of which 4,767 (54\%) were women and 3,360 (39\%) achieved a higher professional or university education. The sociodemographic and lifestyle characteristics of the study sample were overall comparable to the general Dutch population (see Supplementary Table S2.1.

Forty-nine percent $(n=4,379)$ of the study population had at least 1 chronic disease. Table 2.1 presents the characteristics of the population, including the prevalence of each index disease, mean PCS/MCS, and mean (median) health care costs. The overall prevalence of multimorbidity was $19 \%(n=1,722)$, and in $56 \%$ of the cases with multimorbidity ( $n=964)$ an MSKD was present. Two diseases occurred in $12 \%$ of participants ( $n=1,091$, of which $49 \%[n=536]$ had an MSKD), and 3 or more diseases occurred in $8 \%(n=705$, of which $30 \%$ [ $n=211$ ] had an MSKD). PCS and MCS were lowest for MSKDs and mental diseases, respectively. When ranking the average costs per patient, MSKDs had the fifth highest costs. However, when accounting for the prevalence of the diseases, MSKDs contributed to $23 \%$ of the total costs in our sample and ranked first (together with CVDs) in the ordering of total costs.

Association of index diseases, number of diseases, and combinations including and excluding MSKDs with health and health care costs.

Missing values in the study variables never exceeded 6\%, with the exception of PCS and MCS, which varied between $8 \%$ and $20 \%$, and in the variables for health resource utilization, which varied between $2 \%$ and $37 \%$. Comparison of models on unimputed and imputed data showed similar results. Throughout this article only analyses based on imputed data sets are presented. As multilevel analyses did not show a significant association between place of residence and PCS/MCS, results of the one-level linear regression models are presented. 


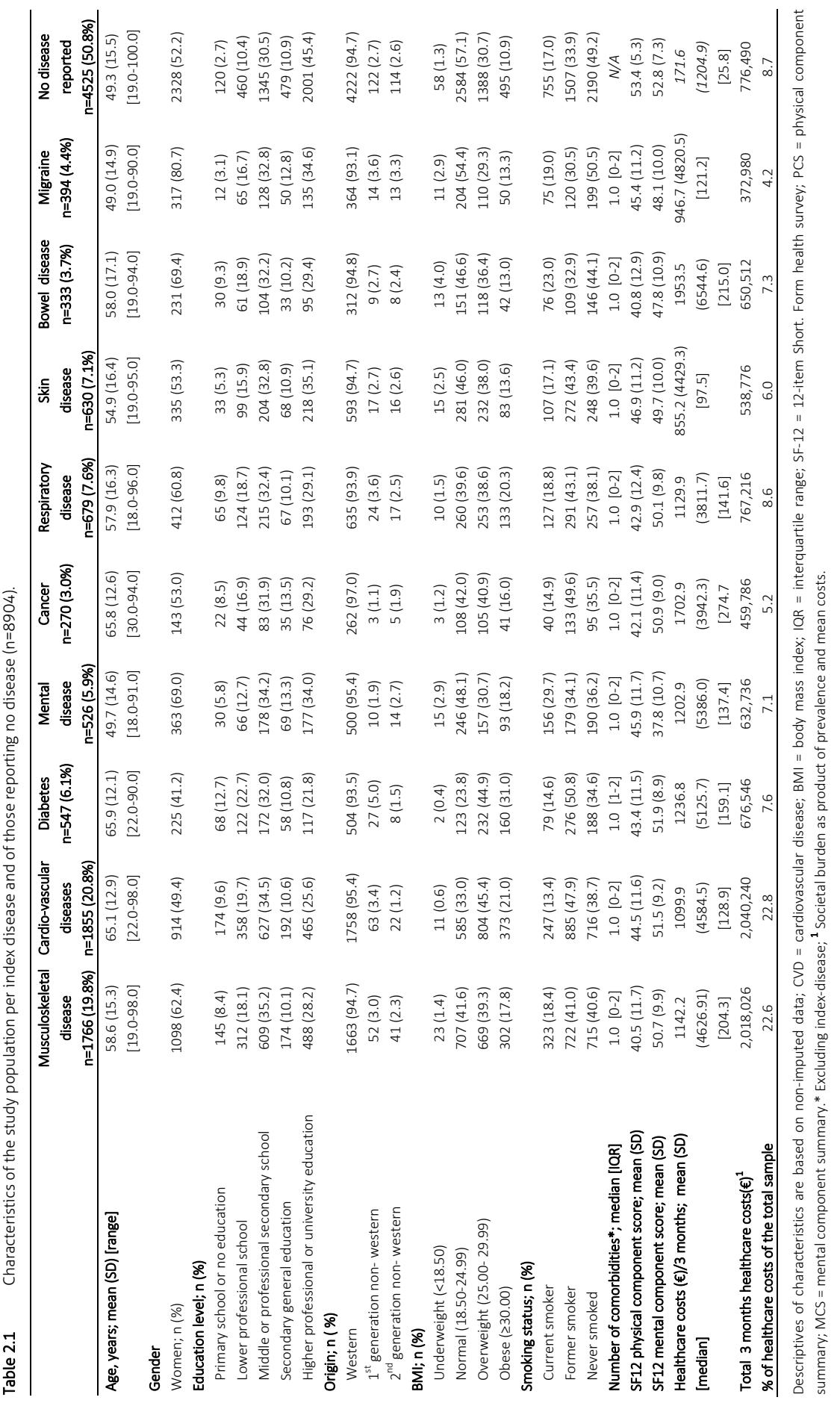


Age, sex, education, smoking status, origin, and BMI were retained as covariates or confounders in the model independent of the outcome and the approach to explore the impact of (multi)morbidity. Results of all (full) models are presented in Supplementary Tables S2.2, S2.3, and S2.4, respectively.

\section{Morbidity and multimorbidity in relation to PCS and MCS}

Each index disease was significantly associated with lower PCS (except skin disease) and lower MCS (except diabetes mellitus) compared to those without the index disease. MSKDs had the most pronounced association with PCS, while mental diseases had the most pronounced association with MCS (Table 2.2). For example, persons diagnosed with an MSKD scored, on average, 8.4 points lower on the PCS, and persons with a mental disease, on average, scored 13.0 points lower compared to persons who do not have an MSKD or mental disease, respectively. For every additional morbidity, PCS and MCS decreased significantly by 4.1 points and 2.0 points, respectively, compared to persons reporting no disease (Figures 2.1 and 2.2).

Comparison of the model fit of the fully adjusted models with index diseases and number of diseases showed that physical health, but especially mental health, was captured better by the type of disease (PCS $R^{2}=0.37$ and $\left.M C S R^{2}=0.19\right)$ than by the number of diseases ( $P C S R^{2}=0.32$ and $M C S R^{2}=0.09$ ).

When $\geq 2$ diseases co-occurred and an MSKD was part of them, physical health was significantly more decreased (-10.5 points) than when an MSKD was not part of the diseases (-5.3 points) (Figure 2.1). In contrast, the decrease in mental health tended to be more pronounced when 2 diseases other than MSKDs co-occurred than when an MSKD was one of the diseases (Figure 2.2), although these differences were not significant. Interactions in the models with PCS and MCS as outcomes were either not significant or not clinically meaningful after stratification.

\section{Morbidity and multimorbidity in relation to 3-month health care costs}

Each index disease resulted in increased 3-month health care costs when compared to persons without that index disease. The largest increase was seen in persons diagnosed with cancer in the last year, where the costs were about 3 times higher than in persons who did not report cancer, followed by persons reporting an MSKD, where the costs were about 2.3 times higher than in persons who did not report an MSKD (Table 2.2). Costs increased significantly with every additional disease: the health care costs of a person with 1 disease were almost 2 times higher than the costs of a person reporting no disease, while costs were 3 times higher and about 5 times higher for persons having any 2 and 3 diseases, respectively (Figure 2.3). 


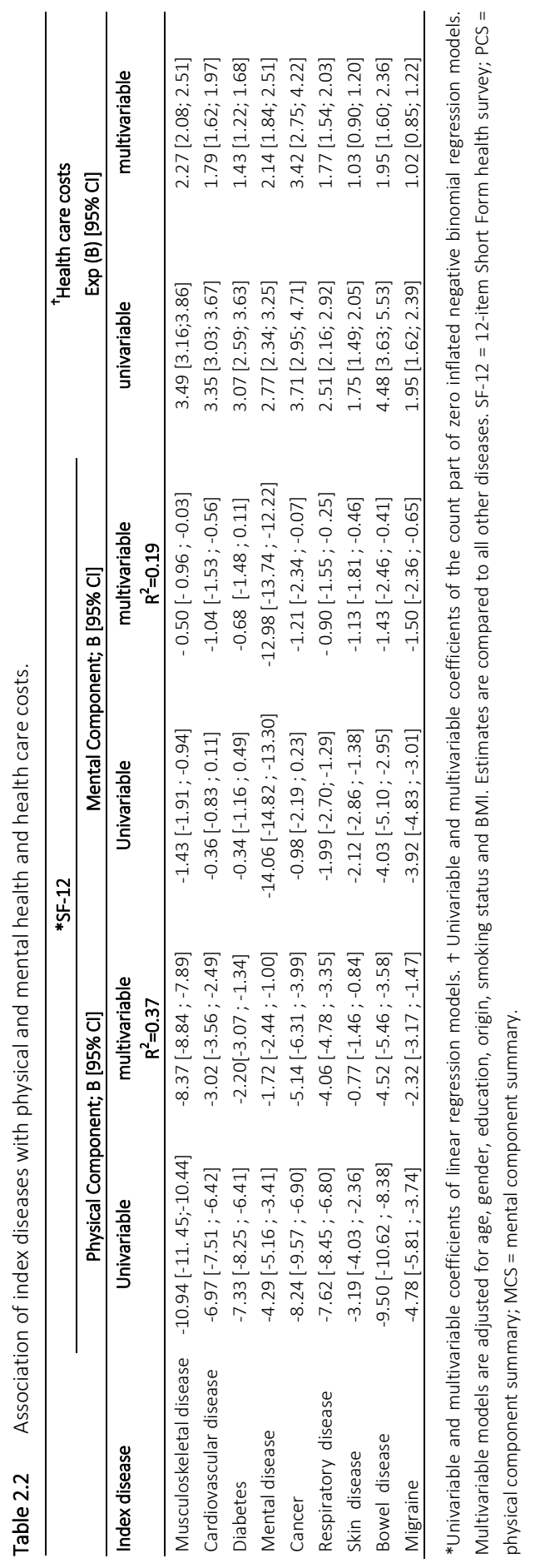




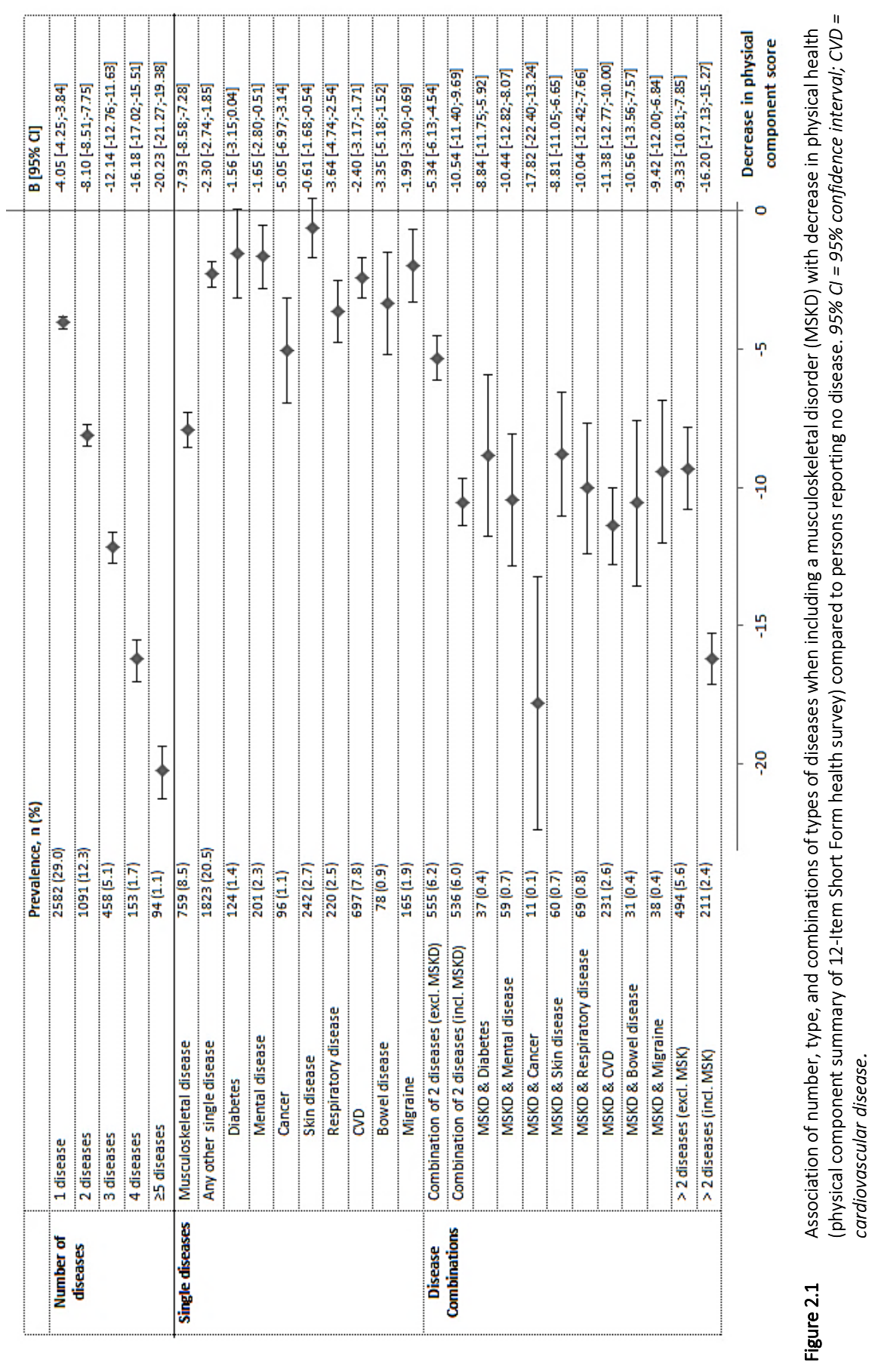



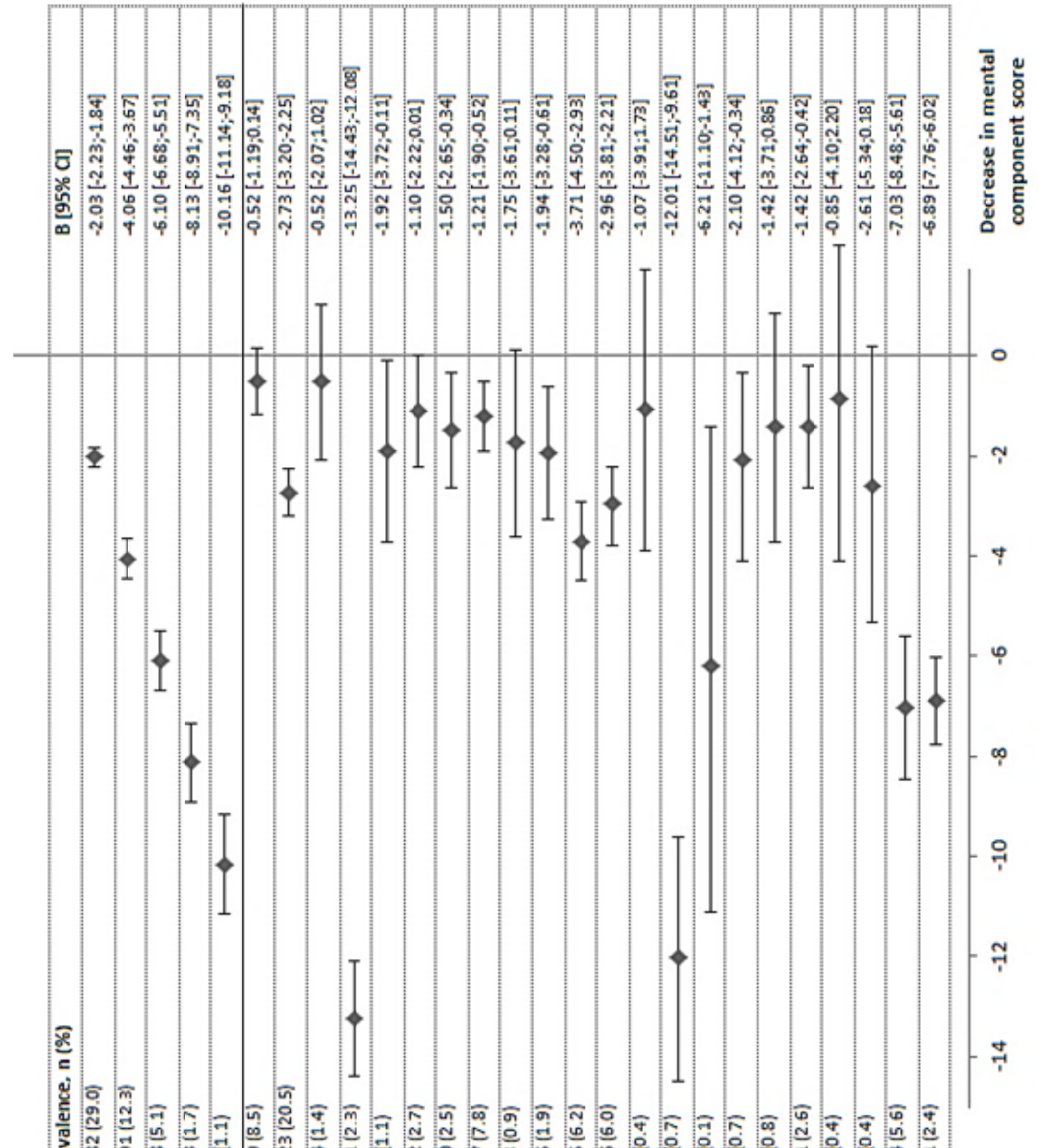

亗

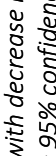

อิ

乡ั

ปั่ ปั่

ํํำ

के

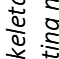

ํํำ

जั

है

워ํ

$1)$

$\int \frac{1}{2}$

-1
$\frac{1}{3}$

₹ $\quad$ पूँ

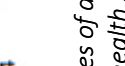

ᄀ

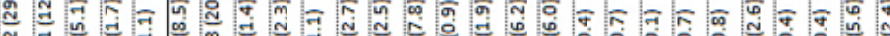

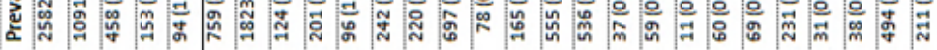

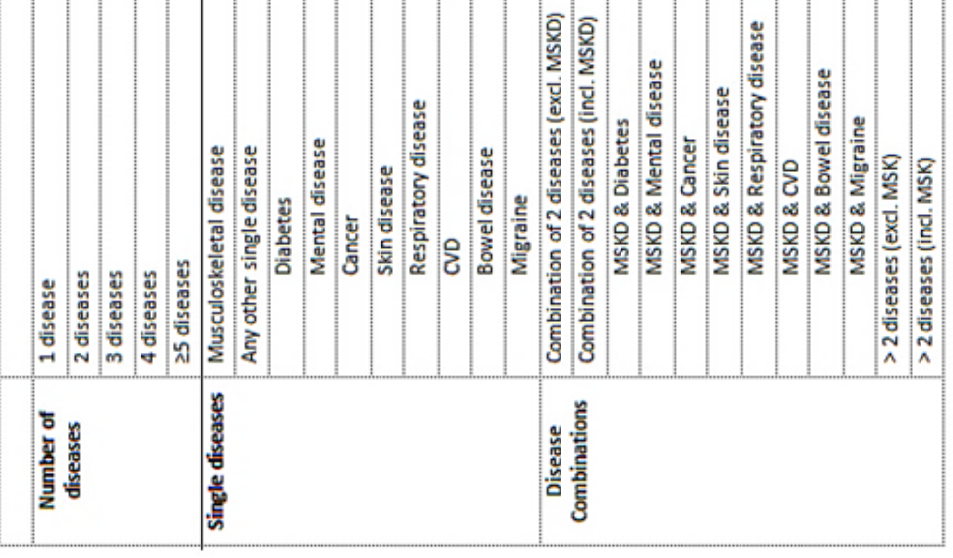

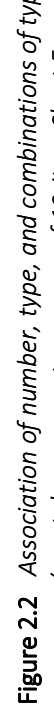

ป

के

हो

c 0

है हे

¿े

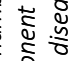

पे है के

范

है ठे 
When 2 diseases co-occurred, costs increased 3.5-fold when an MSKD was part of multimorbidity, compared to 2.5-fold when an MSKD was not part of it. However, only the combination of an MSKD and mental disease resulted in significantly higher health care costs compared to any other combination of diseases. When $>2$ diseases cooccurred, the presence of an MSKD did not change the association with costs significantly (Figure 2.3). Supplementary Table S2.5 shows the modelled 3-month costs (e) for all the morbidity subgroups distinguished in a male and a female with median age (54 years), normal BMI (18.5-25 kg/m2), nonsmoker, middle or secondary professional education, and Western origin.

\section{Discussion}

In an era in which chronic diseases and especially multimorbidity are increasingly prevalent, we show that the presence of any chronic disease is associated with significantly lower physical and (with the exception of diabetes mellitus) mental health, and with increased health care costs when compared to persons reporting no disease. Among all chronic conditions, MSKDs had the strongest association with physical health and (after cancer) with societal health care costs, but not with mental health. In addition, we demonstrated that an increasing number of chronic diseases was associated with a linear decrease in physical and mental health, and a strong raise in health care costs. Finally, MSKDs amplified the adverse effect on physical health when co-occurring with other chronic diseases.

The important adverse association of MSKDs with physical health was already reported by one previous study in the context of the International Quality of Life Assessment (IQOLA) in which arthritis (-4.5 points), together with chronic lung disease (-4.4 points) and congestive heart failure (-4.4 points), had the highest impact on the PCS of the SF36 compared to persons reporting no disease in 8 different countries. ${ }^{5}$ Further, the additive adverse association of MSKDs with physical health (PCS) when occurring in the context of multimorbidity has been shown by Loza et al in the Spanish population ${ }^{20}$; the presence of a rheumatic disease in addition to other morbidities was associated with an additional decrease in PCS of 5 points (when 2 diseases co-occurred) to almost 13 points (when 5 diseases co-occurred). Also, the less pronounced adverse association of MSKDs with mental health (-4.5 on the MCS compared to -1.5 points in those reporting no chronic conditions) was previously found in the IQOLA study, and Loza et al also found that MSKDs, when co-occurring with 1 or more other diseases, had no statistically additional adverse impact on mental health (MCS). 

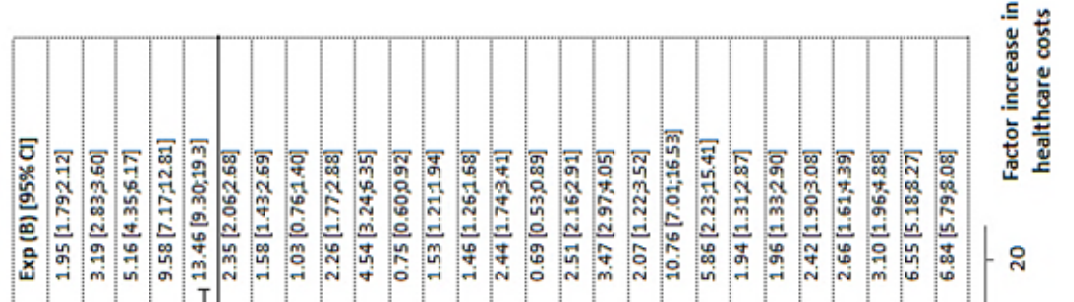

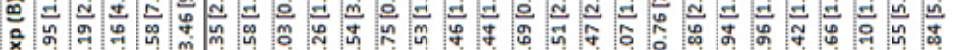

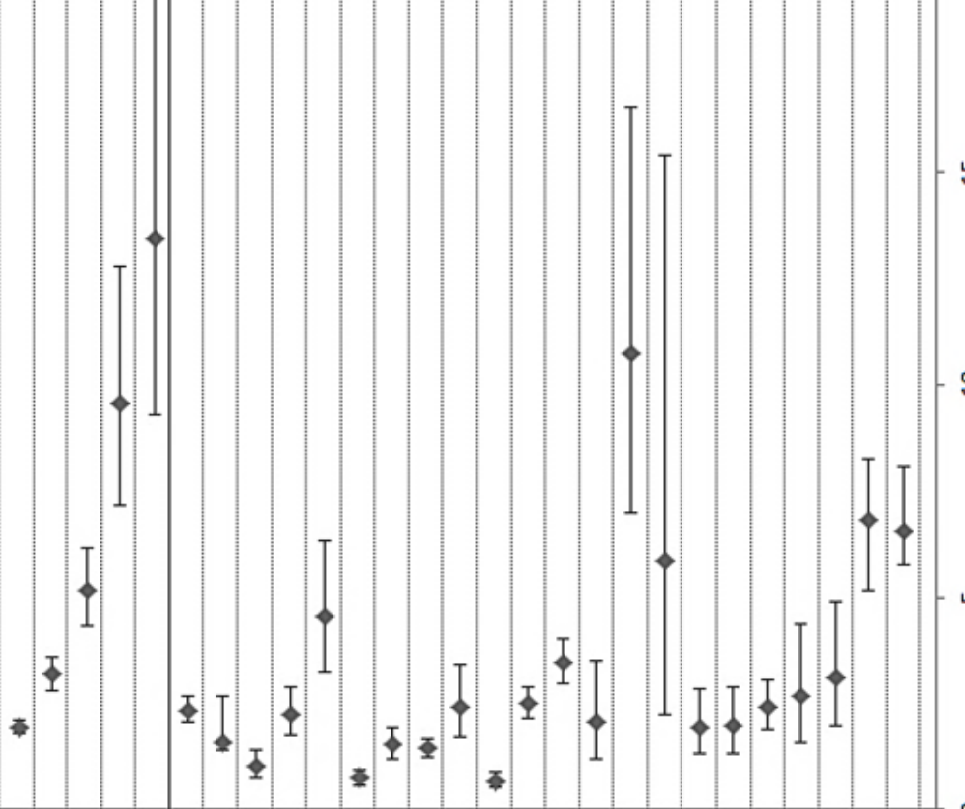

\section{$\frac{2}{6}$}

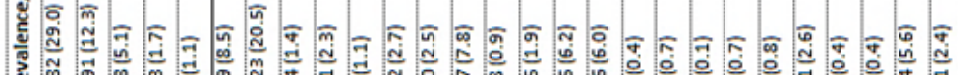

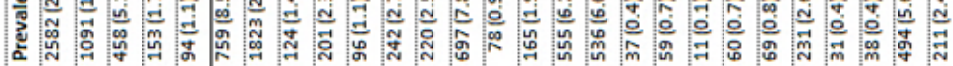

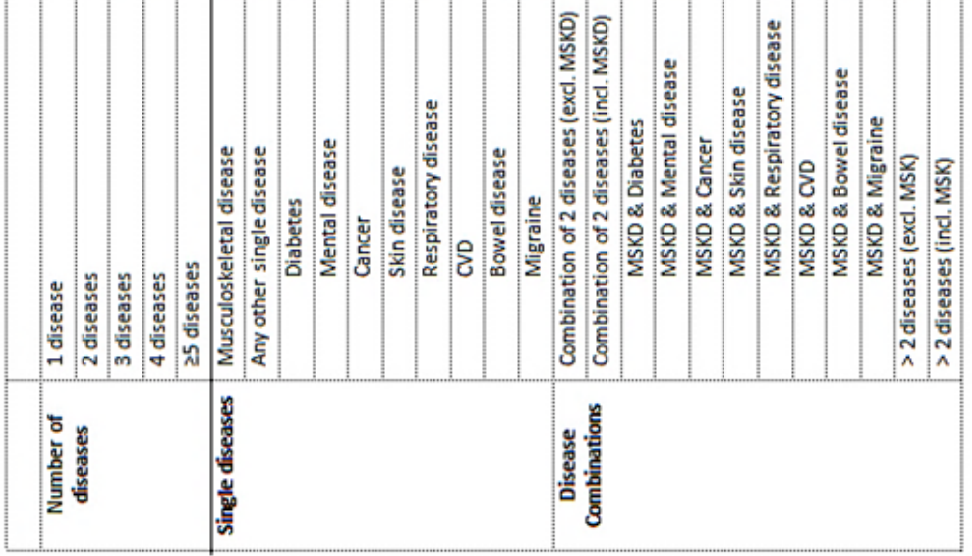


An unanswered question with regard to multimorbidity and HRQoL was whether the number of diseases or the type of diseases better explain the variation in physical or mental health. Based on comparison of the model fit $\left(R^{2}\right)$, we showed that the models containing the number of diseases explained less variance than those including the type of diseases, which was more pronounced when MCS was the outcome. Apparently the specific adverse influence of a mental disease is underestimated when adjusting for disease counts instead of specific diseases.

In The Netherlands the occurrence of chronic diseases is regularly monitored by the Central Bureau for Statistics (CBS), which estimates that approximately $48 \%$ of the Dutch population is diagnosed with at least 1 chronic condition, ${ }^{30}$ which is in line with the prevalence of $49 \%$ in the current study. High prevalence of chronic diseases has also been reported in previous research in Western societies. ${ }^{20,31}$ Data on multimorbidity are scarcer. In The Netherlands, the reported prevalence of multimorbidity ranged from $8 \%$ to $60 \% .{ }^{1,32,33}$ This inconsistency may be attributed to differences in settings, sampling methods, and populations of interest, but also in the definition and type of diseases considered. ${ }^{34}$ In our study population, the overall prevalence of multimorbidity was 20\%. Importantly, an MSKD was present in 56\% of the persons with multimorbidity, which is in line with other studies on multimorbidity patterns in either general or primary care populations. ${ }^{18-20}$

To our knowledge, no studies so far have compared the relative association of MSKDs with health care costs with other chronic diseases nor investigated the additional impact of MSKDs in the association of multimorbidity with health care costs. ${ }^{14,35,36}$ Selfreported physician-diagnosed cancer and mental disease in the past 12 months inferred together with MSKDs the highest factor of increase in health care costs per patient when compared to persons without those diseases. When an MSKD was part of multimorbidity, the increase in cost was limited, except when co-occurring in addition to a mental disease or cancer, where large increases in costs were seen. Of note, the coefficients present the adjusted "relative" difference in the costs per patients between diseases. When comparing total costs of our sample, thus accounting for the prevalence of the different chronic diseases, MSKDs accounted for $23 \%$ of the health care costs in our study population, and costs for MSKDs were, together with CVDs, the highest in the rank of the total population health care costs. The high population health care costs of MSKDs at the population level are in line with previous studies. ${ }^{37-39}$

Some limitations should be discussed. Notwithstanding appropriate sampling, the relatively low response rate (22.4\%) might hamper the overall generalizability of our results. However, characteristics of our study population as well as the occurrence of chronic diseases compare very well with the data of the CBS. Furthermore, other studies showed that low response rates in these types of surveys are common and do not necessarily indicate poor survey quality. ${ }^{40,41}$ The self-reported character of the diseases in this study might be considered a weakness; however, it was shown that asking specifically for a physician-confirmed diagnosis increases the accuracy of self- 
report diseases. ${ }^{42,43}$ Conclusions on the causality of associations found in our crosssectional study cannot be drawn. Moreover, we made comparisons between disease groups while dealing with confounding effects of factors that were used in the models with the limitation of the probable presence of residual confounding. A period of 3 months to assess health care costs is short. As we havemainly focused on visits to health care providers, this is an accurate choice as longer recall periods lose reliability. It should be noted: not all health care costs of health care use were included, such as the costs associated with (early) mortality. Finally, the more limited association of diseases with mental health could partly be attributed to a low discriminative validity of the MCS of the SF-12.

The importance of studies on chronic disease and multimorbidity cannot be underestimated. High prevalence and additive association of multimorbidity with HRQoL and costs underscore the need for further improvement in the effectiveness and efficiency of the Dutch health care system when caring for patients with multimorbidity. Clinical guidelines are needed with a focus on multidisciplinary and patient-centred care by addressing emerging problems such as screening and preventing comorbidities that co-occur frequently, checking actively for interactions between medications prescribed for the different disease, or fine-tuning of nonpharmacologic care.

In conclusion, MSKDs are among the most common chronic diseases and often occur as comorbidity. Compared to other diseases, they have the most pronounced association with physical health and amplify the association of other diseases with physical health, and to a lesser extent with costs. These findings call for adaptations in health care systems with a focus on multidisciplinary care. 


\section{References}

1. Van den Akker M, Buntinx F, Metsemakers JF, Roos S, Knottnerus JA. Multimorbidity in general practice: prevalence, incidence, and determinants of co-occurring chronic and recurrent diseases. J Clin Epidemiol 1998;51:367-75.

2. Starfield B. Challenges to primary care from co- and multimorbidity [editorial]. Prim Health Care Res Dev 2011;12:1-2.

3. Picavet HS, Hazes JM. Prevalence of self-reported musculoskeletal diseases is high. Ann Rheum Dis 2003;62:644-50.

4. Vos T, Flaxman AD, Naghavi M, Lozano R, Michaud C, Ezzati M, et al. Years lived with disability (YLDs) for 1160 sequelae of 289 diseases and injuries 1990-2010: a systematic analysis for the Global Burden of Disease Study 2010. Lancet 2012;380:2163-96.

5. Alonso J, Ferrer M, Gandek B, Ware JE Jr, Aaronson NK, Mosconi P, et al. Health-related quality of life associated with chronic conditions in eight countries: results from the International Quality of Life Assessment (IQOLA) Project. Qual Life Res 2004;13:283-98.

6. Bazzichi L, Maser J, Piccinni A, Rucci P, Del Debbio A, Vivarelli L, et al. Quality of life in rheumatoid arthritis: impact of disability and lifetime depressive spectrum symptomatology. Clin Exp Rheumatol 2005;23:783-8.

7. Cisternas MG, Murphy LB, Yelin EH, Foreman AJ, Pasta DJ, Helmick CG. Trends in medical care expenditures of US adults with arthritis and other rheumatic conditions 1997 to 2005. J Rheumatol 2009;36:2531-8.

8. Orueta JF, Nuño-Solinís R, García-Alvarez A, Alonso-Morán E. Prevalence of multimorbidity according to the deprivation level among the elderly in the Basque Country. BMC Public Health 2013;13:918.

9. Fortin M, Bravo G, Hudon C, Vanasse A, Lapointe L. Prevalence of multimorbidity among adults seen in family practice. Ann Fam Med 2005;3:223-8.

10. Van den Akker M, Buntinx F, Knottnerus JA. Comorbidity or multimorbidity: what's in a name? A review of literature. European J Gen Pract 1996;2:65-70.

11. Fortin M, Lapointe L, Hudon C, Vanasse A, Ntetu AL, Maltais D. Multimorbidity and quality of life in primary care: a systematic review. Health Qual Life Outcomes 2004;2:51.

12. Fortin M, Bravo G, Hudon C, Lapointe L, Almirall J, Dubois MF et al. Relationship between multimorbidity and healthrelated quality of life of patients in primary care. Qual Life Res 2006;15: 83-91.

13. König HH, Leicht $H$, Bickel H, Fuchs A, Gensichen J, Maier W, et al. Effects of multiple chronic conditions on health care costs: an analysis based on an advanced tree-based regression model. BMC Health Serv Res 2013;13:219.

14. Glynn LG, Valderas JM, Healy P, Burke E, Newell J, Gillespie P, et al. The prevalence of multimorbidity in primary care and its effect on health care utilization and cost. Fam Pract 2011;28:516-23.

15. Bock JO, Luppa M, Brettschneider C, Riedel-Heller S, Bickel H, Fuchs A, et al. Impact of depression on health care utilization and costs among multimorbid patients: from the Multi-Care Cohort Study. PloS One 2014;9:e91973.

16. Kadam UT, Uttley J, Jones PW, Iqbal Z. Chronic disease multimorbidity transitions across healthcare interfaces and associated costs: a clinical-linkage database study. BMJ Open 2013;3;e003109.

17. Carreras M, Ibern P, Coderch J, Sánchez I, Inoriza JM. Estimating lifetime healthcare costs with morbidity data. BMC Health Serv Res 2013;13:440.

18. Britt HC, Harrison CM, Miller GC, Knox SA. Prevalence and patterns of multimorbidity in Australia. Med J Australia 2008;189:72-7.

19. Cimarras-Otal C, Calderón-Larrañaga A, Poblador-Plou B, González-Rubio F, Gimeno-Feliu LA, ArjolSerrano JL, et al. Association between physical activity, multimorbidity, selfrated health and functional limitation in the Spanish population. BMC Public Health 2014;14:1170.

20. Loza E, Jover JA, Rodriguez L, Carmona L, and the EPISER Study Group. Multimorbidity: prevalence, effect on quality of life and daily functioning, and variation of this effect when one condition is a rheumatic disease. Semin Arthritis Rheum 2009;38:312-9. 
21. World Health Organization. BMI classification. 2014. URL:

http://apps.who.int/bmi/index.jsp?introPage=intro_3.html\&.

22. Central Bureau of Statistics. Numbers of foreigners according to several definitions (Aantallen allochtonen volgens verschillende definities). Maandstatistiek Bevolking 2000 2005;5:14-7.

23. Valderas JM, Starfield B, Sibbald B, Salisbury C, Roland M. Defining comorbidity: implications for understanding health and health services. Ann Fam Med 2009;7:357-63.

24. Gandek B, Ware JE, Aaronson NK, Apolone G, Bjorner JB, Brazier JE, et al. Cross-validation of item selection and scoring for the SF-12 health survey in nine countries: results from the IQOLA Project. International Quality of Life Assessment. J Clin Epidemiol 1998;51:1171-8.

25. Sprangers MA, Snijders BE, van Gool CH. Health-related quality of life: what is the quality of life of people in the Netherlands? In: Nationaal K, ed. Nationaal Kompas Volksgezondheid; Volksgezondheid Toekomst Verkenning. Bilthoven: RIVM; 2009. In Dutch.

26. Roijen LH, Tan SS, Bouwmans CA. Guide to cost research: methods and standard cost for economic evaluations in health care 2010: Board of Health Insurances. In Dutch.

27. Central Bureau of Statistics (The Netherlands). Consumer price index 2006=100. 2016. URL: http://statline.cbs.nl/StatWeb/publication/?VW=T\&DM=SLNL\&PA=71311NED\&D1=0,4\&D2=0\&D3=194 ,219,232\&HD=131203-1323\&HDR=G1,T\&STB=G2.

28. Samsa G, Edelman D, Rothman ML, Williams GR, Lipscomb J, Matchar D. Determining clinically important differences in health status measures: a general approach with illustration to the Health Utilities Index Mark II. Pharmacoeconomics 1999;15:141-55.

29. Lefèvre T, d'Ivernois JF, de Andrade V, Crozet C, Lombrail P, Gagnayre R. What do we mean by multimorbidity? An analysis of the literature on multimorbidity measures, associated factors, and impact on health services organization. Rev Epidemiol Sante Publique 2014;62:305-14.

30. Central Bureau of Statistics (The Netheralands). Gezondheid aandoeningen beperkingen; persoonskenmerken. 2012. URL: http://statline.cbs.nl/StatWeb/publication/?DM=SLNL\&PA=81 173ned\&D1=2-30\&D2=0-13,47-51\&D3=0\&D4=I\&VW=T.

31. Hoffman C, Rice D, Sung HY. Persons with chronic conditions: their prevalence and costs. JAMA 1996;276:1473-9.

32. Gijsen R, van Oostrom SH, Schellevis FC. How many people have one or more diseases? Report: Volksgezondheid Toekomst Verkenning (Public Health Future Exploration). 2014. URL: http://www.nationaalkompas.nl.

33. Schram MT, Frijters D, van de Lisdonk EH, Ploemacher J, de Craen AJ, de Waal MW, et al. Setting and registry characteristics affect the prevalence and nature of multimorbidity in the elderly. J Clin Epidemiol 2008;61:1104-12.

34. Fortin M, Stewart M, Poitras ME, Almirall J, Maddocks $H$, et al. A systematic review of prevalence studies on multimorbidity: toward a more uniform methodology. Ann Fam Med 2012;10:142-51.

35. Lehnert T, Heider D, Leicht $H$, Heinrich S, Corrieri S, Luppa M, et al. Review: health care utilization and costs of elderly persons with multiple chronic conditions. Med Care Res Rev 2011;68:387-420.

36. Orueta JF, García-Álvarez A, García-Goñi M, Paolucci F, Nuño-Solinís R. Prevalence and costs ofmultimorbidity by deprivation levels in the Basque country: a population based study using health administrative databases. PLoSOne 2014;9:e89787.

37. Oh IH, Yoon SJ, Seo HY, Kim EJ, Kim YA. The economic burden of musculoskeletal disease in Korea: a cross sectional study. BMC Musculoskelet Disord 2011;12:157.

38. Lubeck DP. The costs of musculoskeletal disease: health needs assessment and health economics. Best Pract Res Clin Rheumatol 2003;17:529-39.

39. Woolf AD, Pfleger B. Burden of major musculoskeletal conditions. Bull World Health Organ 2003;81: 646-56.

40. Groves RM. Nonresponse rates and nonresponse bias in household surveys. Public Opin Q 2006;70: 646-75.

41. American Association for Public Opinion Research (AAPOR). 2014. URL: http://www.aapor.org/Response_Rates_An_Overview1. htm\#.U8LxqrFjPO6.

42. Wijnands JM, Boonen A, Arts IC, Dagnelie PC, Stehouwer CD, van der Linden S. Large epidemiologic studies of gout: challenges in diagnosis and diagnostic criteria. Curr Rheumatol Rep 2011;13:167-74. 
43. Haapanen N, Miilunpalo S, Pasanen M, Oja P, Vuori I. Agreement between questionnaire data and medical records of chronic diseases in middle-aged and elderly Finnish men and women. Am J Epidemiol 1997;145:762-9. 


\section{Supplemental tables}

Table S2.1 Characteristics of the study sample and general Dutch population.

\begin{tabular}{lcc}
\hline Characteristics & Study population & General Dutch population \\
\hline Age: years; mean & 53.65 & 48.31 \\
Gender, \% & & 50 \\
$\quad$ women & 54 & 30.49 \\
Education, \% & & \\
$\quad$ primary school or no education & 4.83 & 21.59 \\
lower professional education & 13.46 & 38.11 \\
middle or secondary professional education & 31.99 & \\
secondary education & 11.08 & \\
university education & 38.63 & $\mathrm{n} / \mathrm{a}$ \\
Origin, \% & & $\mathrm{n} / \mathrm{a}$ \\
$\quad$ western & 94.70 & \\
$1^{\text {st }}$ generation non- western & 2.85 & 1.65 \\
$2^{\text {nd }}$ generation non- western & 2.44 & 49.37 \\
BMl, \% & & 36.76 \\
underweight (<18.5) & 1.25 & 12.22 \\
normal (18.5-24.99) & 51.27 & \\
overweight (25.0- 29.99) & 36.06 & \\
obese ( $\geq 30)$ & 11.42 & \\
\hline
\end{tabular}

Reference: CBS. Nederlanders naar opleidingsrichting, opleidingsniveau, leeftijd en geslacht. 2008. 


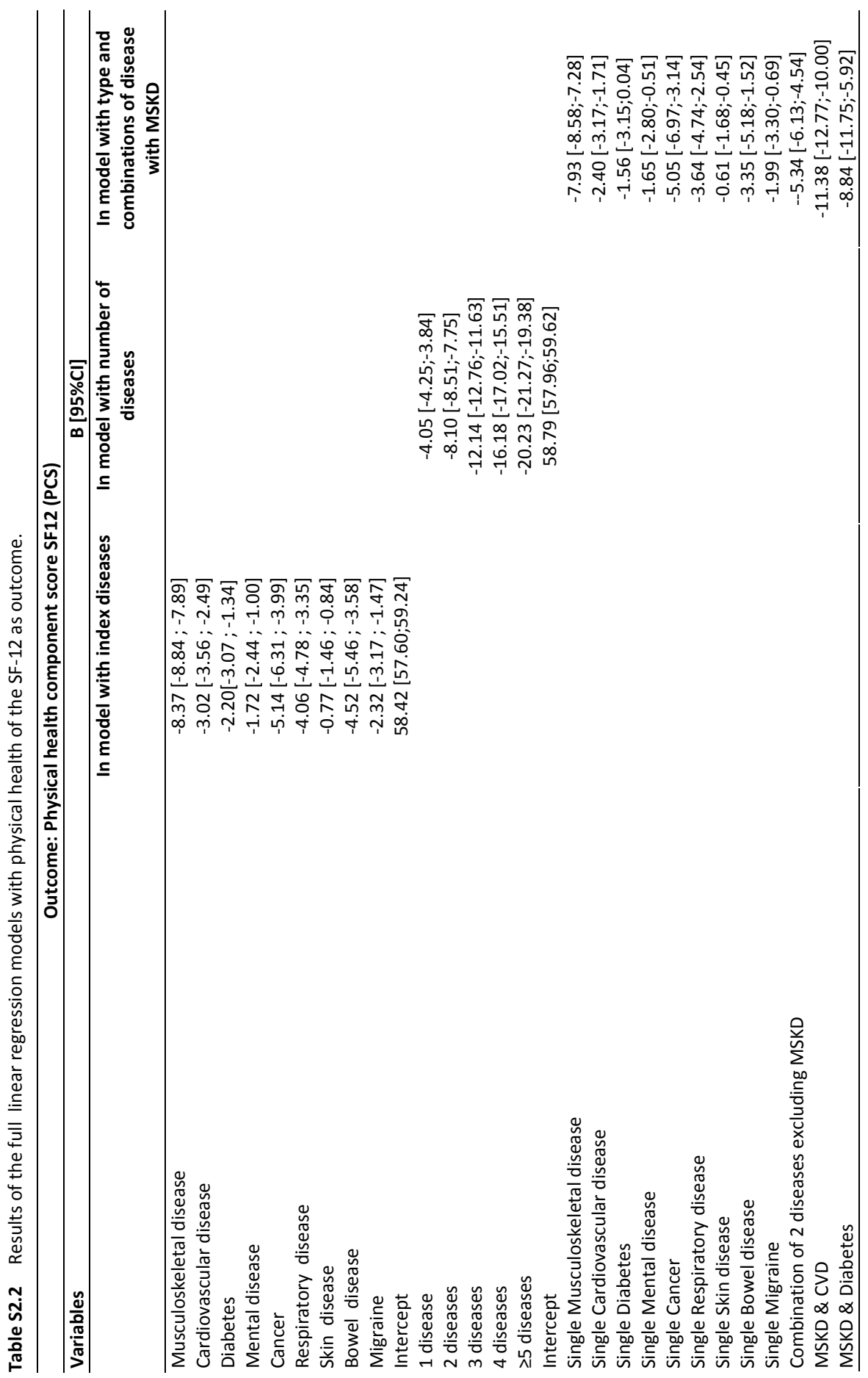




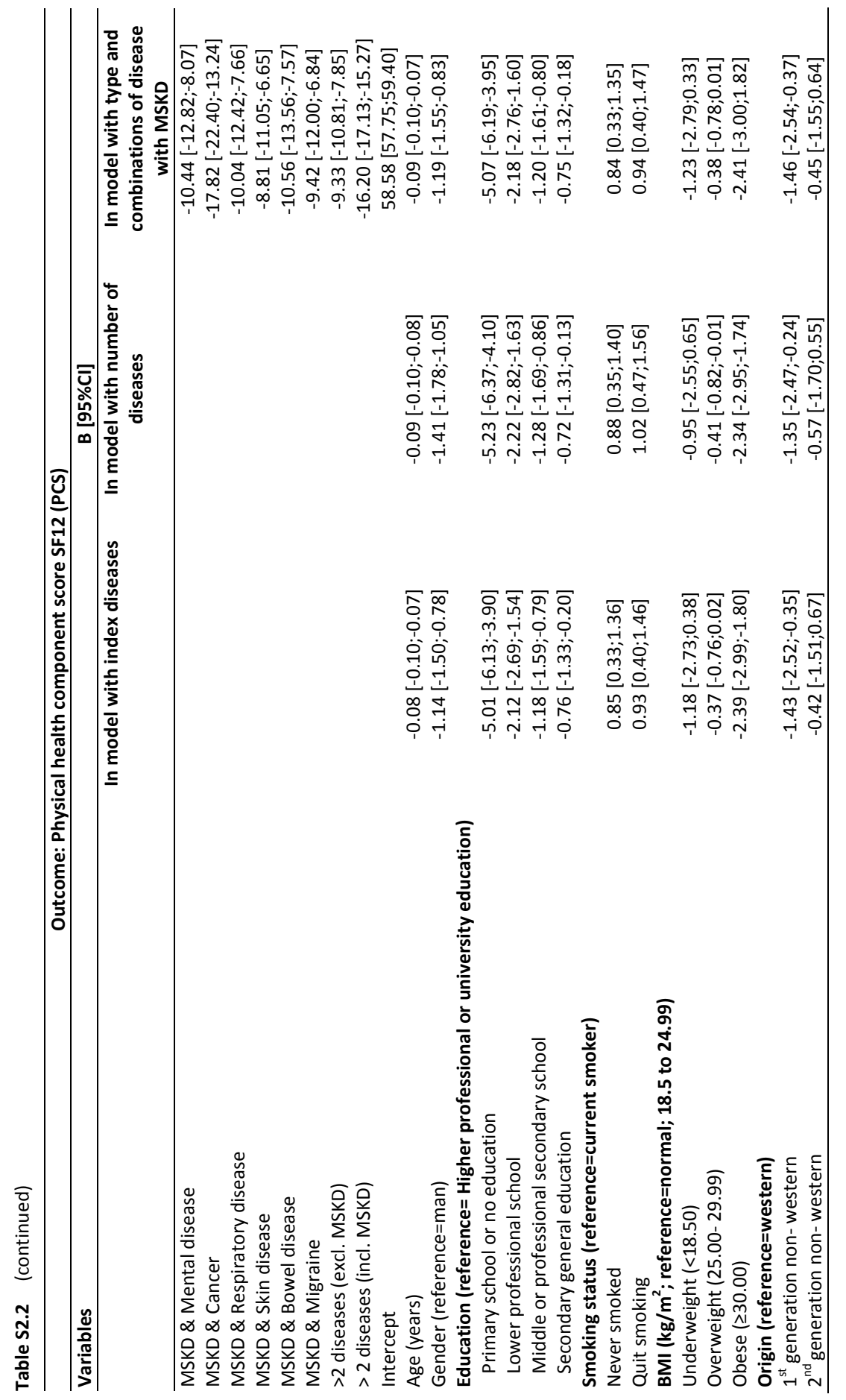




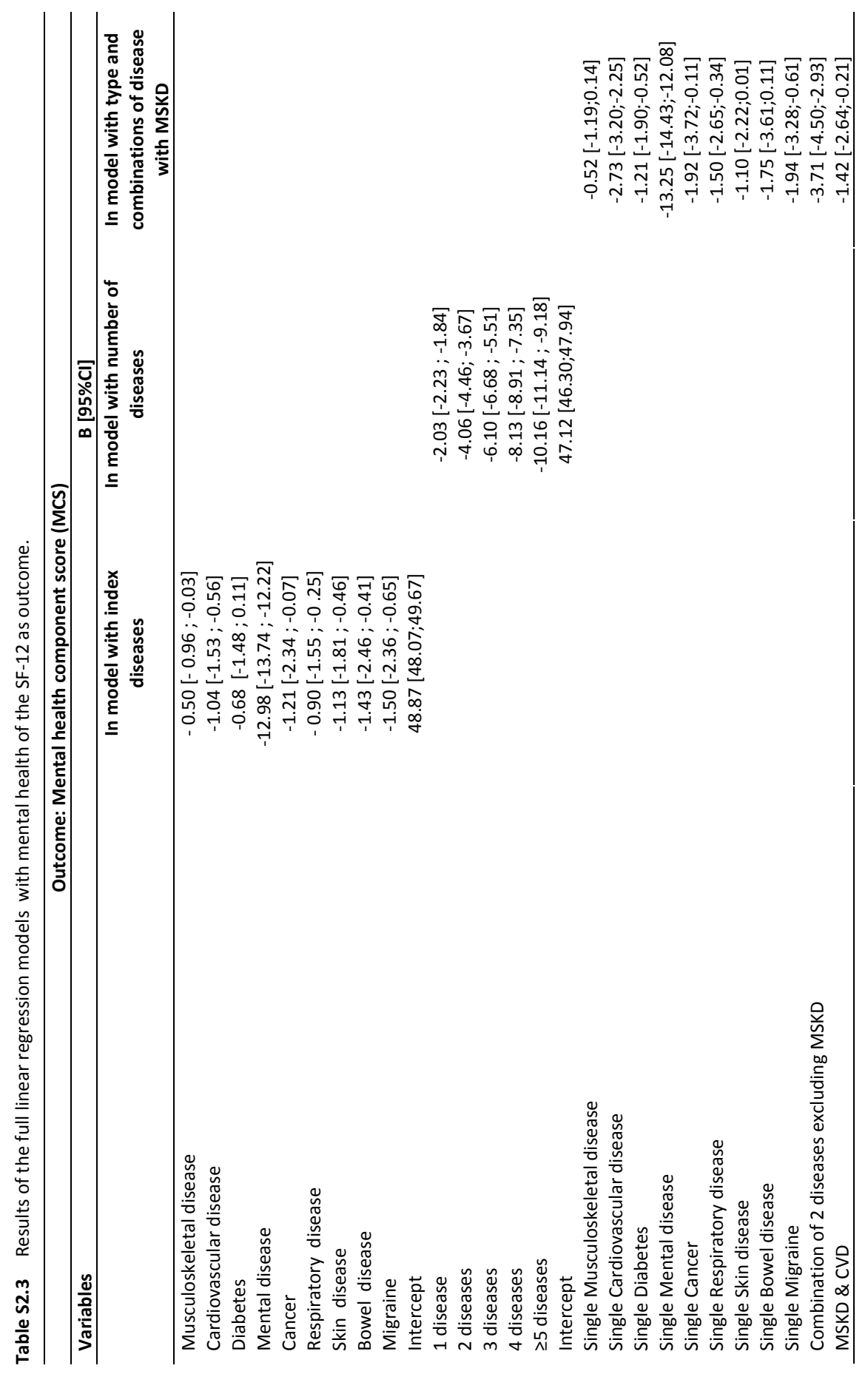




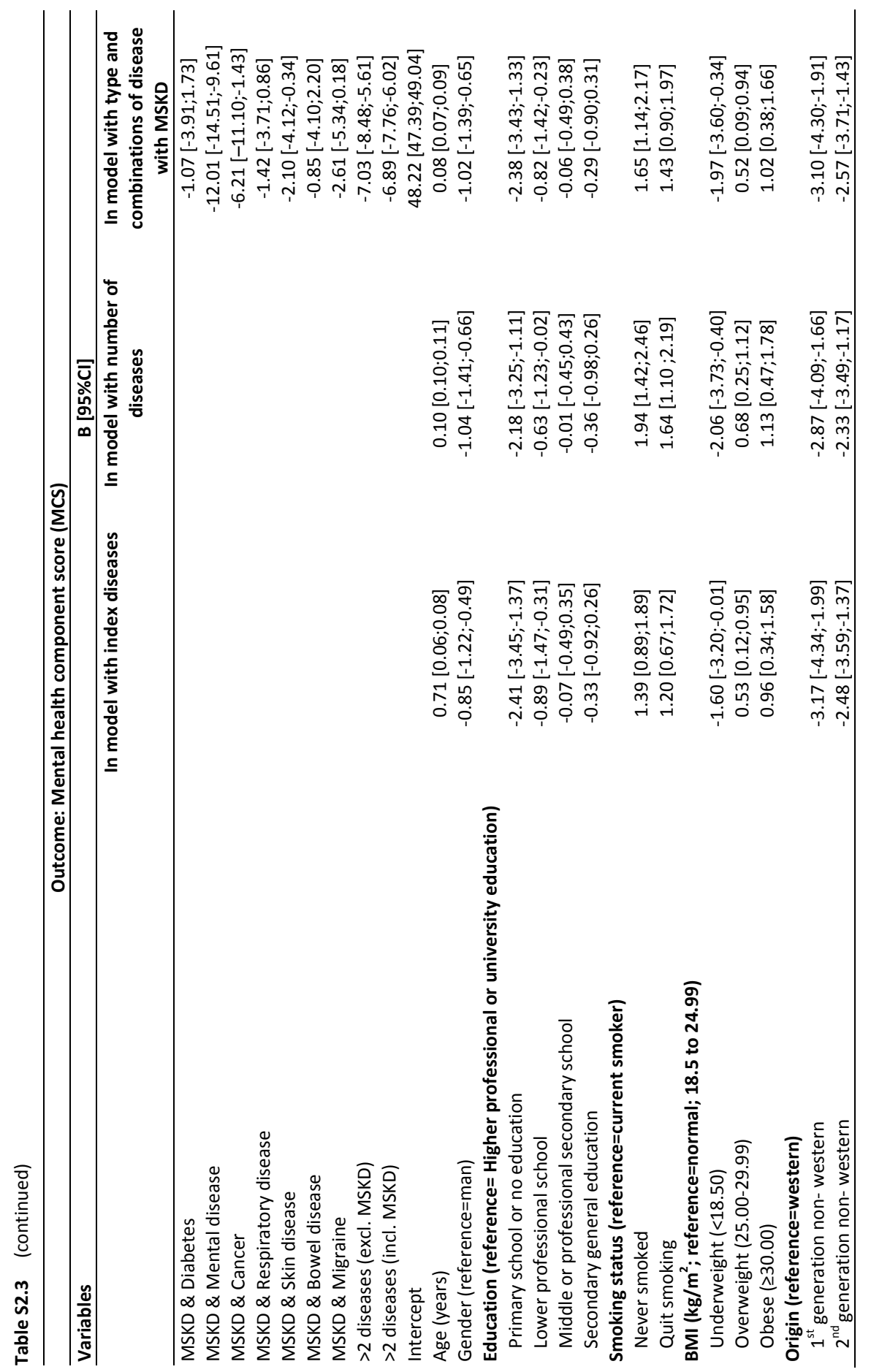




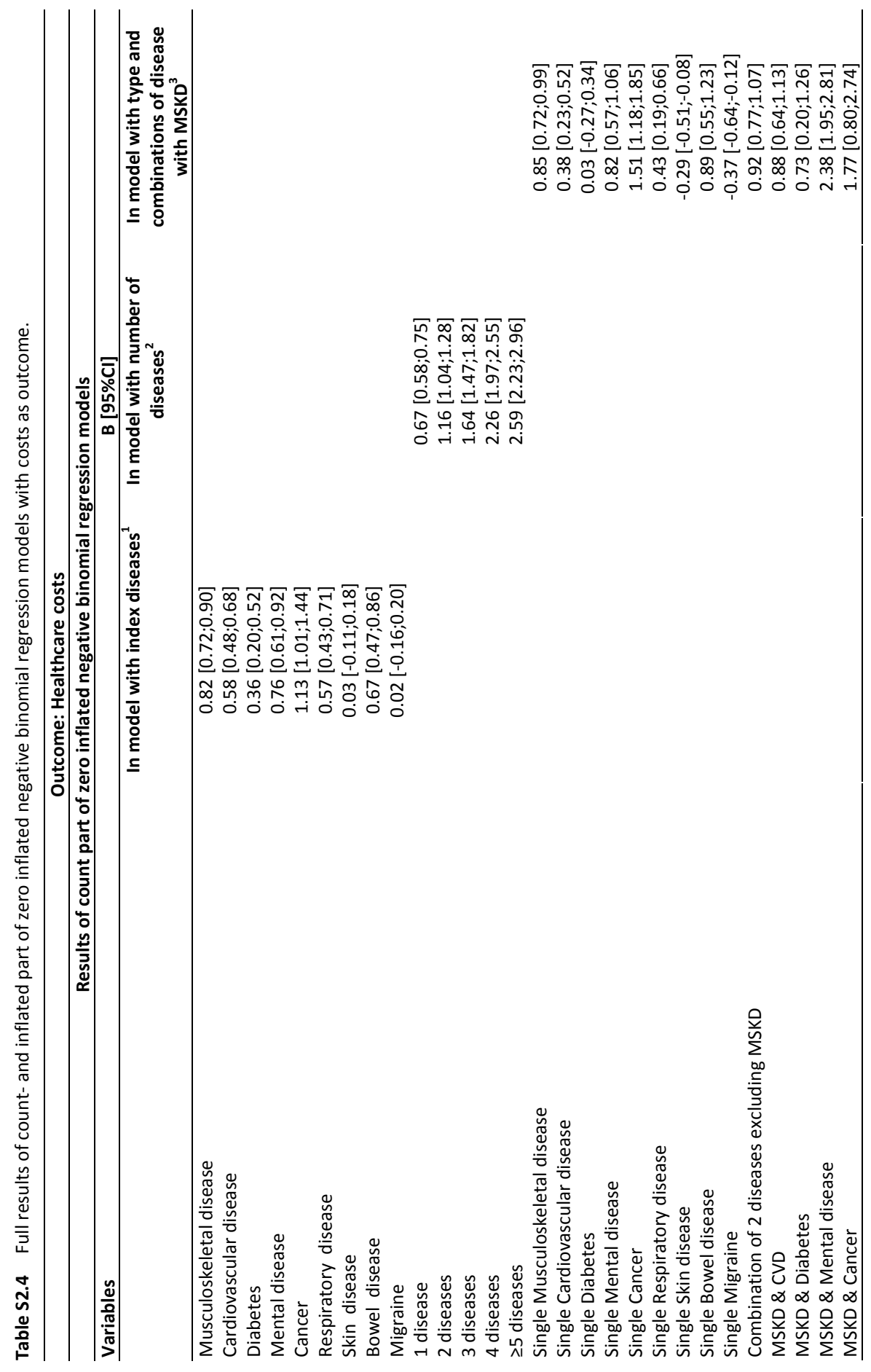




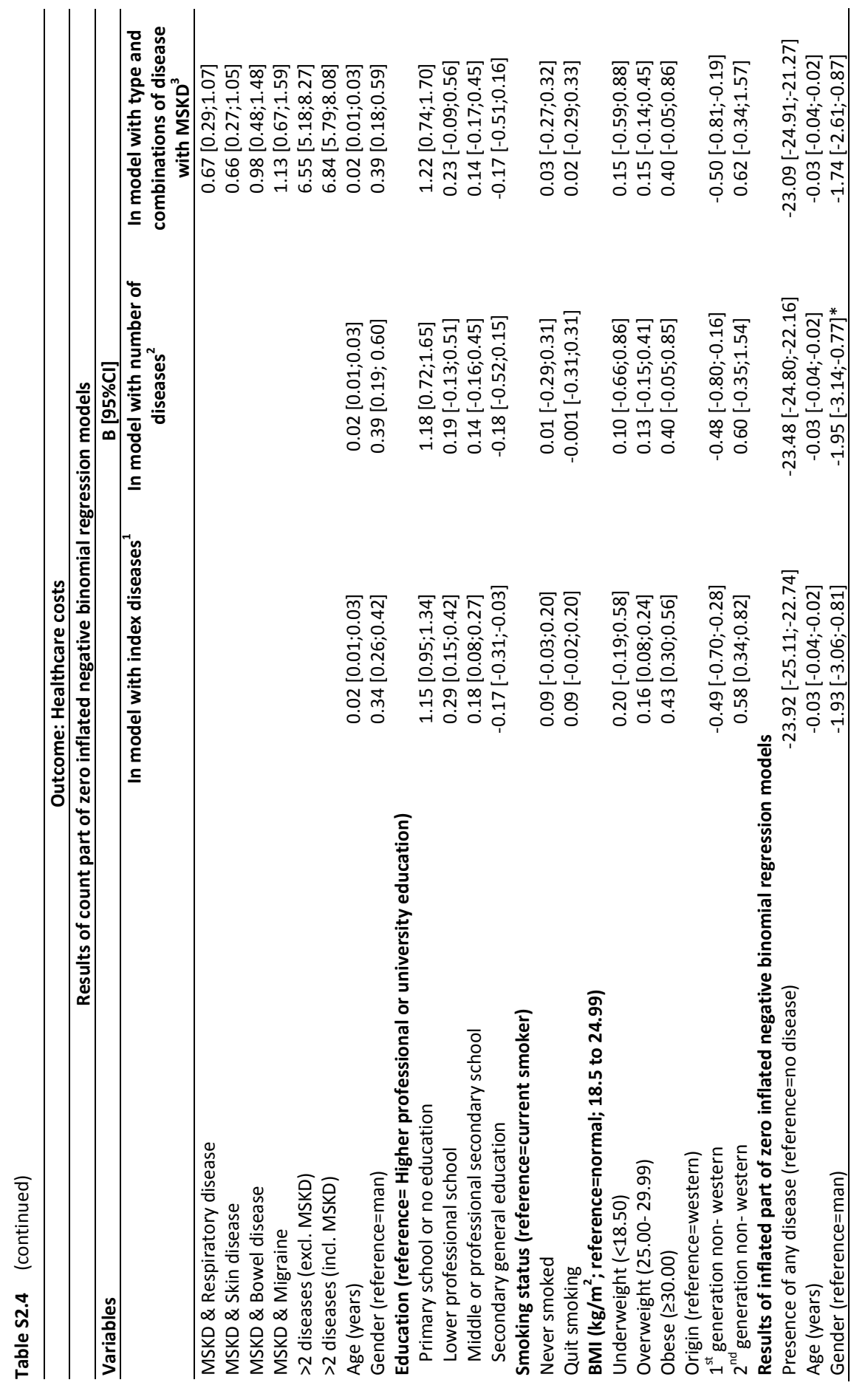




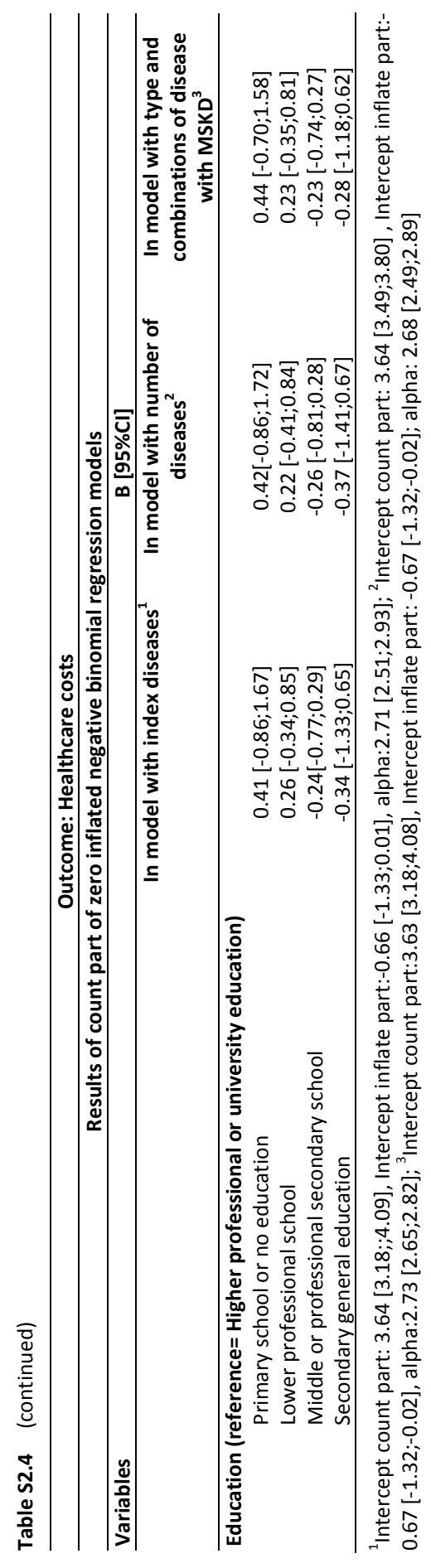


Table S2.5 Modelled 3-months health care costs based on predicted marginal means using the data of the full zero inflated negative binomial models.

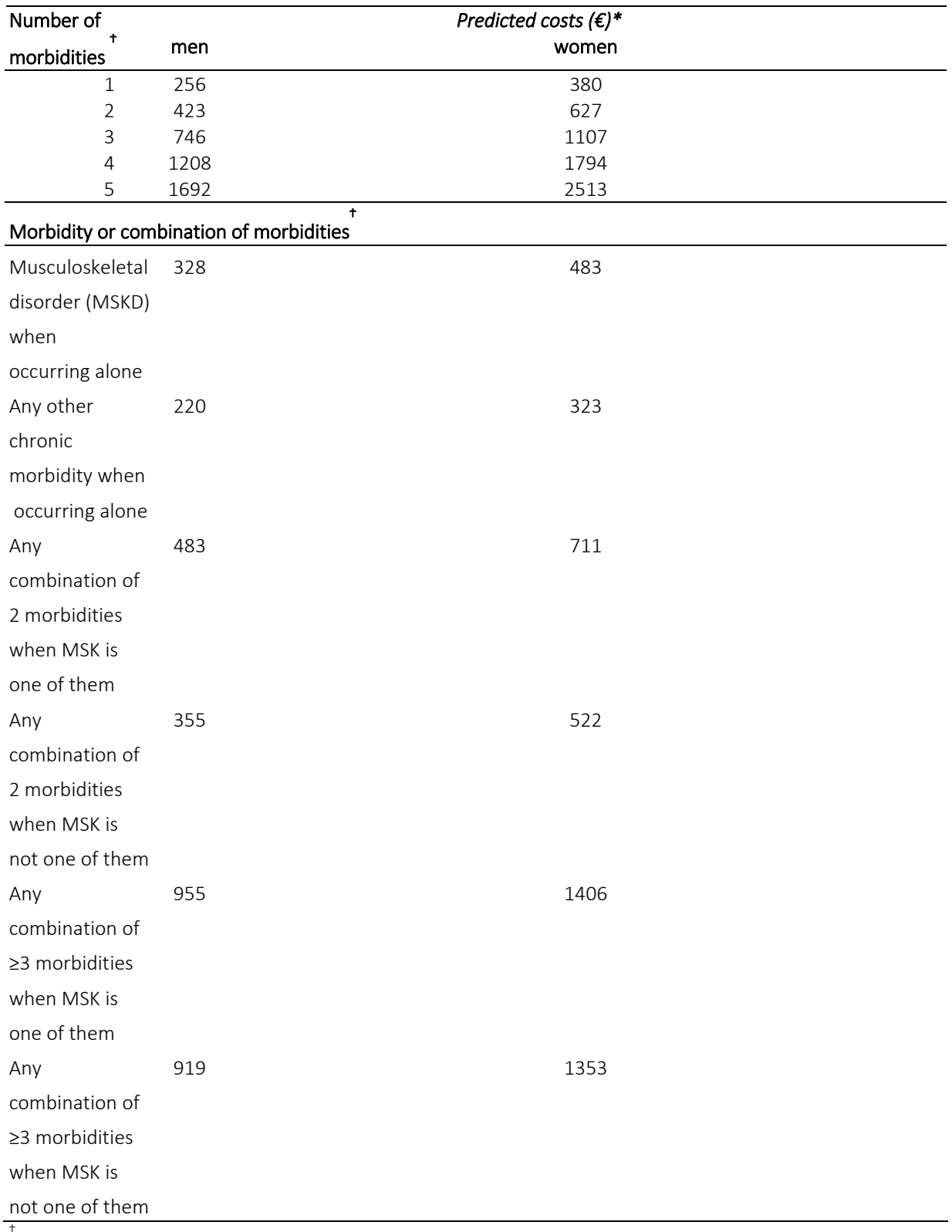

${ }^{\dagger}$ Reference category: no physician diagnosed disease reported. * presented for men and women with median age (54yrs), normal BMI (18.5-25 kg/m²), non-smokers, middle or secondary professional education and western origin 


\section{Chapter 3}

Work outcome in persons with musculoskeletal diseases: comparison with other chronic diseases and the role of musculoskeletal diseases in multimorbidity

Antje van der Zee-Neuen, Polina Putrik, Sofia Ramiro, Andras Keszei, Rob de Bie, Astrid Chorus, Annelies Boonen

BMC Musculoskelet Disord 2017;18(1):10 


\section{Abstract}

\section{Background}

Chronic diseases and multimorbidity are increasingly common among persons in working age. This study explores the impact of type, number and combinations of chronic diseases with focus on the role of MSKD on (1) adverse work status (i.e. work disability (WD), economic unemployment (UE) or receiving a living allowance (LA)) and on (2) the occurrence of sick leave.

\section{Methods}

Subjects participating in a Dutch household survey, who were $\leq 65$ years and could have paid work, provided data on socio-demographics and nine physician diagnosed chronic diseases. To explore the independent association of each chronic disease, of multimorbidity and of MSKD in context of multimorbidity with 1) work status (employed, WD, LA, UE) and 2) sick leave (SL) in those employed, multinomial logistic regressions and logistic regressions were used, respectively.

\section{Results}

Among 5396 subjects, MSKD was the most common morbidity (17\%), multimorbidity occurred in $755 / 5396$ (14\%), 436/755 (61\%) of subjects with multimorbidity had an MSKD. For MSKD the odds of WD, LA and UE were 2.06 [95\% Cl 1.56;2.71], 2.15 [1.18;3.91] and $1.35[0.94 ; 1.96]$, respectively, compared to being employed and the odds of SL in MSKD were 2.29 [1.92;2.73]. Mental diseases had a stronger impact on all these outcomes. The odds for adverse work outcomes increased strongly with an increasing number of diseases. When an MSKD was part of multimorbidity, an additional impact on the association with WD and SL was observed.

\section{Conclusions}

Multimorbidity has a stronger impact on all work outcomes compared to single chronic diseases. The presence of the MSKD in the context of multimorbidity amplifies the chance of WD or SL. 


\section{Introduction}

Worldwide, chronic diseases are becoming increasingly prevalent, partly as a consequence of ageing and earlier diagnosis, but also as a consequence of lifestyle changes. According to the Global Burden of Disease initiative, musculoskeletal (MSKD), cardiovascular (CVD), respiratory, mental and gastro-intestinal diseases, diabetes and, somewhat less frequent, cancer are among the most common chronic diseases. ${ }^{1}$ In the Netherlands, approximately $31 \%$ of the general population reports at least one chronic condition. ${ }^{2}$ As the incidence and prevalence of all these conditions is age dependent, the rise is particularly impressive in persons after the age of 50 years. Parallel with this rise, the occurrence of multimorbidity, i.e. the co-occurrence of two or more diseases in one person, is more frequently observed. ${ }^{3,4}$

Existing literature on chronic diseases and multimorbidity mainly focused on the prevalence and the impact on health related quality of life. However, since diagnoses of chronic diseases are increasingly made at younger age, and as in many Western countries the age of retirement is systematically raised to deal with the financial burden associated with the aging of the population, chronic conditions and multimorbidity have potentially large effects on labor force participation. ${ }^{5-8}$

Among chronic diseases, MKSD, together with mental diseases, are the main reason of expenditures for work disability (WD) and sick leave (SL) in Western countries when accounting for their prevalence. ${ }^{9,10}$ Nonetheless, comparisons of the relative impact of major chronic diseases on work outcomes have rarely been performed. ${ }^{11,12}$ Yet, such knowledge could be of interest, as similar adverse impact of all chronic diseases on work participation could call for a shared responsibility across medical specialties. Also, the majority of studies concentrate on work disability and/or sick leave as adverse work outcome. However, to obtain a broad view on the consequences of chronic diseases on work participation, it is important to study the impact on sick leave in those still working but also the impact on work disability, (economic) unemployment (UE) and dependence on living allowances (LA). With respect to the latter two outcomes it should be recognized that not all persons with a chronic condition are eligible for an official work disability allowance, but will be vulnerable on the labor market and therefore become (or remain) unemployed and finally dependent on a living allowance. Existing literature on the impact of multimorbidity on work outcomes is scarce and often restricted to the study of two specific combinations of diseases such as rheumatoid arthritis (RA) and depression or cardiovascular disease, ${ }^{13,14}$ and as such addresses the influence of comorbidities on the disease of interest (in this example RA). The lack of interest in multimorbidity is surprising, given that multimorbidity might well be a strong and relevant risk factor for adverse work outcome. Several questions can be raised. First, how strong is the impact of increasing numbers of comorbidities on the different work outcomes. Second, what counts most, the number of morbidities or 
the specific combinations of chronic diseases. Especially from the rheumatologist's point of view, it would be interesting to understand whether the presence of an MSKD as part of multimorbidity would amplify the impact of multimorbidity on adverse work outcome. An amplifying role of MSKD would argue for special attention for patients that have an MSKD as part of their multimorbidity.

The current study aimed to compare the impact of type, number and combinations of chronic diseases with focus on the role of MSKD on (1) adverse work status (i.e. work disability, economic unemployment or receiving a living allowance) and on (2) the occurrence of sick leave. We hypothesized that all chronic diseases are associated with an increased risk of work disability compared to the general population and to a lesser extent with unemployment and dependence on a living allowance and that the presence of a MSKD in multimorbidity patterns is associated with a higher risk of adverse work outcome than multimorbidity patterns without MSKD.

\section{Methods}

Data from The National Monitor on Musculoskeletal System 2010, a household survey conducted by the Dutch organization for applied scientific research were used. ${ }^{15}$ The study was approved by the Medical Ethical Committee of the Leiden University Medical Center. The detailed approach of sampling and data collection is described elsewhere. ${ }^{16}$ In brief, a random sample of Dutch households was contacted by letter and members of the household older than 18 years who were the next to have their birthday were invited to complete and return the questionnaire. Among others, information was collected on sociodemographics (age, gender, highest level of achieved education (i.e. no or primary education, lower professional, middle or secondary professional, general secondary (high school) or higher professional or university education), origin (western, first generation non-western, second generation non-western), lifestyle (weight and height, computed into BMI $\left(\mathrm{kg} / \mathrm{m}^{2}\right.$; underweight $<18.5$; normal: 18.5- <25.0; pre-obese: 25.0- <30.0; obese: $\geq 30.0)$ ); smoking-status (never, past, current)), nine self-reported physician-diagnosed diseases over the last year (i.e. MSKD (defined as severe, persisting complaints in or around joints), diabetes, cardiovascular disease (CVD, defined as hypertension, cerebral hemorrhage/stroke, myocardial infarction, other heart-diseases or peripheral vascular disease), cancer, migraine, respiratory disease, skin disease, mental diseases and gastrointestinal disease), work status (being employed, being retired, being economically unemployed, $W D$, receiving $L A$, being housewife or houseman, being a student) and having been on sick leave (SL (yes/no)) during the past 12 months when employed. In this study, we considered $\geq 2$ chronic diseases in one person as multimorbidity. ${ }^{3,4}$ The presence of one of the nine chronic diseases, regardless of the presence of other diseases, was referred 
to as the 'index disease' and the presence of one of the nine diseases only (no other disease present) was referred to as 'single disease'.

\section{Statistical analysis}

Persons of working age (18-65 years) who had paid work, were WD, UE or depending on a LA were included in the analyses when work status was the outcome. When SL in the last 12 months was the outcome, the sample was restricted to those with paid work who answered the question on sick leave.

Work disability, economic unemployment and receiving a living allowance

To assess the odds to be WD, UE or depending on a LA for subjects with the different morbidities or morbidity patterns compared to having paid work, multinomial regressions were used. Multinomial regressions are useful when the outcome (having no work) can be further classified in different categories (work disabled, economically unemployed or receiving a living allowance).

First, a multinomial regression was performed with the different chronic diseases (index disease compared to no index disease) as the independent variables of interest. Next, a multinomial regression was performed with the number of morbidities $(1 ; 2 ; 3$; $\geq 4$ diseases, reference $=$ no disease reported) as independent variable of interest. Thirdly, a multinomial regression was computed with single diseases (i.e. presence of only one disease) and multimorbidity including MSKD and multimorbidity excluding MSKD as independent variables of interest (reference $=$ no disease). In a scenario analysis, this model was repeated when those with multimorbidity were further classified into 2 or $\geq 3$ diseases with or without MSKD. From the results of the model with the number of morbidities, the predicted probability of work disability with increasing morbidities and age was calculated for a non-smoking subject with middle or professional secondary education and normal BMI, averaged for gender.

\section{Sick leave}

To explore the association of the different chronic diseases (index disease), the number of diseases, or single diseases and multimorbidity in- and excluding MSKD with sick leave logistic regressions were computed. In a scenario analysis, the model including single diseases and multimorbidity was repeated when those with multimorbidity were further classified into 2 or $\geq 3$ diseases with or without MSKD. 


\section{Model development}

In all models, age, gender, BMI, smoking status, origin and education were considered potential confounders. Manual forward selection was used to develop fully adjusted models. Variables remained in the multivariable model when they were either significantly associated with the outcome $(p \leq 0.05)$ or confounded the association of the disease (dependent) with the outcome (i.e., $\geq 10 \%$ change in the coefficient). All analyses were performed on complete cases using STATA statistical software $12.0 .^{17}$

\section{Results}

The questionnaire was returned by 8904 (22.4\%) subjects of whom 5396 were $\leq 65$ years and were either employed $(n=4805 ; 89 \%)$, WD ( $n=350 ; 7 \%)$, depending on LA $(n=57 ; 3 \%)$ or UE ( $n=184 ; 3 \%)$.

The mean age was 46 years (SD 11) and 3008 (56\%) were women (Table 3.1). MSKD was reported by 925 subjects (17\%), 662 (12\%) had CVD, 180 (3\%) diabetes, 96 (2\%) cancer, 355 (7\%) respiratory disease, 359 (7\%) skin disease, 376 (7\%) mental disease, 164 (3\%) a bowel (i.e. gastro-intestinal) disease and 275 (5\%) migraine. Multimorbidity was present in $14 \%(n=755)$ of the cases. Of all persons with 2 morbidities 265/490 (54\%) reported an MSKD and of all persons with $\geq 3$ morbidities 198/265 (75\%) reported an MSKD (Table 3.2).

In the total group, the disease that was most prevalent among persons with adverse work outcome was MSKD: 43\% (152/350) of those with a WD, 42\% (24/57) of those with a LA and $23 \%(43 / 184)$ of those with UE had an MSKD.

An overview of the characteristics of the subsample with paid work $(n=4805)$, in which the occurrence of sick leave in the past year was studied, is presented in Supplemental Table S3.1. MSKD was reported by 706 (15\%), multimorbidity was present in 493 (10\%) subjects and of those with multimorbidity 286 (58\%) reported an MSKD.

Work disability, economic unemployment or receiving a living allowance compared to paid work

The model addressing the impact of the different chronic disease on work status showed that patients with MSKD had significantly higher odds to be WD (OR 2.06 [95\% $\mathrm{CI} 1.56 ; 2.71])$ and have a LA $(2.15[1.18 ; 3.91])$ but not to be UE $(1.35[0.94 ; 1.96])$ when using "paid work" as the reference outcome. Similar patterns were observed for other diseases. However, the strongest association with all work outcomes was seen for mental diseases (Table 3.3). 
Table 3.1 Characteristics of the study population*

\begin{tabular}{|c|c|}
\hline & $(\mathrm{N}=5,396)$ \\
\hline Age, mean (SD) & $45.8(11.0)$ \\
\hline Women, n (\%) & $3008(55.8)$ \\
\hline \multicolumn{2}{|l|}{ Work status } \\
\hline Paid work & $4,805(89.1)$ \\
\hline Work disabled & $350(6.5)$ \\
\hline Unemployed & $184(3.4)$ \\
\hline Living allowance & $57(1.1)$ \\
\hline \multicolumn{2}{|l|}{ BMI, n (\%) } \\
\hline underweight & $69(1.3)$ \\
\hline normal & $2,853(52.9)$ \\
\hline pre-obese & $1,784(33.1)$ \\
\hline obese & $690(12.8)$ \\
\hline Level of education, n (\%) & $n=5357$ \\
\hline Primary school or no education & $105(2.0)$ \\
\hline Lower professional school & $544(10.2)$ \\
\hline Middle or professional secondary school & $1677(31.3)$ \\
\hline Secondary education & $567(10.6)$ \\
\hline University education & $2,464(46.0)$ \\
\hline Smoking status, n (\%) & $n=5381$ \\
\hline Current smoker & $1,057(19.6)$ \\
\hline Never smoked & $2,535(47.1)$ \\
\hline Former smoker & $1,789(23.3)$ \\
\hline \multicolumn{2}{|l|}{ Number of morbidities*, n (\%) } \\
\hline 0 & $3,156(58.5)$ \\
\hline 1 & $1,485(27.5)$ \\
\hline 2 & $490(9.1)$ \\
\hline$\geq 3$ & $265(4.9)$ \\
\hline Sick leave during past 12 months in subsample with paid work & $n=4,805$ \\
\hline Yes, sick leave n (\%) & $2264(47.1)$ \\
\hline
\end{tabular}

* Population is $\leq 65$ years, has either paid work, is work disabled, unemployed or is depending on a living allowance.

In the model addressing the association of an increasing number of morbidities with work status, the odds of WD in persons with one morbidity were OR 3.31 [2.35; 4.65]. Each additional morbidity was associated with a steep increase in odds of WD (Table 3.4). Figure 3.1 illustrates the predicted probability of WD with an increasing number of morbidities and with increasing age. The odds of depending on LA or being UE became significantly increased when more than one morbidity was present 


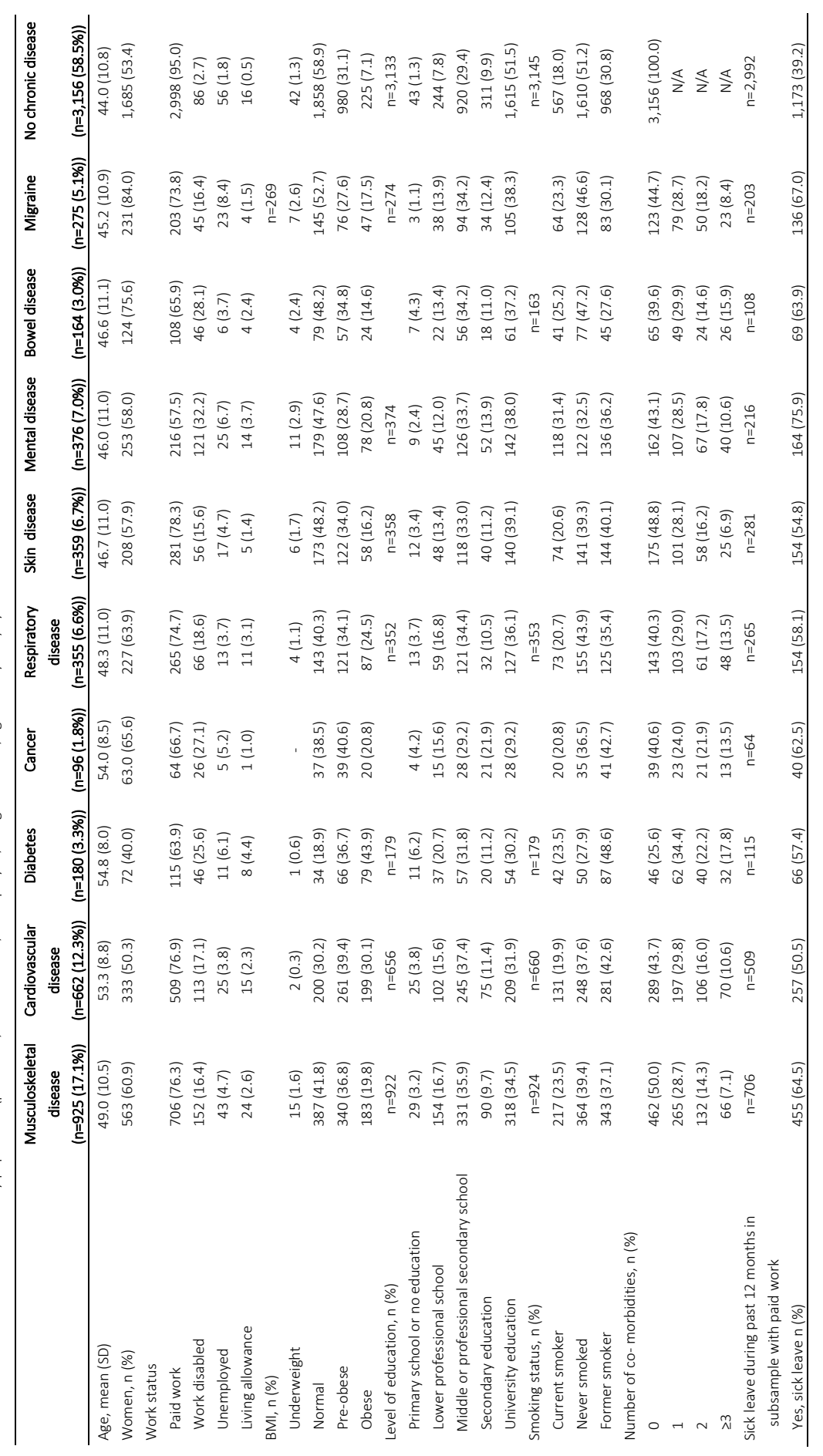


Table 3.3 Adjusted association between the presence of a chronic disease (index disease) and work disability, dependence on living allowances, and economic unemployment compared to 'being employed'.

\begin{tabular}{lccc}
\hline Index diseases $^{+}$ & $\begin{array}{c}\text { Work disabled* } \\
\text { (OR }[95 \% \mathrm{CI}])\end{array}$ & $\begin{array}{c}\text { Living allowances* } \\
\text { (OR }[95 \% \mathrm{CI}])\end{array}$ & $\begin{array}{c}\text { Unemployed* } \\
\text { (OR [95\% CI]) }\end{array}$ \\
\hline Musculoskeletal disease & $2.06[1.56 ; 2.71]$ & $2.15[1.18 ; 3.91]$ & $1.35[0.94 ; 1.96]$ \\
Cardiovascular disease & $1.61[1.18 ; 2.21]$ & $1.29[0.64 ; 2.62]$ & $0.88[0.55 ; 1.40]$ \\
Diabetes & $2.32[1.47 ; 3.67]$ & $3.40[1.38 ; 8.37]$ & $1.88[0.95 ; 3.72]$ \\
Cancer & $3.26[1.82 ; 5.85]$ & $0.69[0.09 ; 5.49]$ & $1.73[0.67 ; 4.48]$ \\
Respiratory disease & $1.72[1.16 ; 2.55]$ & $2.02[0.94 ; 4.38]$ & $1.08[0.59 ; 1.94]$ \\
Skin disease & $1.96[1.34 ; 2.86]$ & $1.02[0.38 ; 2.75]$ & $1.37[0.81 ; 2.32]$ \\
Mental disease & $10.54[7.69 ; 14.44]$ & $5.60[2.77 ; 11.34]$ & $3.03[1.91 ; 4.80]$ \\
Bowel disease & $2.89[1.74 ; 4.79]$ & $1.65[0.52 ; 5.29]$ & $1.10[0.46 ; 2.60]$ \\
Migraine & $2.03[1.30 ; 3.18]$ & $1.13[0.38 ; 3.40]$ & $3.10[1.90 ; 5.04]$ \\
\hline
\end{tabular}

Results of multivariable multinomial regression model adjusted for age, gender, education, BMI, smoking status ( $n=5,340)$. OR: odds ratio; $\mathrm{Cl}$ : confidence interval. * Paid work is the reference outcome; $†$ Absence of index disease is the reference category

Table 3.4 Adjusted association between the number of diseases and multimorbidity, in- and excluding musculoskeletal disease, and work status compared to 'being employed'.

\begin{tabular}{|c|c|c|c|}
\hline Number of diseases $^{\dagger}$ & $\begin{array}{c}\text { Work disabled* } \\
\text { OR }[95 \% \mathrm{Cl}]\end{array}$ & $\begin{array}{c}\text { Living allowances* } \\
\text { OR }[95 \% \mathrm{Cl}]\end{array}$ & $\begin{array}{c}\text { Unemployed* } \\
\text { OR [95\% Cl] }\end{array}$ \\
\hline 1 & $3.31[2.35 ; 4.65]^{a}$ & $1.46[0.69 ; 3.10]$ & $1.32[0.92 ; 1.88]$ \\
\hline 2 & $9.16[6.32 ; 13.27]^{\mathrm{a}}$ & $3.76[1.67 ; 8.46]^{\mathrm{a}}$ & $55[1.63 ; 4.00]^{\mathrm{a}}$ \\
\hline 3 & $14.03[8.88 ; 22.16]$ & $6.37[2.46 ; 16.51]$ & $3.08[1.60 ; 5.92]$ \\
\hline$\geq 4$ & $30.33[14.87 ; 61.85]^{\mathrm{a}}$ & $16.29[4.94 ; 53.67]$ & $4.50[1.58 ; 13.62]$ \\
\hline $\begin{array}{l}\text { Single and multimorbidity in- and } \\
\text { excluding } \mathrm{MSKD}^{+}\end{array}$ & $\begin{array}{c}\text { Work disabled* } \\
\text { OR }[95 \% \mathrm{Cl}]\end{array}$ & $\begin{array}{l}\text { Living allowances* } \\
\quad \text { OR }[95 \% \mathrm{Cl}]\end{array}$ & $\begin{array}{l}\text { Unemployed* } \\
\text { OR }[95 \% \mathrm{Cl}]\end{array}$ \\
\hline Single morbidity being an MSKD & $2.00[1.19 ; 3.39]^{b}$ & $1.39[0.49 ; 3.99]$ & $1.23[0.71 ; 2.14]$ \\
\hline Single morbidity other than MSKD & $3.91[2.73 ; 5.60]$ & $1.48[0.64 ; 3.47]$ & $1.36[0.91 ; 2.02]$ \\
\hline Multimorbidity including MSKD & $14.35[10.02 ; 20.56]$ & $6.32[2.99 ; 13.35]$ & $2.84[1.78 ; 4.53]$ \\
\hline Multimorbidity excluding MSKD & $9.92[6.54 ; 15.05]$ & $3.34[1.25 ; 8.94]$ & $2.65[1.54 ; 4.58]$ \\
\hline
\end{tabular}

Results of multivariable multinomial regression model adjusted for age, gender, education, BMI \& smokingstatus $(n=5,340) *$ Paid work is the reference outcome. + No morbidity is the reference category. ${ }^{a}$ Significantly different from estimate for previous disease count (i.e.1 vs. 0; 2 vs. 1 etcetera); ${ }^{b}$ Significantly different from estimate for single morbidity other than MSKD; ${ }^{c}$ Significantly different from estimate for multimorbidity excluding MSKD. MSKD: musculoskeletal disorder; OR: odds ratio; Cl: confidence interval.

The model addressing the association of single diseases or multimorbidity with or without MSKD with work status revealed that when an MSKD was part of multimorbidity, the odds of WD, dependence on LA and UE increased (although not significantly) (Table 3.4). When exploring the influence of the presence of an MSKD in the context of 2 or $\geq 3$ morbidities similar trends (adverse influence of presence of an MSKD) were seen (Supplemental Table S3.2). Additional analyses on the impact of specific combinations of MSKD with each of the other chronic disease revealed that the co-occurrence of MSKD, cancer and mental diseases had the largest impact on WD and 
that co-occurrence of MSKD and mental diseases had the strongest association with dependence on LA and UE (Supplemental Table S3.3).

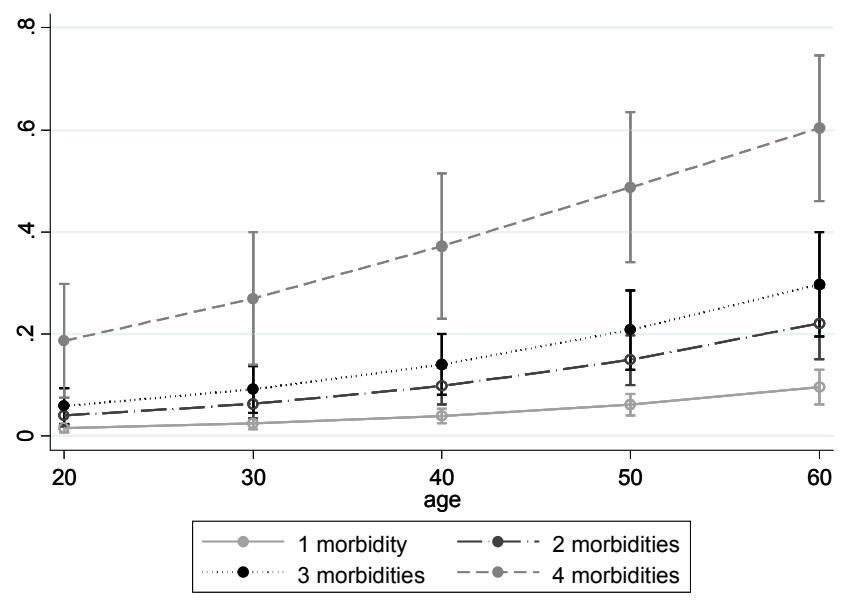

Figure 3.1 Predicted probability* of work disability by number of morbidities at indicated age. ${ }^{*}$ Predicted probability for non-smoking subjects with middle or professional secondary education and normal BMI based on model estimates shown in Table 3.3.

\section{Sick leave}

Among those employed, persons with MSKD had increased odds for sick leave (2.29 [1.92; 2.73]). Persons with mental diseases $(3.24[2.33 ; 4.52])$ or cancer $(2.20$ [1.28;3.76]) had higher or comparable odds, respectively (Table 3.5).

While the odds of sick leave were significantly higher in persons having (any) single morbidity compared to those without a disease (OR 2.00 [95\% Cl 1.75; 2.30]), the odds of sick leave increased with increasing number of morbidities (Table 3.5). The odds of sick leave were significantly higher when a MSKD was part of the multimorbidity (OR 1.70 [95\% Cl 1.15;2.51]) (Table 3.5). An amplifying effect of the presence of an MSKD on SL was seen irrespective of the number of morbidities present (Supplemental Table S3.4). 
Table 3.5 Odds of sick leave in the past 12 months by morbidity (types and number).

\begin{tabular}{|c|c|}
\hline & $\begin{array}{c}\text { Multivariable } \\
\text { OR }[95 \% \mathrm{Cl}]\end{array}$ \\
\hline \multicolumn{2}{|l|}{ Index diseases $^{+}$} \\
\hline Musculoskeletal disease & $2.29[1.92 ; 2.73]$ \\
\hline Cardiovascular disease & $1.21[0.99 ; 1.49]$ \\
\hline Diabetes & $1.46[0.97 ; 2.20]$ \\
\hline Respiratory disease & $1.37[1.05 ; 1.79]$ \\
\hline Mental disease & $3.24[2.33 ; 4.52]$ \\
\hline Cancer & $2.20[1.28 ; 3.76]$ \\
\hline Skin disease & $1.24[0.96 ; 1.61]$ \\
\hline Bowel disease & $1.54[1.01 ; 2.34]$ \\
\hline Migraine & $1.91[1.39 ; 2.63]$ \\
\hline \multicolumn{2}{|l|}{ Number of morbidities* } \\
\hline 1 & $2.00[1.75 ; 2.30]^{a}$ \\
\hline 2 & $2.72[2.14 ; 3.44]^{a}$ \\
\hline 3 & $4.22[2.74 ; 6.51]$ \\
\hline$\geq 4$ & $8.19[2.73 ; 24.59]$ \\
\hline \multicolumn{2}{|c|}{ Single morbidity/multimorbidity in- and excluding MSKD* } \\
\hline Musculoskeletal disease & $2.50[2.01 ; 3.10]^{b}$ \\
\hline Any disease excl. MSKD & $1.81[1.55 ; 2.12]$ \\
\hline Multimorbidity including MSKD & $4.04[3.07 ; 5.34]^{c}$ \\
\hline Multimorbidity excluding MSKD & $2.40[1.78 ; 3.24]$ \\
\hline
\end{tabular}

Results of multivariable logistic regression models adjusted for age, gender, level of education, origin, BMI and smoking status $(n=4,770)$. ' reference category= population without the index disease; *reference category= healthy population; ${ }^{a}$ Significantly different from estimate for previous disease count (i.e.1 vs. 0; 2 vs. 1 etcetera); ${ }^{\text {b }}$ Significantly different from estimate for single morbidity other than MSKD; ${ }^{c}$ Significantly different from estimate for multimorbidity excluding MSKD. MSKD: musculoskeletal disorder; OR: odds ratio; $\mathrm{Cl}$ : confidence interval.

\section{Discussion}

Although we hypothesized that MSKD would have stronger associations with work outcomes when compared to other conditions, data revealed that all chronic diseases were associated with WD and depending on LA. On the same line, the majority of conditions were also associated with the likelihood of incurring SL in the previous 12 months. As expected, when the number of morbidities increases, the odds of any adverse work outcome increased as well. Consistent with our hypothesis, the presence of MSKD in the context of multimorbidity tended to amplify the risk for adverse work outcome and especially of sick leave.

While from a societal point of view MSKD and mental diseases account for the majority of expenditures for SL and WD in most of Western countries, our data emphasize that for MSKD this is mainly attributable to their higher prevalence among persons in the working age range. When comparing the relative impact on adverse work outcomes across diseases, mental diseases clearly have the largest impact on WD and LA, but for 
all other chronic diseases the association with WD and depending on a LA was in the same range. An exception was the association with sick leave, where no impact for CVD, diabetes and skin diseases was observed, but where patients with mental disease followed by MSKD and cancer incurred substantial SL in the previous 12 months.

Only few studies compared the relative impact of distinct chronic diseases on the different types of work outcomes. In an international study across 10 European countries including 11,462 patients, Alavinia et al. compared the association of heart attack, hypertension, stroke, diabetes, chronic lung disease and asthma and depressive symptoms with economic unemployment, after excluding persons with official work disability. ${ }^{12}$ They found that the chronic diseases studied had no impact on economic UE, except for the presence of depressive symptoms. On the other hand, a prospective study among 707 Finnish construction workers showed that health problems predict long term unemployment. In this study unemployment was defined as joblessness longer than 24 months and it is unclear to what extent this was related to economic unemployment or official work disability. ${ }^{18}$ However, our data suggest that not all persons with a chronic condition are eligible for an official work disability allowance, but apparently they are still vulnerable on the labor market and therefore become (or remain) unemployed and finally become dependent on a living allowance.

The large impact of MSKD on increased sick leave, especially in those with mental disease and MSKD, has been previously identified, ${ }^{19,20}$ but our study showed that mental diseases and cancer had an equally large or even larger impact. On the same line, Kessler et al. showed (although not distinguishing between paid and unpaid work) that when comparing the impact of chronic diseases (i.e. arthritis, asthma, diabetes, high blood pressure, autoimmune disease, ulcers, heart disease and several mental diseases) on the number of days that work had to be cut back or in which participants were unable to work, mental diseases had the strongest impact on reduced work-days followed by ulcers and arthritis. ${ }^{11}$ Although our study concentrated on sickness absence in those with paid work, it is not surprising that the same diseases also provided problems in being productive in unpaid work.

Multimorbidity had a consistent and strong impact on all aspects of work outcome, also consistently on sick leave and economic UE. This suggests that the combination of individual chronic diseases is additionally hindering work opportunities, which is supported by the steep increase in odds of unfavorable work outcome with increasing number of diseases. Of interest, in the context of multimorbidity, the presence of an MSKD tended to amplify the adverse impact on work outcome, although only statistically significant when sick leave was the outcome. Unfortunately, our sample was not large enough to retrieve stable estimates for the association of all combinations of two diseases. Within this limitation, analysis revealed that the combination of MSKD and mental diseases as well as also cancer and MSKD had indeed the largest impact on adverse work outcome. The detrimental combination of depression and RA on WD has been shown previously. ${ }^{14,21}$ However, to our knowledge 
no further literature exists regarding the impact of multimorbidity in- and excluding an MSKD on adverse work outcome.

Some limitations deserve attention. The overall response rate of $22.4 \%$ was low but comparison of sociodemographic characteristics with data of the central office for statistics in the Netherlands only showed minor differences (Supplemental Table S3.5), which suggests our results are fairly generalizable. Further, data on chronic diseases and the outcomes were self-reported which might result in misclassification of exposure and outcome. However, studies suggest that self-reported diagnoses that specify that the disease should be confirmed by a physician (which was the case in this study) reduce the bias. ${ }^{22,23}$ While more specific data on diagnoses included in MSKD was available and analyses in subgroups would have been favorable, we were not able to analyze the specific diagnoses in MSKD group due to small numbers of subjects of working age in each diagnosis group. As in all cross-sectional studies, our findings can only be interpreted in terms of associations and no conclusions on causality can be drawn. Furthermore, our sample concerns the Dutch population only and therefore may have limited generalizability to other countries. Existing difference in criteria to receive a work disability pensions, or a LA, and in prevailing UE rates, will obviously impact the likelihood of being eligible for a WD or the likelihood to become long-term UE or dependent on a LA. Last but not least, we have no data on specific diagnoses within the larger disease groups, nor on objective severity and duration of disease, hampering detailed information on disease characteristics related to adverse work outcome.

The strength of this study is the variety of work outcomes included and the novel insights it gives into the impact of (multi)morbidity on these outcomes. Our results call for common action for all those involved in care for patients with chronic diseases to address work ability and assess risk for adverse work outcome in all chronic diseases and especially in those with multimorbidity. First and foremost, prevention of adverse work outcome is mandatory and a duty for all professionals involved in the care of persons with chronic diseases. It is known that sick leave is a strong predictor of WD, and especial persons who are already on sick leave should receive additional support from the medical team to remain in labor force. Rheumatologists may play a role in the identification of patients at risk for adverse work outcome and support them in gaining self-management skills that help in maintaining their work. Further, in currently economically unfavorable times, efforts should be made by policy makers and employers to prevent that persons with (multiple) chronic disease will lose their job and/or to help them return to (other) work. 


\section{Conclusion}

In conclusion, chronic diseases (the presence of any of them) and specifically multimorbidity have an important association with the broad spectrum of adverse work outcomes. Our findings emphasize the need to develop common strategies among all chronic disease to improve work outcome in daily clinical care. Professionals in rheumatological care could take the lead for such initiatives. 


\section{References}

1. Vos T, et al. Years lived with disability (YLDs) for 1160 sequelae of 289 diseases and injuries 1990-2010: a systematic analysis for the global burden of disease study 2010. Lancet. 2012;380(9859):2163-96.

2. Centraal Bureau voor de Statistiek, D.H.H. Gezondheid aandoeningen beperkingen; persoonskenmerken. 2012 Available from: http://statline.cbs.nl/ StatWeb/publication/?DM=SLNL\&PA=81173ned\&D1=2-30\&D2=0-13,47-51\&D3=0\&D4=|\&VW=T.

3. Orueta JF, et al. Prevalence of multimorbidity according to the deprivation level among the elderly in the Basque country. BMC Public Health. 2013;13:918.

4. Fortin $\mathrm{M}$, et al. Prevalence of multimorbidity among adults seen in family practice. Ann Fam Med. 2005;3(3):223-8.

5. Kessler RC, et al. Age of onset of mental disorders: a review of recent literature. Curr Opin Psychiatry. 2007;20(4):359-64.

6. Kessler RC, et al. Lifetime prevalence and age-of-onset distributions of mental disorders in the world health Organization's world mental health survey initiative. World psychiatry. 2007;6(3):168-76.

7. C.f.D.C.a.P.-D.P.H.R.-. Mean and Median Age at Diagnosis of Diabetes Among Adult Incident Cases Aged 18-79 Years, United States, 1997-2011. http://www.cdc.gov/diabetes/statistics/age/fig2.htm. Accessed 31 Mar 2015.

8. C.R.U.-. Cancer incidence by age. http://www.cancerresearchuk.org/cancerinfo/cancerstats/incidence/age/. Accessed 31 Mar 2015.

9. Wilkie R, Pransky G. Improving work participation for adults with musculoskeletal conditions. Best practice \& research. Clin Rheumatol. 2012;26(5):733-42.

10. Black DC. Working for a healthier tomorrow. London: The Stationery Office, 2008.

11. Kessler RC, et al. The effects of chronic medical conditions on work loss and work cutback. J occup environ med/American College of Occup Environ Med. 2001;43(3):218-25.

12. Alavinia SM, Burdorf A. Unemployment and retirement and ill-health: a cross-sectional analysis across European countries. Int Arch Occup Environ Health. 2008;82(1):39-45.

13. Ubalde-Lopez $\mathrm{M}$, et al. 0095 Multimorbidity and previous sickness absence episodes are determinants of incidence and duration of future episodes. Occup Environ Med. 2014;71 Suppl 1:A10-0.

14. Callhoff J, A K, Schett G, Zink A, Westhoff G. Depression is a stronger predictor of the risk to consider work disability in early arthritis than disease activity or response to therapy. RMD Open. 2015;1:e000020. doi:10.1136/rmdopen-2014-000020.

15. Chorus AMJ, Schokker D. National monitor on the musculoskeletal system 2010. Leiden, 2010. TNO.

16. van den Akker-van Marle ME, et al. Cost of rheumatic disorders in the Netherlands. Best Practice Res Clin Rheumatol. 2012;26(5):721-31.

17. Lefevre $T$, et al. What do we mean by multimorbidity? an analysis of the literature on multimorbidity measures, associated factors, and impact on health services organization. Rev Epidemiol Sante Publique. 2014;62(5):305-14

18. Leino-Arjas $P$, et al. Predictors and consequences of unemployment among construction workers: prospective cohort study. BMJ. 1999;319(7210):600-5.

19. Hubertsson J, et al. Sick leave patterns in common musculoskeletal disorders-a study of doctor prescribed sick leave. BMC Musculoskelet Disord. 2014;15:176.

20. Woolf AD, Pfleger B. Burden of major musculoskeletal conditions. Bull World Health Organ. 2003;81(9):646-56.

21. Matcham F, et al. The prevalence of depression in rheumatoid arthritis: a systematic review and metaanalysis. Rheumatology. 2013;52(12):2136-48.

22. Wijnands JM, et al. Large epidemiologic studies of gout: challenges in diagnosis and diagnostic criteria. Curr Rheumatol Rep. 2011;13(2):167-74.

23. Haapanen $\mathrm{N}$, et al. Agreement between questionnaire data and medical records of chronic diseases in middle-aged and elderly Finnish men and women. Am J Epidemiol. 1997;145(8):762-9. 


\section{Supplemental tables}

Table S3.1 Characteristics of study population with paid work $\leq 65$ years $n=4,805$.

\begin{tabular}{|c|c|}
\hline \multicolumn{2}{|l|}{ Age, mean (SD) } \\
\hline Women, n (\%) & $2669(55.6)$ \\
\hline \multicolumn{2}{|l|}{$\mathrm{BMI}, \mathrm{n}(\%)$} \\
\hline underweight & $57(1.2)$ \\
\hline normal & $2615(54.4)$ \\
\hline pre-obese & $1598(33.3)$ \\
\hline obese & 535 (11.1) \\
\hline Level of education, n (\%) & $n=4,770$ \\
\hline Primary school or no education & $55(1.2)$ \\
\hline Lower professional school & $421(8.8)$ \\
\hline Middle or professional secondary school & $1467(30.8)$ \\
\hline Secondary education & $489(10.3)$ \\
\hline University education & $2338(49.0)$ \\
\hline Smoking status, n (\%) & $n=4,791$ \\
\hline Current smoker & 858 (17.9) \\
\hline Never smoked & $2361(49.3)$ \\
\hline Former smoker & $1572(32.8)$ \\
\hline \multicolumn{2}{|l|}{ Number of morbidities, n (\%) } \\
\hline 0 & $2998(62.4)$ \\
\hline 1 & $1314(27.4)$ \\
\hline 2 & $358(7.45)$ \\
\hline$\geq 3$ & $135(2.8)$ \\
\hline \multicolumn{2}{|l|}{ Sick leave during past 12 months } \\
\hline Yes, sick leave n (\%) & $2264(47.1)$ \\
\hline \multicolumn{2}{|l|}{ Index-diseases } \\
\hline Musculoskeletal disease & $706(14.7)$ \\
\hline Cardiovascular disease & 509 (10.6) \\
\hline Diabetes & $115(2.4)$ \\
\hline Cancer & 64 (1.3) \\
\hline Respiratory disease & $265(5.5)$ \\
\hline Skin disease & $281(5.9)$ \\
\hline Mental disease & $216(4.5)$ \\
\hline Bowel disease & $108(2.3)$ \\
\hline Migraine & $203(4.2)$ \\
\hline
\end{tabular}


Table S3.2 Association of multimorbidity of 2 or $\geq 3$ diseases in- and excluding musculoskeletal disease with work status compared to 'being employed'.

\begin{tabular}{lccc}
\hline $\begin{array}{l}\text { Single morbidity/ } \\
\begin{array}{l}\text { Multimorbidity in- and } \\
\text { excluding MSKD }\end{array}\end{array}$ & $\begin{array}{c}\text { Work disabled* } \\
\text { OR }[95 \% \text { Cl] }\end{array}$ & $\begin{array}{c}\text { Living allowances* } \\
\text { OR }[95 \% \text { Cl] }\end{array}$ & $\begin{array}{c}\text { Unemployed* } \\
\text { OR }[95 \% \text { Cl] }\end{array}$ \\
\hline Musculoskeletal disease & $2.00(1.19 ; 3.39)^{\mathrm{a}}$ & $1.39(0.49 ; 3.99)$ & $1.23(0.71 ; 2.14)$ \\
Any disease excl. MSKD & $3.91(2.73 ; 5.60)$ & $1.48(0.64 ; 3.47)$ & $1.36(0.91 ; 2.02)$ \\
2 diseases incl. MSKD & $9.22(5.98 ; 14.23)$ & $5.61(2.32 ; 13.55)$ & $2.66(1.51 ; 4.68)$ \\
2 diseases excl. MSKD & $8.84(5.59 ; 14.00)$ & $1.74(0.47 ; 6.54)$ & $2.43(1.31 ; 4.51)$ \\
$\geq 3$ diseases incl. MSKD & $23.73(15.42 ; 36.53)$ & $7.70(3.05 ; 19.45)$ & $3.21(1.62 ; 6.35)$ \\
$\geq 3$ diseases excl. MSKD & $14.89(7.73 ; 28.71)$ & $10.45(2.86 ; 38.13)$ & $3.58(1.34 ; 9.54)$ \\
\hline
\end{tabular}

Results of multivariable multinomial regression model adjusted for age, gender, education, BMI \& smokingstatus, $n=5,340 . *$ Paid work is reference outcome. + No morbidity is reference category. ${ }^{a}$ Significantly different from estimate for previous disease count (i.e. 1 vs. 0; 2 vs. 1 etcetera). ${ }^{b}$ Significantly different from estimate for single morbidity other than MSKD. ${ }^{c}$ Significantly different from estimate for multimorbidity excluding MSKD. MSKD: musculoskeletal disorder; OR: odds ratio; $\mathrm{Cl}$ : confidence interval.

Table S3.3 Association of specific disease combinations in- and excluding musculoskeletal disease with work status compared to 'being employed'; OR [95\% Cl].

\begin{tabular}{lccc}
\hline Single morbidity/ & Work disabled* & Living allowances* & Unemployed* \\
Multimorbidity in- and & & & \\
excluding MSKD & & & \\
\hline Musculoskeletal disease & $1.89[1.12 ; 3.19]$ & $1.38[0.48 ; 3.95]$ & $1.24[0.71 ; 2.14]$ \\
Cardiovascular disease & $1.22[0.62 ; 2.40]$ & $1.28[0.35 ; 4.69]$ & $0.89[0.42 ; 1.89]$ \\
Diabetes & $2.91[1.04 ; 8.10]$ & $2.05[0.24 ; 17.68]$ & $2.02[0.60 ; 6.82]$ \\
Respiratory disease & $2.61[1.14 ; 5.97]$ & - & $1.09[0.39 ; 3.02]$ \\
Mental disease & $21.11[13.10 ; 34.03]$ & $3.90[0.85 ; 17.91]$ & $2.21[0.99 ; 4.92]$ \\
Cancer & $4.03[1.43 ; 11.37]$ & -1 & $0.95[0.13 ; 7.08]$ \\
Skin disease & $2.33[1.10 ; 4.92]$ & $0.83[0.11 ; 6.48]$ & $1.57[0.74 ; 3.31]$ \\
Bowel disease & $1.44[0.33 ; 6.26]$ & $2.24[0.25 ; 20.18]$ & $1.05[0.25 ; 4.43]$ \\
Migraine & $1.79[0.63 ; 5.14]$ & $2.59[0.53 ; 12.73]$ & $2.63[1.22 ; 5.64]$ \\
MSKD \& Diabetes & $13.56[4.06 ; 45.25]$ & $13.24[1.27 ; 138.09]$ & $2.78[0.34 ; 22.76]$ \\
MSKD \& CVD & $4.52[2.03 ; 10.04]$ & $1.56[0.17 ; 14.53]$ & $0.54[0.07 ; 4.02]$ \\
MSKD \& Cancer & $35.49[5.57 ; 226.13]$ & -1 & -1 \\
MSKD \& Respiratory disease & $5.21[1.84 ; 14.78]$ & $3.34[0.38 ; 29.05]$ & $1.07[0.14 ; 8.04]$ \\
MSKD \& Skin disease & $4.68[1.90 ; 11.54]$ & -1 & $1.24[0.27 ; 5.60]$ \\
MSKD \& Mental disease & $30.81[13.93 ; 68.12]$ & $23.29[6.18 ; 87.75]$ & $7.95[2.86 ; 22.10]$ \\
MSKD \& Migraine & $4.89[1.61 ; 14.91]$ & $5.36[0.60 ; 48.10]$ & $6.38[2.30 ; 17.65]$ \\
MSKD \& Bowel disease & $3.99[1.09 ; 14.59]$ & $7.66[1.19 ; 49.51]$ & $0.94[0.11 ; 8.01]$ \\
Any 2 diseases excluding MSKD & $8.23[5.21 ; 13.01]$ & $1.75[0.47 ; 6.55]$ & $2.42[1.31 ; 4.49]$ \\
$\geq 3$ diseases incl. MSKD & $23.73(15.42 ; 36.53)$ & $7.70(3.05 ; 19.45)$ & $3.21(1.62 ; 6.35)$ \\
$\geq 3$ diseases excl. MSKD & $14.89(7.73 ; 28.71)$ & $10.45(2.86 ; 38.13)$ & $3.58(1.34 ; 9.54)$ \\
\hline
\end{tabular}

Results of multivariable multinomial regression model with age, gender, education, BMI \& smoking-status, single diseases and combinations of $\geq$ diseases as covariates $(n=5340)$. * Paid work is reference outcome. + No morbidity is reference category. ${ }^{1}$ not estimated due to insufficient sample size. 
Table S3.4 Association of multimorbidity of 2 or $\geq 3$ diseases in- and excluding musculoskeletal disease with sick leave in the past 12 months in employed population $\leq 65$ years.

\begin{tabular}{lc}
\hline Single morbidity/Multimorbidity in- and excluding MSKD & OR $[95 \% \mathrm{Cl}]$ \\
\hline Musculoskeletal disease & $2.50[2.01 ; 3.10]$ \\
Any disease excl. MSKD & $1.81[1.55 ; 2.12]^{\mathrm{a}}$ \\
2 diseases incl. MSKD & $3.48[2.51 ; 4.83]$ \\
2 diseases excl. MSKD & $2.09[1.51 ; 2.90]$ \\
$\geq 3$ diseases incl. MSKD & $5.10[3.15 ; 8.24]$ \\
$\geq 3$ diseases excl. MSKD & $3.71[1.80 ; 7.64]$ \\
\hline
\end{tabular}

Results of multivariable logistic regression models adjusted for age, gender, level of education, origin, BMI and smoking status $(n=5340) .{ }^{*}$ reference category= healthy population. ${ }^{a}$ Significantly different from estimate for any disease excluding MSKD. ${ }^{b}$ Significantly different from estimate for multimorbidity of 2 diseases excluding MSKD. ' Significantly different from estimate for multimorbidity of $\geq 3$ diseases excluding MSKD.

Table S3.5 Characteristics of the study sample and general Dutch population

\begin{tabular}{|c|c|c|}
\hline Characteristics & Study population & General Dutch population \\
\hline Age: years; mean (SD) [range] & $45.80(11.0)[18-65]$ & 48.31 \\
\hline Gender & $\mathrm{n}(\%)$ & \\
\hline women & $3008(55.8)$ & $50 \%$ \\
\hline Education & $\mathrm{n}(\%)$ & \\
\hline primary school or no education & $105(2.0)$ & $30.49 \%$ \\
\hline lower professional education & $544(10.2)$ & \\
\hline middle or secondary professional education & $1677(31.3)$ & $21.59 \%$ \\
\hline secondary education & $567(10.6)$ & $38.11 \%$ \\
\hline university education & $2464(46.0)$ & \\
\hline Origin & $\mathrm{n}(\%)$ & \\
\hline western & $8332 \quad(94.70)$ & $89 \%$ \\
\hline $1^{\text {st }}$ generation non- western & $(2.85)$ & $\mathrm{n} / \mathrm{a}$ \\
\hline $2^{\text {nd }}$ generation non- western & $215 \quad(2.44)$ & $\mathrm{n} / \mathrm{a}$ \\
\hline BMI & $\mathrm{n}(\%)$ & \\
\hline underweight $(<18.5)$ & $69(1.3)$ & $1.65 \%$ \\
\hline normal (18.5-24.99) & $2853(52.9)$ & $49.37 \%$ \\
\hline overweight (25.0- 29.99) & $1784(33.1)$ & $36.76 \%$ \\
\hline obese $(\geq 30)$ & $690(12.8)$ & $12.22 \%$ \\
\hline
\end{tabular}

Reference: CBS. Nederlanders naar opleidingsrichting, opleidingsniveau, leeftijd en geslacht. 2008. 


\section{Part II}

\section{Early intervention to improve}

work outcome of patients with musculoskeletal diseases 



\section{Chapter 4}

\section{Effects and costs of an intensive return to work program for patients with recent sick leave due to musculoskeletal disorders}

Antje van der Zee-Neuen, Sjef van der Linden, Andras Keszei, Rob de Bie, Nico Wolter, Pieter Rodenburg, Annelies Boonen BMC Musculoskelet Disord 2017;18(1):10 


\section{Abstract}

\section{Objectives}

To explore effects and costs of a 4-weeks intensive multidisciplinary program combined with spaelements in persons with recent sick leave due to musculoskeletal disorders (MSKD) when compared to usual care.

\section{Methods}

Participants were matched for age, gender and type of MSKD to subjects from an occupational database and were followed from first day of sick-leave till 6 months after the program. Days sick-leave and hazard of work resumption were compared by bootstrapped independent sample t-test and Cox-regression respectively. Program costs per working day gained were calculated. Within the program-group, healthcare costs, EuroQol-5D (EQ-5D) and EQ-VAS 6 months before and after the program were compared.

\section{Results}

111 program-participants were evaluated (mean age 47( \pm 9.9$)$ years; 77(69.4\%) women). Total days sick-leave were $58.2( \pm 34.4)$ in the program-group and $75.5( \pm 39.8)$ in UC-group $(p=0.002)$. At 20 days sick-leave the hazard curves on work resumption of both groups crossed, and thereafter the hazard of work resumption in program-participants was significantly higher [HR 1.60 (95\% Cl:1.22-2.11)] compared to UC. Program costs were €6,172/patient, resulting in €356 per working day gained. Among program-participants, EQ5D/EQ-VAS improved significantly from $0.57( \pm 0.26) / 56.1( \pm 15.1)$ before the program to $0.70( \pm 0.22) / 69.4( \pm 13.6)$ and healthcare costs decreased non-significantly from $€ 1,887 /$ patient $( \pm 3755)$ to $€ 1,112 /$ patient $( \pm 1470)$ per 6 months.

\section{Conclusions}

In patients with MSKD on recent sick leave, the intensive multidisciplinary program reduced days sick leave and enhanced return to work. Extra program costs seem to be further offset by improvements in health and healthcare costs. 


\section{Introduction}

Musculoskeletal disorders (MSKD) are among the leading causes of work disability (WD) and sick leave (SL) in the Western world. ${ }^{1-5}$ There is evidence that work reintegration (i.e. return to work) and rehabilitation (i.e. restore health) programs in persons who are already work disabled lack efficacy. ${ }^{6,7}$ Therefore, a shift has been made towards interventions early in the period of SL aiming at prevention of long term SL and WD. ${ }^{8-11}$

As work participation is the resultant of a complex interaction between biomedical and psychosocial determinants, interventions directed exclusively at improvement of impairments and limitations are often insufficient. Several contextual factors in the personal and physical environment (i.e. workload, dealing with stress, work-life balance, etc.) have been identified as possible barriers or facilitators in relation to work participation. ${ }^{12-14}$ Typically, modern multidisciplinary interventions should therefore aim to modify disability as well as context, when trying to prevent adverse work outcome, or when enhancing work resumption in case of SL. ${ }^{15}$ Within such setting, graded activity offers a suitable therapeutic method to improve physical functioning and exercise tolerance within a pre-determined timeframe and within the personal and social context. ${ }^{16}$ In addition, a workplace examination to adjust the physical work environment to the work capacity is standard for many occupational physicians. Next, strengthening mental resilience and social skills directed at self-management of the work situation can be achieved by mental coaching and conveying principles such as using goalsetting and goal control. ${ }^{17}$ Finally, a previous randomized controlled trial (RCT) in ankylosing spondylitis showed beneficial effects of a combined spa-exercise programs on SL when compared to usual care (UC) in those with paid work and suggested part of the effect was likely due to the wellness experience. ${ }^{18,19}$

Usually, patients with recent SL in the Netherlands are offered one or more of the components of the above mentioned treatment principles, classically in a stepwise approach and without integration of the different parts. To reassure the broad management paradigm, an intensive reintegration program was developed for patients on recent SL due to MSKD, in which patients were offered an integrated 4 weeks program that included physical fitness training, mental work-directed coaching, workplace adjustments and wellness components. Consistent with its objective, the program received the name "Rehabilitation and Reintegration in patients with Rheumatic disease (3R-program)".

The current study aimed to evaluate from a societal perspective (1) whether the integrated intensive multidisciplinary program with wellness component had beneficial effects on days absent from work and time until work resumption when compared to UC, (2) whether program costs would be worth the gain in working days and (3) to 
what extent the program would reduce resource utilization and improve health in those participating.

\section{Patients and methods}

\section{Subjects}

Subjects participating in the 3R-program between May $2^{\text {nd }}, 2011$ and January $31^{\text {st }}, 2013$ and for whom follow-up data for 6 months after the end of the program was available were eligible for evaluation. Referral could be initiated by the patients' occupational physician or employer, or could be self-initiated (but not without approval from employer). Subjects had to be between 18 and 65 years, had to have paid work, be on SL for maximal 12 weeks because of non-traumatic MSKD, have incurred a maximum of 30 SL days in the year prior to the current sickness episode and have written approval from their employer to participate for the full length of the program. Severe comorbidities or other conditions posing a contra-indication to attend the program (i.e. severe endogenous depression, severe cardiac or pulmonary diseases, and pregnancy) were reasons for exclusion from participation.

To be able to compare the effects of the new multidisciplinary program with existing alternative interventions, patients were matched to persons receiving care as usual (UC-group) from an occupational health service (OHS) database containing information about age, gender, type of MSKD (inflammatory, a-specific, degenerative, other), contractual working hours and exact date of start and end of the SL in 360,000 individuals. Matches were eligible if the diagnosis (primary reason for SL) was available, and if the first day of SL was available and fell in the inclusion-period of the $3 R$ program. As 3R-participants were potentially at increased risk of long term sickness absence (as otherwise the $3 R$ program would not be considered), yet likely motivated to resume their work (as otherwise they would be unlikely to be willing to participate in the program), matches were selected using three approaches to fit these (unmeasured) sample characteristics. In the base-case scenario, only control subjects with at least 14 working days SL days were included, equalling the average number of days SL of patients referred to the 3R-program, and being the period that is assumed to be a risk for prolonged sickness absence in the Netherlands. ${ }^{20}$ In two scenario-analyses control subjects were included firstly independent of the duration of SL (likely including those with minor illness and no risk factors for long-term SL; i.e. the minimum scenario) and secondly after a minimum of $30 \mathrm{SL}$ days (corresponding to the point in time at which Dutch health executives/occupational physicians are legally obliged to provide a problem-analysis and re-integration and rehabilitation plan and likely including those with severe disease and high risk for long-term absence; i.e. the maximum scenario). For each of the scenario's, each participant in the 3R-program was randomly matched 
to three UC controls by using frequency matching based on age ( 4 age groups: 18 to 30; 31 to 40; 41 to 50; 51 to 65), type of MSKD and gender. As the current study concerned the evaluation of a program, no informed consent was available and used data were fully anonymized before analyses.

\section{Content of 3R-program and usual care}

Participants received a 4-weeks in-patient multidisciplinary graded activity and mental coaching program combined with spa-treatment aiming to assimilate work-ability and work-load in a wellness-environment (Supplementary Table S4.1). Prior to the program an individual intake-interview took place, consisting of medical and societal history taking and clinical examination by an occupational practitioner for final exclusion of contra-indications for participation, a psychologist, a physiotherapist and an employment expert. Treatment goals were established by the multidisciplinary team in agreement with the participant. The program consisted of 5 active days per week with individual activities comprising physiotherapy, workplace analysis and counselling and psychological treatment as well as group activities such as exercise/sports, Nordic walking and hydrotherapy. Visits to the sauna were scheduled on a daily base. All activities and assessments were coached by highly qualified and experienced professionals in the field of re-integration. Patients were considered to remain in the spa-facility for the full length of the program as seclusion of practical daily concerns and interaction with fellow patients was considered part of the program. At the end of the program an individual outtake-assessment was conducted by the same professionals as during the intake, resulting in a written recommendation regarding ability and conditions for sustainable work resumption, and which was send to the employer after signed approval by the participant.

With regard to UC, all employees that experience SL in the Netherlands receive a rehabilitation and re-integration plan after 30 working days absence. A plan for MSKD may contain one or more elements of the 3R-program. Potentially, patients can be referred to a commercial organization or hospital providing multidisciplinary (occupational) programs.

If considered necessary by the program physician or if requested by the patient, additional care was provided by a general practitioner or medical specialist upon referral of the program physician.

\section{Assessments available for the evaluation}

During the intake-interview of the 3R-program information was collected on sociodemographic factors (age, gender, highest level of education attained (no or primary-, lower professional-, middle professional-, secondary general-, and higher professionalor university education), work characteristics (number of contractual hours per week, 
number of days on SL 3 months prior to the 3R-program, date of initial SL and work resumption, type of work (physically, mentally or physically and mentally demanding work)) and resource utilization (number of visits to general practitioner, occupational practitioner, medical specialist, physiotherapist, or psychologist; number of days of hospitalization; and number of hours of weekly homecare during a period of 6 months before the program). Participants were evaluated 6 months after the end of the 3Rprogram and asked about the actual date of work resumption, number of days SL after work resumption and resource utilization in the past 6 months. Finally, and consistent with the trend in the Netherlands to include patient reported outcomes in healthcare, the EuroQol-5 dimensions (EQ-5D) was administered at the start of the 3R-program as well as 6 months thereafter. The EQ-5D comprises 5 dimensions of health: mobility, self-care, daily activities, pain/complaints, mood with 3 levels per dimension, no problems to extreme problems) and the EQ-Visual Analogue Scale (VAS) is a vertical rating scale ranging from zero (worst health state) to 100 (best health state). ${ }^{21}$ Based on the EQ-5D the societal value of health was calculated using the Dutch EQ-5D tariff. ${ }^{22}$

\section{Costs}

Costs of health resource utilization were calculated by multiplying the number of resources reported by patients with the unit price of the resource as advised by the Dutch manual for pharmaco-economic healthcare evaluations and representing the true societal cost. ${ }^{23}$

Productivity costs were calculated by converting working days on SL during the observation time to actual work hours lost and multiplying these by reference hourly wages for age and gender after adjusting for the Dutch work time elasticity factor of $0.8 \%$ (as productivity loss is considered not proportional to the time absent). ${ }^{23}$ To account for inflation the appropriate collective labor agreement-index was applied. To estimate the costs of the 3R-intervention, activity based costing (based on time and frequency of all activities in the 3R-program) was used while accounting for individual or group activities, overhead of the program location as well as salaries, security and governmental fees. To value accommodation costs, the market price of the specific location was used.

\section{Statistical analysis}

Subjects that started the 3R-program between May, 2011 and January 2013 and for whom data for the six months follow-up was available were included in the analyses. Baseline characteristics of participants with incomplete follow-up were compared to those with complete follow-up. Analyses were performed using a per-protocol approach. 
In base- as well as min and max scenarios, working days absent and associated productivity costs for the average observation time of 163 working days after the start of the intervention (mean observation time in working days in 3R-group including 4 weeks program time $3 R$ ) were compared between $3 R$ and UC subjects using bootstrapped independent t-tests. In the base case, the effect size (Cohen's d) based on absent working days was calculated by dividing the mean difference between groups by the standard deviation of the 3R-group $\left[d=\left(\mu_{U C}-\mu_{3 R}\right) / S D_{3 R}\right]$. Next, for each scenario, Kaplan Meier survival analysis was performed to compare time until work resumption (TWR) between the 3R-program and UC-group. Censoring occurred when work resumption was not achieved within the observation time. In the base scenario, univariable Cox regression explored whether group-membership (3R versus $U C$ ), age, gender (reference=men), contractual working hours (per week) and type of MSKD (reference=inflammatory) predicted TWR. Two-way interactions of groupmembership with gender, age and type of MSKD were tested.

To understand the economic benefits of the program compared to UC, the cost per workday gained was calculated by dividing the $3 \mathrm{R}$-program costs by the difference in working days absent from work from the first day of SL until the end of the observation in the $3 \mathrm{R}$ and UC-group for the base case, min- and max-scenario.

Finally, within the 3R-group, univariable Cox regression analyses were performed using the same predictors as in the total group (except group) and in addition type of work (reference: mentally demanding work) and level of education (reference: higher professional or university education) to explore their impact on the hazard of work resumption. In addition, healthcare utilization and associated direct costs during the 6 months before and after the program as well as health utility from societal (EQ-5D) and patient (EQ-VAS) perspective at baseline and 6 months follow-up were compared by Bootstrapped paired sample t-tests and Wilcoxon signed rank test respectively P-values of $p \leq 0.05$ were considered statistically significant. All analyses were performed using IBM SPSS Statistics 20.

\section{Results}

One-hundred thirty-eight participants started the 3R-program during the inclusion period and 111 (80.4\%) provided information regarding work resumption 6 months after the end of the intervention (Figure 4.1).

Baseline characteristics of these 111 persons were only modestly different from those who did not provide information regarding work resumption (Supplementary Table S4.2). Characteristics of 3R-participants are described in Table 4.1. Successful matching for all scenarios was confirmed by comparable estimates of age, gender, and type of MSKD of the 3R-group compared UC. 
Table 4.1 Characteristics of participants in the 3R-group who provided information on work resumption.

\begin{tabular}{ll}
\hline Characteristics & $\mathrm{n}=111$ \\
\hline Gender; $\mathrm{n}(\%)$ & $77(69.4)$ \\
women & \\
Age & $46.9(9.9) / 48.0$ \\
mean (SD)/median & \\
Type of work; $\mathrm{( \% )}$ & $10(9.0)$ \\
Physically demanding & $39(35.1)$ \\
Mentally demanding & $62(55.9)$ \\
Physically and mentally demanding & $\mathrm{n}=109$ \\
Level of education; $\mathrm{n}(\%)$ & $16(14.7)$ \\
Primary school or no education or lower professional education & $42(38.5)$ \\
$\quad$ Middle professional education & $15(13.8)$ \\
Secondary general education & $36(33.0)$ \\
Higher professional or university education & \\
Type of musculoskeletal disease; $\mathrm{n}(\%)$ & $31(27.9)$ \\
Inflammatory & $46(41.4)$ \\
Non-specific & $19(17.1)$ \\
Degenerative & $15(13.5)$ \\
Other & $\mathrm{n}=107$ \\
Contractual working hours per week & $30.3(9.8) / 32.0$ \\
mean (SD)/median & $\mathrm{n}=103$ \\
Baseline value for health & $0.57(0.26) / 0.70$ \\
EQ-5D utility index, mean (SD)/median & $56.07(15.06) / 58.50$ \\
EQ-5D VAS, mean (SD)/median &
\end{tabular}

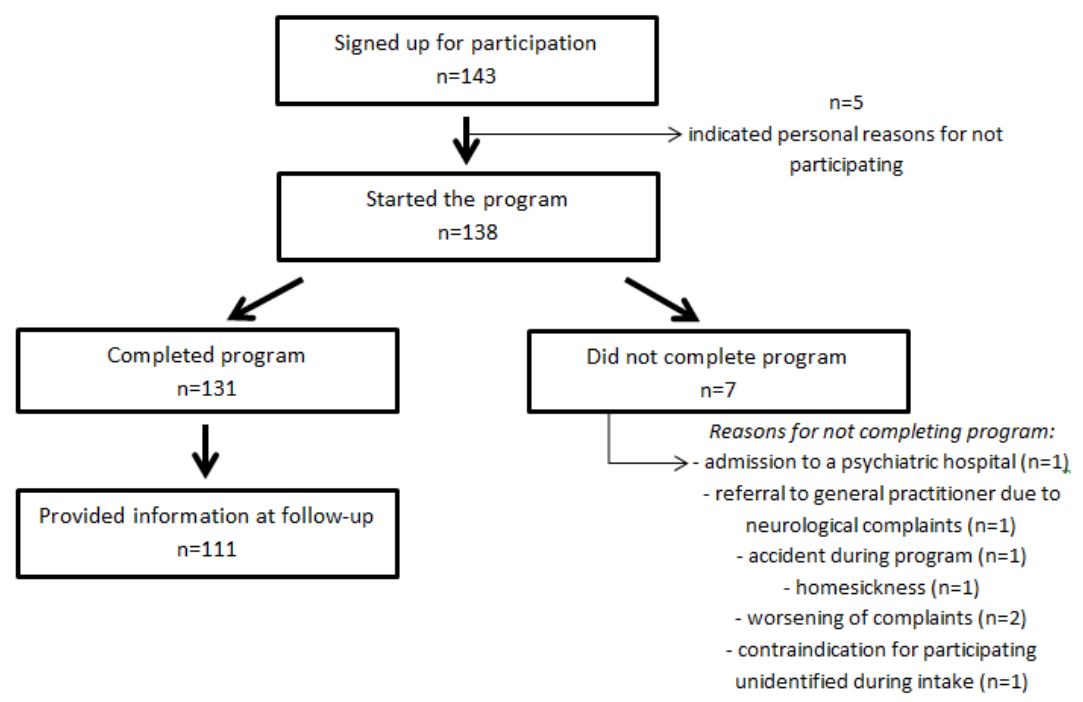

Figure 4.1 Flow-chart of participants in the program-group. 
Table 4.2 Healthcare consumption and associated costs during 6 months before and after the treatment program.* $^{*}$

\begin{tabular}{|c|c|c|c|c|c|}
\hline & \multicolumn{2}{|c|}{$\begin{array}{c}6 \text { months before the program } \\
\text { mean (SD)/median }\end{array}$} & \multicolumn{2}{|c|}{$\begin{array}{c}6 \text { months after end of program } \\
\text { mean (SD)/median }\end{array}$} & \multirow[t]{2}{*}{ P-value } \\
\hline & Number of visits & Costs of visits $(€)$ & Number of visits & Costs of visits $(€)$ & \\
\hline $\begin{array}{l}\text { Visits to general } \\
\text { practitioner }(n=93)\end{array}$ & $\begin{array}{c}6.1 \\
(16.0) / 4.0\end{array}$ & $\begin{array}{c}182.9 \\
(480.0) / 120.4\end{array}$ & $\begin{array}{c}2.2 \\
(3.0) / 1.0\end{array}$ & $\begin{array}{c}64.7 \\
(90.4) / 30.1\end{array}$ & 0.20 \\
\hline $\begin{array}{l}\text { Visits to medical } \\
\text { specialist }(n=95)\end{array}$ & $\begin{array}{c}4.6 \\
(15.9) / 2.0\end{array}$ & $\begin{array}{c}355.2 \\
(1230.1) / 154.8\end{array}$ & $\begin{array}{c}1.6 \\
(2.1) / 1.0\end{array}$ & $\begin{array}{c}123.0 \\
(163.0) / 77.4\end{array}$ & 0.27 \\
\hline $\begin{array}{l}\text { Visits to occupational } \\
\text { practitioner }(n=94)\end{array}$ & $\begin{array}{c}2.1 \\
(3.1) / 1.0\end{array}$ & $\begin{array}{c}62.4 \\
(92.3) / 30.1\end{array}$ & $\begin{array}{c}1.2 \\
(1.7) / 0.0\end{array}$ & $\begin{array}{c}35.5 \\
(51.3) / 0.0\end{array}$ & 0.28 \\
\hline $\begin{array}{l}\text { Visits to } \\
\text { physiotherapist ( } n=94)\end{array}$ & $\begin{array}{c}10.2 \\
(15.5) / 4.0\end{array}$ & $\begin{array}{c}393.2 \\
(598.2) / 154.8\end{array}$ & $\begin{array}{c}8.8 \\
(13.5) / 2.0\end{array}$ & $\begin{array}{c}339.7 \\
(522.4) / 77.4\end{array}$ & 0.44 \\
\hline $\begin{array}{l}\text { Visits to psychologist } \\
(n=95)\end{array}$ & $\begin{array}{c}1.3 \\
(2.9) / 0.0\end{array}$ & $\begin{array}{c}113.2 \\
(252.2) / 0.0\end{array}$ & $\begin{array}{c}1.6 \\
(5.4) / 0.0\end{array}$ & $\begin{array}{c}138.5 \\
460.1 / 0.0\end{array}$ & 0.63 \\
\hline $\begin{array}{l}\text { Nights in hospital } \\
(n=95)\end{array}$ & $\begin{array}{c}0.1 \\
(0.4) / 0.0\end{array}$ & $\begin{array}{c}32.3 \\
(194.4) / 0.0\end{array}$ & $\begin{array}{c}0.1 \\
(0.5) / 0.0\end{array}$ & $\begin{array}{c}37.6 \\
(260.6) / 0.0\end{array}$ & 0.88 \\
\hline $\begin{array}{l}\text { Hours of homecare } \\
(n=95)\end{array}$ & $\begin{array}{c}21.5 \\
(87.1) / 0.0\end{array}$ & $\begin{array}{c}808.2 \\
(3275.1) / 0.0\end{array}$ & $\begin{array}{c}10.0 \\
(30.0) / 0.0\end{array}$ & $\begin{array}{c}375.8 \\
(1129.0) / 0.0\end{array}$ & 0.36 \\
\hline $\begin{array}{l}\text { Total costs }(€) \text { of } \\
\text { healthcare utilization } \\
(n=92)\end{array}$ & \multicolumn{2}{|c|}{$1886.8(3755.3) / 821.3$} & \multicolumn{2}{|c|}{$1111.8(1470.0) / 496.6$} & 0.16 \\
\hline
\end{tabular}

* Results of bootstrapped paired sample t-test

\section{Base case analyses}

Six months after the 3R-program $n=99$ (89.2\%) of the participants had resumed work ( $n=88(79.3 \%)$ in their original work, $n=11(7.6 \%)$ in a different job or with a different employer). In the UC-group the proportion of persons resuming work during the observation time was 285 (69.3\%).

The average (working) days SL since the first day of sickness and for the duration of the observation were $58.2( \pm 34.4)$ in the $3 R$-group and $75.5( \pm 39.8)$ in the UC-group $(p=0.002)$ and Cohen's $d$ was 0.5 , suggesting a moderate effect size. ${ }^{24}$ Average productivity costs over the follow-up time were $€ 11,457( \pm 9,265 /$ median 8,549$)$ in the $3 R$-group and $€ 15,680( \pm 10,864 /$ median 12,848$)$ in the UC-group ( $p=0.001)$.

Kaplan Meier's survival analyses showed that median TWR in the 3R-group was 60 working days and 85 working days in the UC-group (Figure 4.2).

A violation of the proportional hazards assumption was apparent when comparing TWR of the $3 R$ program and UC- group, as survival curves of both groups crossed at workday 20 following the first day sick-leave (3R participants catching up work resumption after the end of the treatment program). Therefore, a time-dependent covariate (TWR $>20$, reflecting the time before and after crossing of the curves) was added. The hazard of work resumption in 3Rparticipants was not significantly lower than in the UC-group when TWR $\leq 20$ [hazard ratio (HR) 0.54 (95\% Cl 0.25-1.15)] but significantly higher when TWR was >20 [HR 1.60 (95\% Cl 1.22-2.11)]. Neither age [HR 1.00 (95\% Cl 0.99-1.01)], 
nor gender [female HR $0.96(95 \% \mathrm{Cl}$ 0.77-1.19)], contractual working hours [HR 1.00 (95\% Cl 0.99-1.01)], type of MSKD (non-specific: HR 1.13 (95\% Cl 0.87-1.47), degenerative: HR $0.93(95 \% \mathrm{Cl} 0.67-1.28)$, other $\mathrm{HR}$ : $0.89(95 \% \mathrm{Cl} 0.64-1.25)$ when compared to subjects with inflammatory MSKD) had a significant effect on the hazard of work. No significant interaction was found between group and age, gender and type of MSKD and the effect on work resumption.

Within the 3R-group, neither age [HR 1.01 (95\% Cl 0.99-1.04)], nor female gender [HR 0.94 (95\% Cl 0.58-1.50)], level of education (low [HR 1.70 (95\% Cl 0.87-3.30)], middle professional [HR $1.03(95 \% \mathrm{Cl}$ 0.59-1.78)], secondary general [HR $1.04(95 \% \mathrm{Cl}$ 0.52-2.09)] compared to higher professional or university), nor type of MSKD (nonspecific MSKD [HR $0.94(95 \% \mathrm{Cl} 0.55-1.60)]$, degenerative MSKD [HR $0.84(95 \% \mathrm{Cl}$ 0.42-1.68)], other MSKD [HR 1.46 (95\% Cl 0.73-2.94)] compared to inflammatory MSKD) were significant predictors for the hazard of work resumption.

The average costs for the 4 weeks 3R-program were $€ 6,172$ per patient (Supplementary Table S4.3). The highest cost-categories were hotel costs (€ $1600 / 26 \%)$, psychological coaching (€982/16\%) and labor expert counselling (€873/14\%). This resulted in an incremental intervention cost of €356 per working day gained for the 3R-program compared to UC.

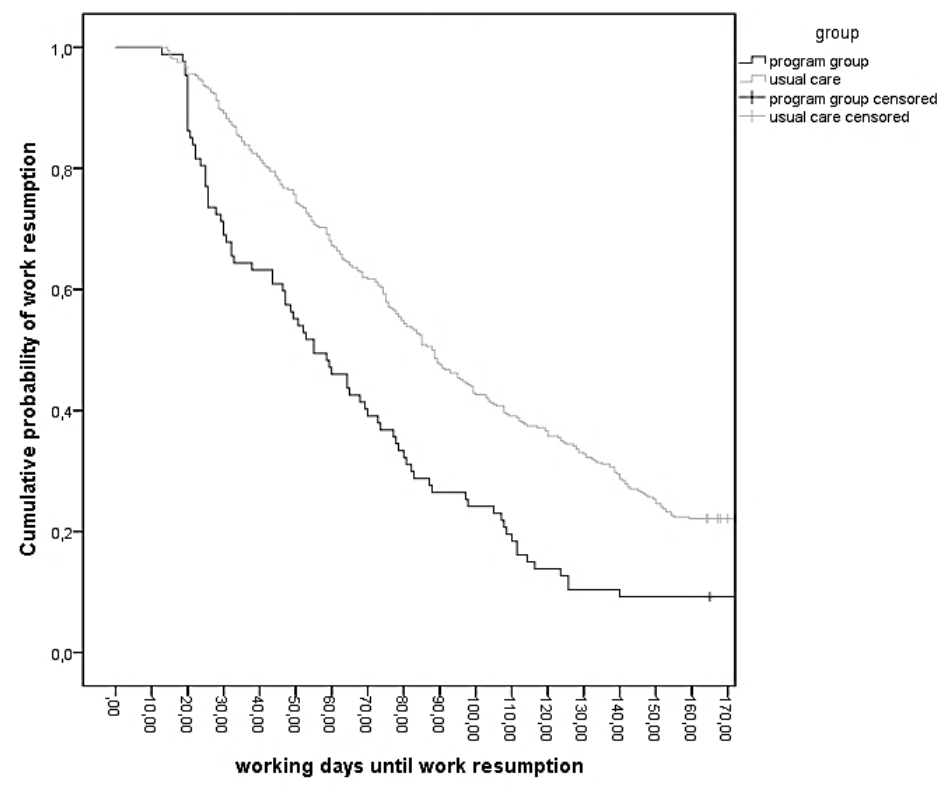

Figure 4.2 Kaplan-Meier survival curve for comparison of working days until work resumption in the program- and usual care group. 
In the six-month period after the end of the 3R-program, the healthcare utilization tended to be lower for the majority of cost-categories compared to the 6 months period before (Table 4.2).

Significant improvements in EQ-5D utility were found with an average of $0.57( \pm 0.26)$ in the beginning of the program and $0.70( \pm 0.22) 6$ months thereafter $(p<0.01)$. For the mean VAS score this was $56.1( \pm 15.1)$ and $69.4( \pm 13.6)$ respectively $(p<0.01)$.

\section{Scenario-analyses}

The between groups difference in (working) days SL and associated productivity costs over the follow-up time was non-significant in the min scenario, and became larger than in the base case (and again significant) in the max scenario (Table 4.3). In the Kaplan Meier's survival analyses of the min-scenario, proportional hazard assumption was again violated, but after inclusion of a the time-dependent covariate (TWR $>20$ ) the hazard for work resumption in 3R-participants was significantly lower in compared to $\mathrm{UC}$ in the first period [hazard ratio (HR) 0.26 (95\% Cl 0.13-0.51)] but significantly higher in the second period [HR $1.84(95 \% \mathrm{Cl} 1.40-2.41)]$. In the max-scenario, the hazard of work resumption was significantly higher in the 3R-group [HR 2.10 (95\% Cl 1.64-2.67)] throughout the entire observation period. (Supplementary Figure S4.1)

The incremental intervention costs per working day gained through the 3R-program compared to UC were approximately $€ 830$ in the min- and $€ 287$ in the max-scenario.

Table 4.3 Working days on sick leave and associated productivity costs during observation time of 163 working days for 3R-group and usual care group.*

\begin{tabular}{llccc}
\hline & & 3R-group & UC-group & P-value \\
\hline Base scenario & Working days on sick leave, & $58.21(34.43)$ & $75.54(39.78)$ & 0.002 \\
& mean (SD) & & & \\
& Productivity costs (€), & $€ 11,457(9,265 /$ & $€ 15,680(10,864 /$ & 0.001 \\
& mean (SD)/median & $8,549)$ & $12,848)$ & \\
Min-scenario & Working days on sick leave, & $58.21(34.43)$ & $65.65(44.17)$ & 0.11 \\
& mean (SD) & & & 0.12 \\
& Productivity costs (€), & $€ 11,457(9,265 /$ & $€ 13,290(10,588 /$ & \\
& mean (SD)/median & $8,549)$ & $10,155)$ & 0.001 \\
Max-scenario & Working days on sick leave, & $58.21(34.43)$ & $79.74(35.64)$ & \\
& mean (SD) & & & 0.001 \\
& Productivity costs (€), & $€ 11,457(9,265 /$ & $€ 16,565( \pm 10,361 /$ & $14,739)$ \\
\hline
\end{tabular}

* Results of bootstrapped paired sample t-test. Min-scenario: Matches are randomly selected from the control dataset independent of the sick leave duration, Max-scenario: Matches are randomly selected from the control dataset when the minimum sick leave duration was 30 working days. 


\section{Discussion}

A multidisciplinary intensive return to work program with a wellness component in patients with recent SL due to MSKD resulted in a significantly higher (1.6 times) chance to return to work sooner compared to usual care, representing a gain of 17 working days and a reduction in productivity costs of $€ 4223$ in the 6 months following the program. In addition, a tendency for reduction in resource utilization and substantial improvements in health were observed within the program-group.

While it is not straightforward to pinpoint why the new program was successful in improving work outcome, there are some outstanding differences in the treatment when compared to UC as well as to earlier studied programs. First, all aspects of care that are nowadays considered to be relevant in work reintegration (i.e. graded activity, education in self-management skills, labor counselling, physiotherapy etc.) were included and were given simultaneously in an individualized approach. Second, the program combines these traditional components with spa-exercise and relaxation components. Finally, the absence of home-duties and the opportunity to share experiences with fellow patients might enhance full recovery. ${ }^{25}$ However, it is not possible to know which aspect of the treatment contributed most to the beneficial effect, nor whether all aspects are required to achieve the observed effects. It should be acknowledged that the program under study was intensive due to the inpatient setting on the one hand and the amount of daily activity level during the program on the other hand. Participating subjects must have been externally but also intrinsically motivated to participate in this intensive program, which likely contributed to the success. Motivation as a success-factor for nonpharmacological interventions has been identified previously. ${ }^{26}$ Clearly, in real life, such intensive programs should not be forced upon persons that are not motivated to put time and effort in demanding programs.

Existing evidence on the effectiveness of multidisciplinary programs in improving occupational outcomes is contradictory. In chronic low back pain a systematic literature review and one additional paper on multidisciplinary rehabilitation ${ }^{27,28}$ included 4 studies that reported on vocational outcomes of which two showed no benefit on $\mathrm{SL}^{29,30}$ one found an improvement in so-called work readiness, ${ }^{31}$ and one a beneficial effect on time to and rate of return to work. ${ }^{28} \mathrm{~A}$ more recent systematic review of 23 papers on intervention characteristics that facilitate return to work after sickness absence included 11 studies in MSKD. The authors suggested that early and multidisciplinary interventions seemed to be effective in supporting return to work. ${ }^{32}$

However, to our knowledge until now no study explored the effectiveness of an intensive multidisciplinary program for the full spectrum of MSKD (i.e. inflammatory, degenerative, a-specific and other MSKD) in patients that are only recently on sickleave. Interestingly, in our analyses socio-demographics, work and disease 
characteristics had no influence on the hazard for work resumption, in the total group nor in the program-group.

Some study limitations deserve attention. Firstly, since this analysis was the evaluation of an initiative of a consortium of several private providers of return to work assistance, no formal randomized controlled trial was conducted and no formal control data were available. To adjust for the absence of a control group, initially a Bayesian approach was planned to assess the magnitude of effect compared to UC. However, Dutch RCT's with a work-intervention in a population comparable to our study population was not found, and consequently no pre-intervention estimate on hazard to return to work or length of sick-leave could be made. Therefore, we matched subjects to persons included in an existing OHS- database. Three approaches of selection were applied to adjust for differences in risk for long term absence and in motivation to reintegrate in work. Although, scenario analyses did not change results dramatically, this approach might be insufficient to fully adjust for differences in motivation, or other risk factors of prolonged SL. Analyses were only performed on completers which seems reasonable as the main aim of the study was to prove the concept of the intensive intervention.

While RCTs should be performed to prove causality in terms of effectiveness and costeffectiveness, they are limited when it comes to non-pharmacological interventions with need for long-term outcome evaluation. Occupational Registers have the ability to improve insight into facilitators and barriers to long-term work outcomes and data could be used as comparator in Bayesian approaches to show long-term (cost)effectiveness of new interventions.

Possibilities to implement the current program in other regions or countries depend not only on local availability of professional expertise and facilities to offer this intensive multidisciplinary program, but also on modalities to (co-)finance the program. In the Netherlands, employers are expected to pay for (some of) the costs of reintegration and rehabilitation and this might even increase the patient's commitment to reintegration. It should be recognised that program costs were quite high. Locations that offer hotel costs at lower pricing may substantially reduce program costs. Further, some patients might have achieved goals already within the current fixed period of 4 weeks, thereby further reduce program costs.

In conclusion, an intensive multidisciplinary program in subjects on recent term sickness due to MSKD but with a high risk for long-term absence resulted in sooner work-reintegration and in lower workdays absent. The type of MSKD did not affect this result. Extra costs of the treatment program for one working day gained may be partially offset by improvement in health and healthcare costs. 


\section{References}

1. Yelin EH, Felts WR. A summary of the impact of musculoskeletal conditions in the United States. Arthritis Rheum. 1990;33:750-755.

2. Yelin E, Callahan LF. The economic cost and social and psychological impact of musculoskeletal conditions. National Arthritis Data Work Groups. Arthritis Rheum. 1995;38:1351-1362.

3. Badley EM. The economic burden of musculoskeletal disorders in Canada is similar to that for cancer, and may be higher. J Rheumatol. 1995;22:204-206.

4. Lubeck DP. The economic impact of arthritis. Arthritis Care Res. 1995;8(4):304-310.

5. Gabriel SE, Crowson CS, Campion ME, O'Fallon WM. Indirect and nonmedical costs among people with rheumatoid arthritis and osteoarthritis compared with nonarthritic controls. J Rheumatol. 1997;24: 43-48.

6. Marhold C, Linton SJ, Melin L. A cognitive-behavioral return-to-work program: effects on pain patients with a history of long-term versus short-term sick leave. Pain. 2001;91:155-163.

7. Henderson M, Glozier N, Holland Elliott K. Long term sickness absence. BMJ. 2005;330(7495):802-803.

8. de Buck PD, van Amstel RJ, Buijs PC, et al. Communication between Dutch rheumatologists and occupational physicians in the occupational rehabilitation of patients with rheumatic diseases. Ann Rheum Dis. 2002;6:62-65.

9. Karjalainen K, Malmivaara A, van Tulder M, et al. Multidisciplinary biopsychosocial rehabilitation for neck and shoulder pain among working age adults. Cochrane Database Syst Rev. 2003:CD002194.

10. Lacaille D, White MA, Rogers PA, Backman CL, Gignac MA, Esdaile JM. A proof-of-concept study of the "Employment and Arthritis: Making It Work" program. Arthritis Rheum. 2008;59:1647-1655.

11. Van Tubergen A, Debats I, Ryser L, et al. Use of a numerical rating scale as an answer modality in ankylosing spondylitis-specific questionnaires. Arthritis Rheum. 2002;47:242-248.

12. Tang K, Escorpizo R, Beaton DE, et al. Measuring the impact of arthritis on worker productivity: perspectives, methodologic issues, and contextual factors. J Rheumatol. 2011;38:1776-1790.

13. Stolwijk C, Castillo-Ortiz JD, Gignac M, Luime J, Boonen A. Importance of Contextual Factors When Measuring Work Outcome in Ankylosing Spondylitis: A Systematic Review by the OMERACT Worker Productivity Group. Arthritis Care Res. 2015;67:1316-1327.

14. Lenssinck ML, Burdorf A, Boonen A, Gignac MA, Hazes JM, Luime JJ. Consequences of inflammatory arthritis for workplace productivity loss and sick leave: a systematic review. Ann Rheum Dis. 2013; 72:493-505.

15. Waddell G, Burton AK, Kendall NA. Vocational rehabilitation-what works, for whom, and when?(Report for the Vocational Rehabilitation Task Group): TSO; 2008.

16. Staal JB, Hlobil H, Twisk JWR, Smid T, Köke ArJA, van Mechelen W. Graded activity for low back pain in occupational health care. A randomized, controlled trial. Ann Intern Med. 2004;140:77-84.

17. Geilen J, Wilgen CP, Köke A. Graded Activity: Bohn Stafleu van Loghum; 2008.

18. Van Tubergen A, Boonen A, Landewe R, et al. Cost effectiveness of combined spa-exercise therapy in ankylosing spondylitis: a randomized controlled trial. Arthritis Rheum. 2002;47:459-467.

19. van Tubergen A, Landewe R, van der Heijde D, et al. Combined spa-exercise therapy is effective in patients with ankylosing spondylitis: a randomized controlled trial. Arthritis Rheum. 2001;45:430-438.

20. Adviseurs BO. http://www.wetpoortwachter.nu/page.php?id=3. VERZUIM TUSSEN WEEK 2 EN WEEK 132014.

21. Hurst NP, Kind P, Ruta D, Hunter M, Stubbings A. Measuring health-related quality of life in rheumatoid arthritis: validity, responsiveness and reliability of EuroQol (EQ-5D). Br J Rheumatol. 1997;36:551-559.

22. Lamers LMS, P.F.M.; McDonnell, J.; Krabbe, P.F.M.; van Busschbach, J.J. Kwaliteit van leven meten in economische evaluaties: het Nederlands EQ-5D-tarief. Ned Tijdschr Geneeskd. 2005;149:1574-1578.

23. Oostenbrink JB, Koopmanschap MA, Rutten FFH. Handleiding voor kostenonderzoek: methoden en richtlijnprijzen voor economische evaluaties in de gezondheidszorg: College voor zorgverzekeringen; 2000.

24. Cohen J. Statistical power analysis for the behavioral sciences: Academic press; 2013. 
25. Verhagen A, Bierma-Zeinstra S, Lambeck J, et al. Balneotherapy for osteoarthritis. A cochrane review. J Rheumatol. 2008;35:1118-1123.

26. Tan V, Cheatle MD, Mackin S, Moberg PJ, Esterhai JL. Goal setting as a predictor of return to work in a population of chronic musculoskeletal pain patients. Int J Neurosci. 1997;92:161-170.

27. Guzman J, Esmail R, Karjalainen K, Malmivaara A, Irvin E, Bombardier C. Multidisciplinary rehabilitation for chronic low back pain: systematic review. BMJ. 2001;322(7301):1511-1516.

28. Schaafsma F, Schonstein E, Whelan KM, Ulvestad E, Kenny DT, Verbeek JH. Physical conditioning programs for improving work outcomes in workers with back pain. The Cochrane database of systematic reviews. 2010:CD001822.

29. Alaranta $H$, Rytokoski $U$, Rissanen A, et al. Intensive physical and psychosocial training program for patients with chronic low back pain. A controlled clinical trial. Spine. 1994;19:1339-1349.

30. Mitchell RI, Carmen GM. The functional restoration approach to the treatment of chronic pain in patients with soft tissue and back injuries. Spine. 1994;19:633-642.

31. Bendix AF, Bendix T, Ostenfeld S, Bush E, Andersen. Active treatment programs for patients with chronic low back pain: a prospective, randomized, observer-blinded study. Eur Spine J. 1995;4: 148-152.

32. Hoefsmit N, Houkes I, Nijhuis FJN. Intervention Characteristics that Facilitate Return to Work After Sickness Absence: A Systematic Literature Review. J Occup Rehabil. 2012;22:462-477. 


\section{Supplementary tables and figure}

Table S4.1 Description of the treatment program.

\begin{tabular}{|c|c|}
\hline Treatment component & Physiological aim \\
\hline $\begin{array}{l}\text { Physiotherapy } \\
\text { (individually) } \\
\text { (4 hours per } 4 \text { weeks) }\end{array}$ & $\begin{array}{l}\text { Improvement of physical capacity, specifically for own } \\
\text { work and individual reason of sick leave }\end{array}$ \\
\hline $\begin{array}{l}\text { Sauna } \\
\text { (in group) } \\
\text { (10 hours per } 4 \text { weeks) }\end{array}$ & Improvement of blood circulation, mental relaxation \\
\hline $\begin{array}{l}\text { Hydrotherapy } \\
\text { (in group) } \\
\text { (10 hours per } 4 \text { weeks) }\end{array}$ & $\begin{array}{l}\text { Stimulation of blood circulation by thermal water (ca. } \\
31^{\circ} \mathrm{C} \text { ), active mobilization with relative resistance of } \\
\text { water and with minimum body weight (10\%) }\end{array}$ \\
\hline $\begin{array}{l}\text { Swimming } \\
\text { (in group) } \\
\text { (10 hours per } 4 \text { weeks) }\end{array}$ & Improvement of muscle strengths and endurance \\
\hline $\begin{array}{l}\text { Nordic-walking } \\
\text { (in group) } \\
\text { (10 hours per } 4 \text { weeks) }\end{array}$ & Improvement of muscle strengths and endurance \\
\hline $\begin{array}{l}\text { Exercise therapy } \\
\text { (in group) } \\
\text { ( } 9 \text { hours per } 4 \text { weeks) }\end{array}$ & Improvement of muscle strengths and endurance \\
\hline $\begin{array}{l}\text { Physiotherapeutic fitness } \\
\text { (in group) } \\
\text { (12 hours per } 4 \text { weeks) }\end{array}$ & Improvement of muscle strengths and endurance \\
\hline $\begin{array}{l}\text { Treatment employment specialist } \\
\text { (individual) } \\
\text { (12 hours per } 4 \text { weeks) }\end{array}$ & $\begin{array}{l}\text { Inventory and assimilation of work-related load and } \\
\text { capacity specifically for own work }\end{array}$ \\
\hline $\begin{array}{l}\text { Psychological intervention } \\
\text { (individual) } \\
\text { (12 hours per } 4 \text { weeks) }\end{array}$ & $\begin{array}{l}\text { Improvement of mental capacity, specifically for own } \\
\text { work and individual reason of sick leave }\end{array}$ \\
\hline $\begin{array}{l}\text { Theoretical workshop regarding cognitive- } \\
\text { behavioral approach for symptom-management } \\
\text { (in group) } \\
\text { (8 hours per } 4 \text { weeks) }\end{array}$ & $\begin{array}{l}\text { Improvement of health literacy and stimulation of self- } \\
\text { initiated activity }\end{array}$ \\
\hline
\end{tabular}


Table S4.2 Comparison of baseline-characteristics of participants in program group who did or did not provide information regarding the main outcome of interest (work resumption).

\begin{tabular}{|c|c|c|c|c|}
\hline Characteristics & $\begin{array}{l}\text { Information } \\
\text { provided at } \\
\text { start of the } \\
\text { program } \\
n=137\end{array}$ & $\begin{array}{c}\text { A } \\
\text { Information } 6 \\
\text { months after } \\
\text { program } \\
\text { provided } \\
n=111 \\
\end{array}$ & $\begin{array}{c}\text { B } \\
\text { Information } 6 \\
\text { months after } \\
\text { program not } \\
\text { provided } \\
n=36 \\
\end{array}$ & $\begin{array}{c}\text { p-value for } \\
\text { comparison } \\
\text { between } \\
\text { A \& B }\end{array}$ \\
\hline \multirow[t]{2}{*}{ Women, $n(\%)$} & & & $n=26$ & $0.17^{*}$ \\
\hline & $91(66.4)$ & $77(69.4)$ & $14(53.8)$ & \\
\hline \multirow[t]{2}{*}{ Age, mean(SD)/median } & & & $\mathrm{n}=26$ & 0.77 \\
\hline & $\begin{array}{c}46.7 \\
(9.8) / 48.0\end{array}$ & $\begin{array}{c}46.86 \\
(9.93) / 48.0\end{array}$ & $\begin{array}{c}46.23 \\
(9.40) / 48.0\end{array}$ & \\
\hline Type of work, n(\%) & & & $n=26$ & 0.67 \\
\hline physically demanding & $13(9.5)$ & $10(9.0)$ & $3(11.5)$ & \\
\hline mentally demanding & $50(36.5)$ & $39(35.1)$ & $11(42.3)$ & \\
\hline physically and mentally demanding & $74(54.0)$ & $62(55.9)$ & $12(46.2)$ & \\
\hline Education, $\mathrm{n}(\%)$ & $\mathrm{n}=135$ & $n=109$ & $n=26$ & 0.22 \\
\hline Primary school or no education & $3(2.1)$ & $3(2.8)$ & - & \\
\hline Lower professional education & $17(11.8)$ & $13(11.9)$ & $4(15.4)$ & \\
\hline $\begin{array}{l}\text { Middle or professional secondary } \\
\text { education }\end{array}$ & $56(38.9)$ & $42(38.5)$ & $14(53.8)$ & \\
\hline Secondary general education & $15(10.4)$ & $15(13.8)$ & - & \\
\hline $\begin{array}{l}\text { Higher professional or university } \\
\text { education }\end{array}$ & $44(30.6)$ & $36(33.0)$ & $8(30.8)$ & \\
\hline $\begin{array}{l}\text { Type of musculoskeletal condition, } \\
n(\%)\end{array}$ & & & $n=26$ & 0.32 \\
\hline inflammatory & $34(24.8)$ & $31(27.9)$ & $3(11.5)$ & \\
\hline non-specific & $60(43.8)$ & $46(41.4)$ & $14(53.8)$ & \\
\hline degenerative & $23(16.8)$ & $19(17.1)$ & $4(15.4)$ & \\
\hline other & $20(14.6)$ & $15(13.5)$ & $5(19.2)$ & \\
\hline \multirow{2}{*}{$\begin{array}{l}\text { Contractual working hours per week, } \\
\text { mean (SD)/median }\end{array}$} & $n=132$ & & & \\
\hline & $\begin{array}{c}30.69 \\
(9.9) / 32.0 \\
\end{array}$ & $30.3(9.8) / 32.0$ & $32.6(10.09) / 36.0$ & 0.29 \\
\hline
\end{tabular}

Comparison of categorical variables: Fisher's exact test or Chi-square test. Comparison of continuous variables: Anova 
Table S4.3 Results of Activity based costing for the treatment program.

\begin{tabular}{lc}
\hline Activity & Costs per patient for total program (€) \\
\hline Group-activities & \\
Walking & 90.95 \\
Hydrotherapy & 90.95 \\
Swimming & 90.95 \\
Sauna & 37.50 \\
Fitness & 78.75 \\
Individual activities & \\
Physiotherapy & 291.04 \\
Labor expert counseling & 873.12 \\
Coaching graded activity & 582.08 \\
Psychological coaching & 982.20 \\
Intake/Outtake & \\
Intake & 421.85 \\
Outtake & 253.90 \\
Administration & 454.00 \\
Cleaning & 137.50 \\
Lodging & 1600.00 \\
Catering & 187.50 \\
Total & 6172.29 \\
\hline
\end{tabular}

\section{Kaplan-Meier-curves}

Min scenario (i.e. matches in control group were selected independent of the working days on sick leave)

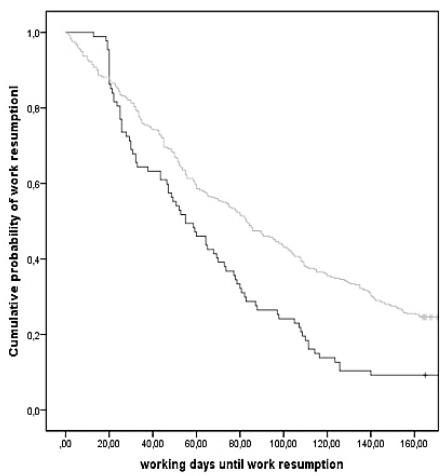

Max scenario (i.e. matches were selected if they had a minimum of 30 working days of sick leave)

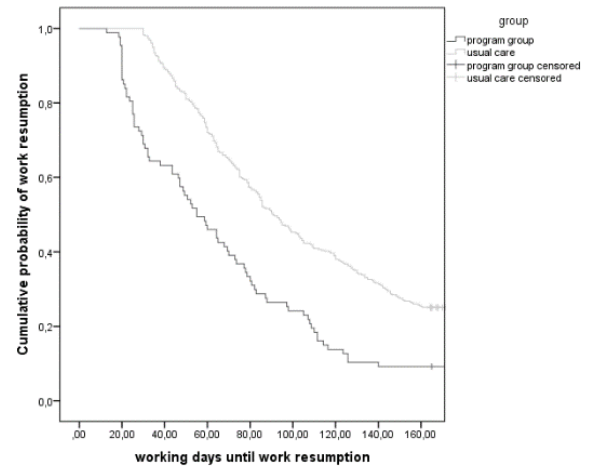

Figure S4.1 Results of Kaplan-analyses to explore group differences between program and usual care group in probability of work resumption (min-max scenario). 


\section{Part III}

Influence of country of residence on work outcomes and validity of presenteeism measures in patients with rheumatoid arthritis 



\section{Chapter 5}

Large country differences in work outcomes in patients with RA - an analysis in the multinational study COMORA

Antje van der Zee-Neuen, Polina Putrik, Sofia Ramiro, Andras P. Keszei, Ihsane Hmamouchi, Maxime Dougados Annelies Boonen 


\section{Abstract}

\section{Objectives}

To explore whether country of residence or specific country characteristics are associated with work outcomes in rheumatoid arthritis (RA) patients.

\section{Methods}

Data from the cross-sectional multinational study COMORA (17 countries) were used. Work outcomes were measured by the Work Productivity and Activity Impairment Questionnaire (WPAl) assessing employment (yes/no), absenteeism (\% of time) and presenteeism (\% of normal productivity). Contribution of country of residence, gross domestic product (GDP), human development index (HDI), unemployment rate, social protection expenditures (SPE) or world region to work outcomes was investigated in (ordinal) logistic regression models adjusted for clinical and sociodemographic factors.

\section{Results}

The sample comprised 3,920 patients. Mean age was 56 years (SD 13), 3,191 (82\%) were female and 1,225 (31\%) were employed. Large country differences were found for all work outcomes. Taking the country with the best work outcome as reference, patients in Morocco had lowest odds to be employed (OR 0.2; [95\% Cl 0.1;0.3] vs. USA) and highest odds of absenteeism (OR 12.6 [4.5;35.9] vs. Japan), while presenteeism was highest in Taiwan (OR 13.8[5.9;32.0] vs. Venezuela). All country indices except SPE were associated with work outcomes. E.g. patients in low GDP countries had lower odds of employment (OR $0.7[0.5 ; 0.8]$ ), higher odds of absenteeism (OR $2.7[1.9 ; 3.8]$ ) but lower odds of presenteeism (OR $0.5[0.3 ; 0.6]$ ) compared to high GDP countries.

\section{Conclusion}

Substantial differences in work outcomes among RA patients were observed between countries. Lower economic wealth and human development of countries were associated with worse employment, higher absenteeism but lower presenteeism. 


\section{Background}

The worldwide economic crisis and the aging of the population pose challenges to employment perspectives. On the one hand, there is pressure on individuals to work longer and more efficiently, and on the other hand the number of available jobs is increasingly limited. Persons suffering from a chronic disease such as rheumatoid arthritis (RA) are already at increased risk for adverse work outcomes including restrictions in productivity while at work (presenteeism), sick leave (absenteeism) and eventually work disability or unemployment ${ }^{1}$ and therefore are particularly vulnerable to a negative economic climate.

There is increasing evidence that environmental contextual factors such as nature of work or support form colleagues influence work outcome independent of biomedical and personal contextual factors. ${ }^{1,2}$ On this line, limited evidence suggests that system level environmental factors, such as the prosperity or development of a country play a decisive role. Dadoniene et al. showed lower employment rates among patients with RA in Lithuania, a country with an economy in transition, when compared to Norway, one of the wealthiest countries in Europe. ${ }^{3}$ Mau et al. reported lower employment in RA patients residing in the former Eastern compared to Western German states, and attributed this to higher prevailing economic unemployment in former Eastern German states. ${ }^{4}$ Chung et al. found a higher hazard of withdrawal from work due to RA-related work disability in Finland compared to the USA, for similar clinical and sociodemographic characteristics, ${ }^{5}$ and suggested the more supportive Finnish social security system with favorable disability allowance in case of disease related work disability partly explained such differences. Finally, the QUEST RA study among 32 countries showed that patients in low income countries continued to work with high levels of disease activity. ${ }^{6}$

Better insight into system related differences in work outcomes might be important when designing and implementing intervention programs aiming to improve short- and long-term work outcomes of patients with RA as the outcome may be strongly depending on culture or regulations of the country from which participants originate. Moreover, such knowledge is crucial in multinational studies, as stratification by country or (groups of countries) based on a specific characteristic may be essential to avoid bias. As the focus of research on work outcome in rheumatology shifts towards presenteeism (i.e. productivity loss while at work) and sick leave, and as there is increasing evidence that the various work outcomes, are differentially influenced by biomedical and contextual factors, ${ }^{7}$ it is important to address each of these outcomes in addition to employment status.

The COMOrbidities in Rheumatoid Arthritis international study (COMORA) collected recent patient level data from 17 countries across 5 continents including data on work outcomes. These data offer a unique opportunity to explore the impact of country of 
residence as well as specific country characteristics on employment, absenteeism and presenteeism.

We hypothesized that higher economic wealth and human development of a country is associated with higher employment and lower absenteeism and presenteeism.

\section{Methods}

COMORA, an international, cross-sectional multicenter study in 17 countries, collected data in patients diagnosed with RA according to the 1987 American College of Rheumatology classification criteria for RA, older than 18 years, and with sufficient command of the questionnaire language. The study protocol was approved by one central and all local institutional ethics committees. Written informed consent was obtained from all subjects. Investigators and patients completed a questionnaire on demographics and self-reported health, including questions on work outcome. ${ }^{8}$

\section{Outcome variables}

Work outcome was measured by the Work Productivity Impairment Questionnaire (WPAI). ${ }^{9-11}$ Outcomes comprised employment status (employed vs. not employed), and in those employed the percentage of working hours absent and percent presenteeism (converted from a 0-10 numeric rating scale of impairments in productivity; 10 indicating health completely prevented work) due to health problems during the past 7 days.

\section{Socio-demographic and clinical characteristics}

Socio-demographic and lifestyle information comprised age, gender, highest level of education achieved (primary school, secondary school, university), marital status (single, married, widowed, divorced), smoking status (past, current, never smoked) and weight $(\mathrm{kg})$ and height $(\mathrm{cm})$ from which the body mass index (BMI) was calculated (underweight: $\mathrm{BMI}<18.5$, normal weight:18.5 $\geq \mathrm{BMI}<25$, overweight: $25 \geq \mathrm{BMI} \leq 30$, and obese: BMI>30). ${ }^{12,13}$

Clinical characteristics comprised the modified 8-item health assessment questionnaire (mHAQ) assessing the level of physical function and ranging from 0 to 3 (worst function), ${ }^{14,15}$ the 28 -joints disease activity scale DAS28 ranging from 0 to (virtually) $10,{ }^{16}$ presence of high rheumatoid factor (RF)/high positive anti-citrullinated protein antibody (ACPA). Physician-confirmed ischemic cardiovascular disease (myocardial infarction, stroke), cancer (colon, skin, lung, breast and uterus for women, prostate for men, and lymphoma), gastrointestinal diseases (diverticulitis, ulcers), infections (hepatitis), lung disease (chronic obstructive pulmonary disease and asthma) and 
psychiatric disorders (depression) were used to compute the Rheumatic Disease Comorbidity Index (RDCl). ${ }^{17,18}$ As the history of fractures was not collected, these were not included in the RDCl and therefore the score ranged from 0-8.

\section{Country characteristics}

Data on socio-economic country indices were extracted from the International Monetary Fund (for Gross Domestic Product (GDP)), the International Labour Organization (for unemployment rates and social protection expenditures (SPE)) and the United Nations Development program (for Human Development Index (HDI)). ${ }^{19-22}$ The GDP per capita is an indicator for economic wealth and expressed in International dollars (int\$), to adjust local currency for purchasing power parity (PPP) allowing crosscountry comparison. ${ }^{19}$ Based on the visual inspection of data, GDP was dichotomized as $\leq 20,000$ or $>20,000 \mathrm{Int} \$$. Unemployment rate reflecting economic growth and efficiency, was dichotomized based on the median as $\leq 7.6 \%$ or $>7.6 \%$. ${ }^{20}$ The $\mathrm{HDI}$ reflects a country's level of development and includes life expectancy, education assessed by years of school attendance and the standard of living (GDP/capita). ${ }^{21} \mathrm{HDI}$ was dichotomized based on the United Nations Development Program classification resulting in two categories (moderate versus high \& very high). The SPE reflects social expenditure for sickness, maternity, employment injury \& disability, and was dichotomized using (a) the percentage SPE of the country's GDP, dichotomized at the median $(<2.15 \%$ vs $\geq 2.15 \%)$ and (b) the absolute SPE in int. \$ dichotomized at the median (SPE <801.50 int. \$ vs $\geq 801.50$ ). ${ }^{22}$ Finally, countries were categorized by world region (Africa, Asia, North America, Europe, and Latin America) reflecting socio-cultural coherence. Supplementary Table S5.1 provides an overview of the countries according to the categories of the different indices and the overlap between categories.

\section{Statistical analysis}

Descriptive statistics were used to characterize the sample. To understand factors contributing to employment, logistic regressions were used. When absenteeism or presenteeism were the outcome, the sample was limited to those employed and only countries with at least 30 employed persons were considered. A considerable proportion of participants indicated no absence or presenteeism. Based on the model fit (deviance), ordered logistic regressions were preferred above zero-inflated regression approaches. Based on inspection and testing for the proportional odds assumption for ordered logistic regression, the categories chosen for absenteeism were: $0 \%$; $>0 \%$ to $<100 \%$; $100 \%$, and categories of presenteeism: $0 \%$; $>0 \%$ to $30 \%$; $>30 \%$ to $50 \%$ and $>50 \%$ to $100 \%$. To select the individual covariates associated with each outcome in multivariable models, manual forward selection (cut-off p-value $<0.05)$ was used. To understand the additional influence of country of residence, 
'country' was added to the multivariable model as a categorical variable, using the country with the highest employment, or the lowest absenteeism or presenteeism in the raw data as reference. Finally, 'country' was replaced by the different country indices. For each model, the fit of models with the different country-related variables was compared to the model without any country variable using log-likelihood ratio tests (with a cut-off of $p<0.05$ for significance). Statistical models were restricted to complete cases.

Interactions between socio-demographic and clinical characteristics and GDP were explored for each work outcome. Analyses were performed using Stata $12{ }^{23}$

\section{Results}

Overall, 3,920 individuals (with a mean age of 56 and of which $81 \%$ women) from 17 countries in 5 world regions comprising Europe (i.e. Austria [AT], France [ FR], Germany [DE], Hungary [HU], Italy [IT], Netherlands [NL], Spain [ES], United Kingdom $[\mathrm{UK}]$ ), Latin America (i.e. Uruguay [UR], Venezuela [VE], Argentina [AR]), Asia (i.e. Taiwan [TW], Japan [JP], Korea [KR]), Africa (i.e. Morocco [MA], Egypt [EG]) and North America (i.e. the United States of America [USA]) were included in COMORA. Clinical and disease characteristics are described in Table 5.1. In total, 1,225 patients (31.4\%) were employed with the highest percentage of employment in the USA ( $n=183 / 400$; $45.8 \%)$ and the lowest in Morocco ( $n=34 / 227 ; 15.0 \%)$. As in the UK and Uruguay only $16(37.2 \%)$ and 12 (40.0\%) persons were employed respectively, these countries were excluded from analyses on absenteeism and presenteeism. Of the 1225 employed persons, 1,139 of completed the question on absenteeism. The number of persons in each of the categories for absenteeism was: $0 \%(n=874) ;>0 \%$ and $<100 \%(n=193)$; $100 \%(n=72)$. For the 1,054 completing the question on presenteeism the distribution was: $0 \%(n=327) ;>0 \%$ and $\leq 30 \%(n=486) ;>30 \%$ and $\leq 50 \%(n=231)$ and $>50 \%$ and $\leq 100 \%(n=10)$. The mean absenteeism was $11.5 \%(S D \pm 27.50)$ and was highest in Morocco 45.6\% (SD 44.40) and lowest in Japan 3.0\% (SD 9.6\%) and Taiwan 3.4\% (SD 12.1). The mean presenteeism was $31.9 \%$ (SD 31.18) and was highest in Morocco $34.0 \%$ (SD 22.3) and lowest in Venezuela 11.8\% (SD 21.2). Supplementary Table S5.2 shows characteristics of the employed sample. 


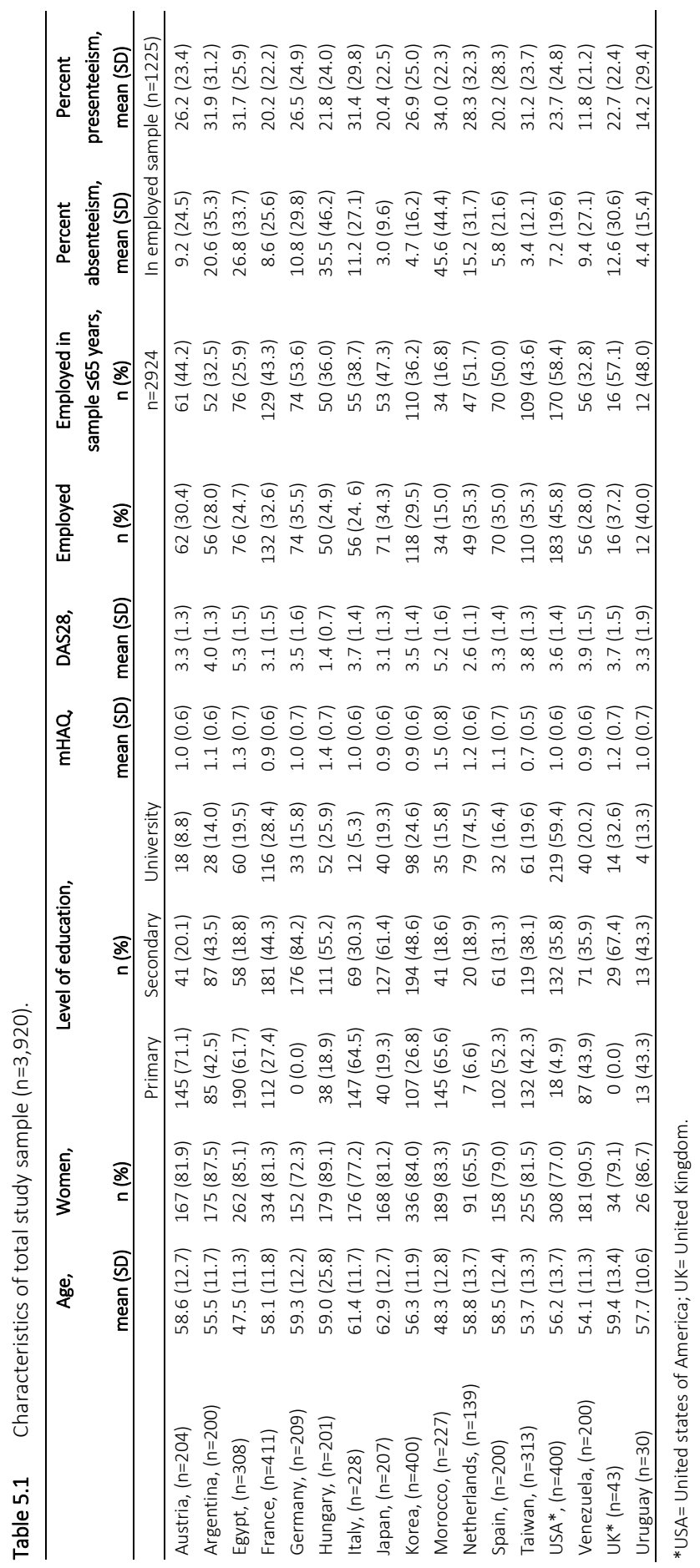




\section{Multivariable models with work outcomes}

\section{Employment}

Older age (OR 0.94 [95\% Cl 0.93; 0.94] per year), female gender (OR 0.38 [95\% Cl 0.31; 0.47]), lower educational level (low vs. high: OR 0.33 [95\% Cl 0.26; 0.41], medium vs. high: OR 0.67 [95\% Cl 0.55;0.81]), worse HAQ (OR 0.62 [95\% Cl 0.52;0.72]) and higher DAS28 (OR 0.84 [95\% Cl 0.79;0.89]) were all significantly associated with lower odds of employment while RDCl had no significant influence (OR 0.94 [95\% Cl 0.87;1.01]).

In the next step, country of residence was significantly associated with employment. Since the USA showed the highest employment rate we used it as reference category. Morocco (OR 0.17 [95\% Cl 0.10;0.30]), Egypt (OR 0.37 [95\% Cl 0.24;0.56]), Venezuela (OR 0.53 [95\% Cl 0.34;0.84]), Korea (OR 0.45 [95\% Cl 0.31;0.65]), France (OR 0.66 [95\% $\mathrm{Cl} 0.46 ; 0.95]$ ) and Taiwan (OR 0.54 [95\% Cl 0.36;0.80]) showed significantly lower odds of being employed compared to the USA (Figure 5.1A).

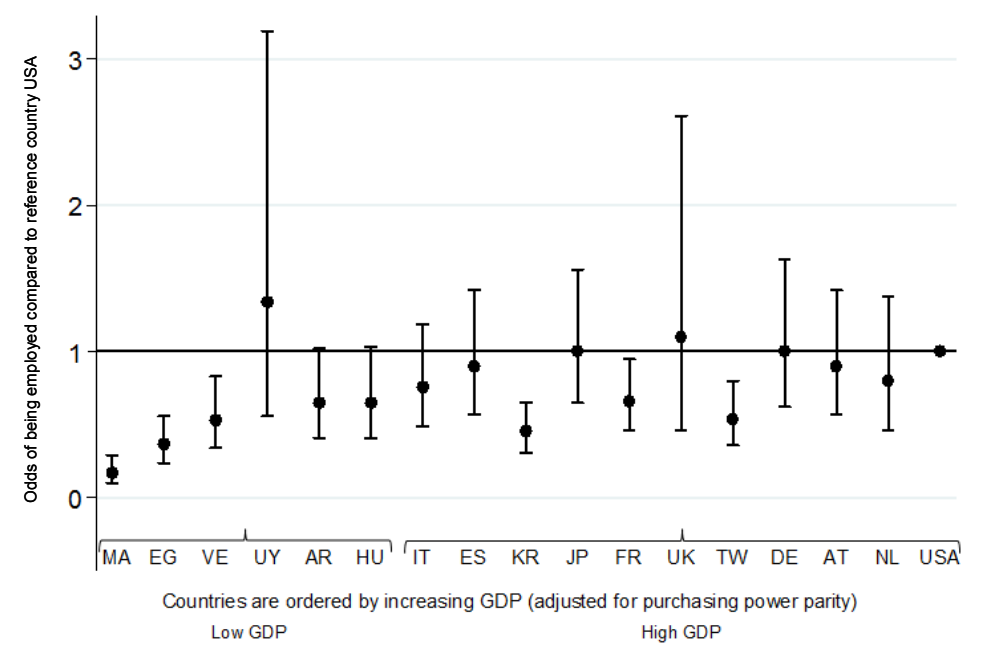

Figure 5.1A Odds of being employed per cpuntry compared to reference country USA.

When replacing country by GDP, patients from low GDP countries showed significantly lower odds of employment compared to high GDP countries (OR $0.66[95 \% \mathrm{Cl}$ $0.54 ; 0.80]$ ). As significant interactions were found between GDP with age, gender, level of education and the $\mathrm{RDCl}$, analyses were stratified by GDP. In high GDP countries, older age and presence of comorbidities amplified the chance of not being employed, 
while in lower GDP countries lower education and female sex reinforced the odds of not being employed (Table 5.2)

Lower HDI, higher unemployment, but not the level of SPE were significantly associated with lower odds of employment and each of the country indices significantly improved the model fit compared to the model without any country indices. Countries in Africa, Latin America, Asia and (not significant) Europe, had lower odds of employment compared to North America (Supplementary Table S5.5).

Table 5.2 Association of individual sociodemographic \& clinical characteristics with being employed stratified by gross domestic product (GDP).*

\begin{tabular}{lcc}
\hline & $\begin{array}{c}\text { Countries with high GDP; } \\
\mathrm{n}=2,754 \\
\text { OR }[95 \% \mathrm{Cl}]\end{array}$ & $\begin{array}{c}\text { Countries with low GDP; } \\
\mathrm{n}=1,166 \\
\text { OR [95\%Cl] }\end{array}$ \\
\hline Age $^{1}$ (years) & $0.92[0.91 ; 0.93]$ & $0.96[0.94 ; 0.97]$ \\
Gender (female vs. male) $^{1}$ & $0.44[0.35 ; 0.56]$ & $0.24[0.16 ; 0.36]$ \\
Level of education $^{1}$ & & \\
$\quad$ Low vs. high & $0.44[0.34 ; 0.58]$ & $0.23[0.16 ; 0.35]$ \\
$\quad$ Medium vs. high & $0.79[0.63 ; 0.99]$ & $0.42[0.28 ; 0.62]$ \\
mHaq (0-3) & $0.55[0.45 ; 0.67]$ & $0.83[0.63 ; 1.10]$ \\
DAS28 & $0.90[0.82 ; 0.98]$ & $0.79[0.70 ; 0.89]$ \\
Rheumatic Disease Comorbidity Index ${ }^{1}(0-8)$ & $0.90[0.84 ; 0.98]$ & $1.02[0.88 ; 1.18]$ \\
\hline
\end{tabular}

*Results from multivariable logistic regression analysis. ${ }^{1}$ Significant interaction with GDP (GDP $\leq 20,000$ : high; GDP>20,000: low). Abbreviations: OR: odds ratio; $\mathrm{Cl}$ : confidence interval; $\mathrm{mHAQ}$ : modified health assessment questionnaire; DAS28: 28-joints disease activity scale. High GDP-countries: Morocco, Egypt, Venezuela, Uruguay, Argentina, Hungary. Low GDP-countries: Italy, Spain, Korea, Japan, France, United Kingdom, Taiwan, Germany, Austria, the Netherlands, United States of America.

\section{Absenteeism}

Higher HAQ (OR 2.65 [95\% Cl 1.89;3.70]), DAS28 (OR 1.35 [95\%Cl 1.18;1.54]) and RDCl (OR $1.35[95 \% \mathrm{Cl} 1.17 ; 1.56]$ ) increased the odds to be in a higher category of absenteeism. When adding country of residence, country was significantly associated with absenteeism. Since Japan had the lowest absenteeism we used it as reference category. The odds of being in the next higher category of absenteeism were significantly higher for Argentina (OR 3.25 [95\% Cl 1.25;8.45]), Hungary (OR 6.49 [95\%Cl $2.45 ; 17.23]$ ) and Morocco (OR 12.63 [95\% Cl 4.45;35.89]) compared to Japan (Figure 5.1B).

When replacing country of residence by GDP, low GDP countries showed higher odds of being in the higher absenteeism group (OR 2.68 [95\% CI 1.91;3.76]) than high GDP countries (Table 5.3). Interactions between GDP and the other covariates were not significant.

Similarly, lower HDI, higher unemployment rate but not SPE were associated with significantly increased odds of being in the higher absenteeism group, and each of the indices significantly improved the model fit compared to the model without any 
country indices. Countries in Europe, Africa and Latin America had significantly higher odds of absenteeism than countries in Asia. (Supplementary Table S5.5)

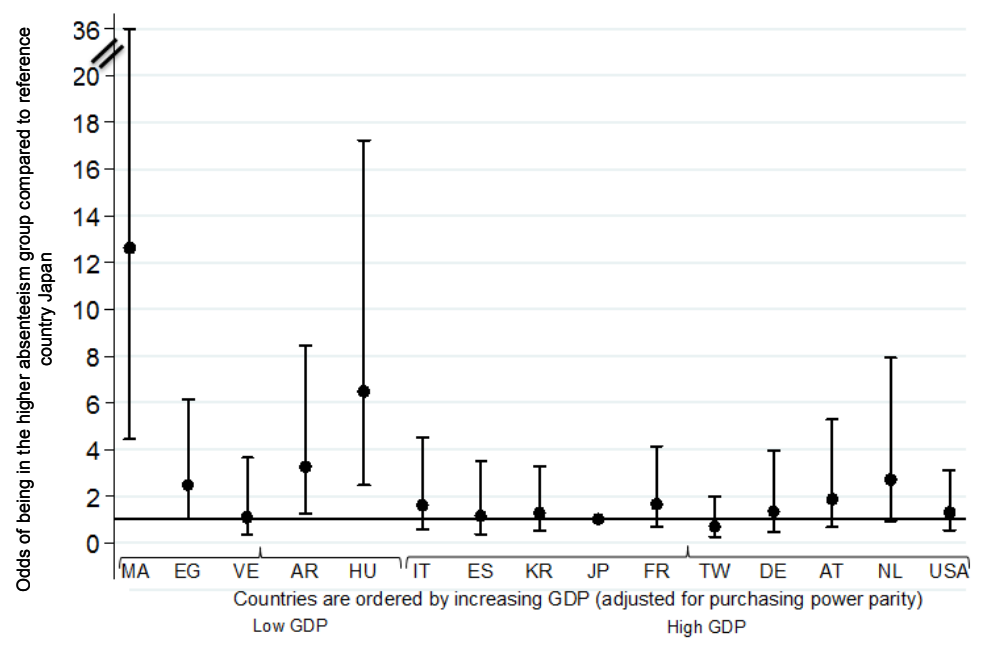

Figure 5.1B Odds of being in the higher absebteeism group per country compared to reference country Japan.

\section{Presenteeism}

Higher HAQ (OR 4.63 [95\%Cl 3.29;6.51]) and DAS28 (OR 1.60 [95\%Cl 1.42;1.80]) increased the odds of belonging to a higher category of presenteeism. Country of residence was significantly associated with presenteeism. Since Venezuela had the lowest presenteeism we used it as reference category. All countries had significantly higher odds for being in a higher presenteeism group compared to Venezuela. The highest odds were found for Taiwan (OR 13.81 [95\%Cl 5.95;32.04]), Korea (OR 10.95 [95\% Cl 4.77;25.13]) and Italy (OR 8.96 [95\% Cl 3.53;22.76]) (Figure 5.1C).

When replacing country of residence by GDP, low GDP countries had significantly lower odds of being in a higher presenteeism group (0.45 [0.32;0.60]) compared to high GDP countries (Table 5.3). Interactions between GDP and the other covariates were not significant.

Similarly, lower HDI and higher unemployment rate were associated with lower odds for being in a higher presenteeism group while lower SPE was associated with increased odds of being in the higher presenteeism group. Countries in Europe, Asia and North America had significantly higher odds of being in a higher presenteeism group compared to Latin America (Supplementary Table S5.5). 


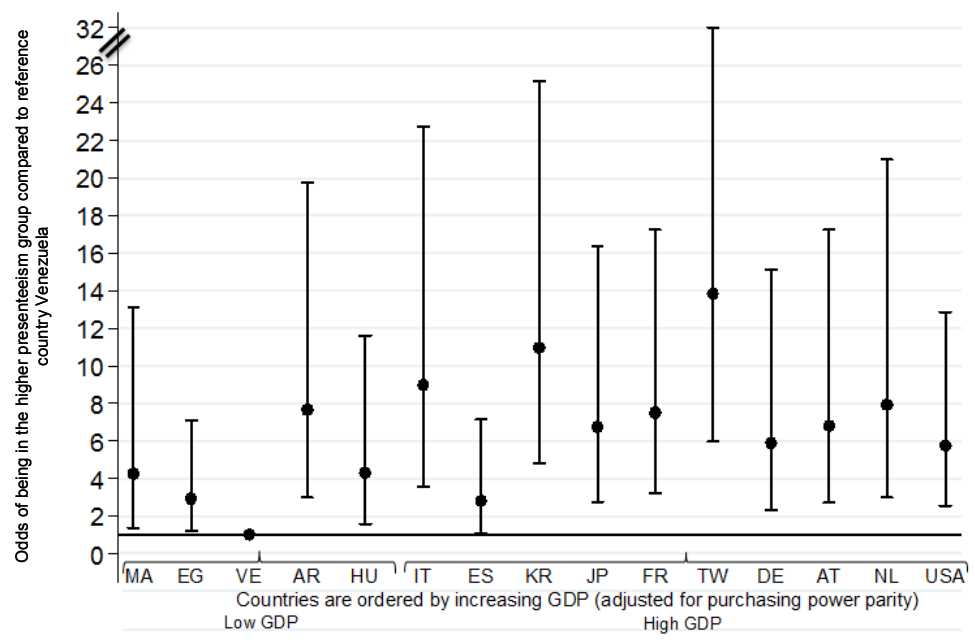

Figure 5.1C Odds of being in the higher presemteeism group per country compared to reference country Venezuela.

Table 5.3 Association of individual sociodemographic \& clinical characteristics and gross domestic product (GDP) with absenteeism and presenteeism.

\begin{tabular}{lcc}
\hline & $\begin{array}{c}\text { Absenteeism } \\
\text { OR [95\% Cl] }\end{array}$ & $\begin{array}{c}\text { Presenteeism } \\
\text { OR [95\% Cl] }\end{array}$ \\
\hline Age (years) & $0.99[0.98 ; 1.02]$ & $0.99[0.98 ; 1.01]$ \\
Gender (female vs. male) & $0.82[0.58 ; 1.17]$ & $0.90[0.68 ; 1.20]$ \\
mHAQ (0-3) & $2.68[1.98 ; 3.63]$ & $4.85[3.57 ; 6.61]$ \\
DAS28 & $1.26[1.12 ; 1.42]$ & $1.64[1.48 ; 1.82]$ \\
Rheumatic Disease Comorbidity Index (0-8) & $1.39[1.21 ; 1.59]$ & - \\
GDP (low vs. high GDP) & $2.68[1.91 ; 3.76]$ & $0.45[0.32 ; 0.62]$ \\
\hline
\end{tabular}

Results of ordinal logistic regression models (odds of being in a higher absenteeism or presenteeism group) absenteeism categories: $1=0 \% ; 2=>0 \%$ to $<100 ; 3=100 \%$ presenteeism categories: $1=0 \% ; 2=>0 \%$ to $30 \%$; $3=>30 \%$ to $50 \%$; $4=>50-100 \%$. OR: odds ratio; $\mathrm{Cl}$ : confidence interval; $\mathrm{mHAQ}$ : modified health assessment questionnaire; DAS28: 28-joints disease activity scale.

\section{Contribution of country indices to explanation of the work outcomes}

When employment and presenteeism were the outcome, the largest improvement in log-likelihood compared to the model without country index was found when the variable HDI was added (log likelihood chi-square test statistic 26.10 and 35.06, respectively; $p<0.001$ ). When absenteeism was the outcome, the largest improvement in log-likelihood compared to the model without country index was found when the variable GDP was added (log likelihood chi-square test statistic 31.47, p<0.001) 
(Supplementary File S5.5). Naturally, when adding country of residence or continent the difference was largest for all outcomes due to the number of categories included in this variable but also indicating the complexity of the construct 'country of residence' comprising various cultural and system related facets.

\section{Missing variables}

Missing values in covariates were present in 300/3920 (7.7\%) cases when employment was the outcome, in 90/1,139 (7.9\%) when absenteeism was the outcome in 85/1,054 (8.1\%) of those who had completed the presenteeism question (of note: persons with $100 \%$ absenteeism could not indicate presenteeism). An overview of missing values per variable and differences in characteristics of the sample with and without missing values are presented in the Supplementary Table S5.3 and S5.4, respectively.

\section{Discussion}

This study is the first to explore the impact of country of residence on sick leave (absenteeism) and presenteeism (at work productivity loss) in addition to employment in patients with RA. We showed that country of residence was associated with relevant differences in employment status, absenteeism and presenteeism, independent of individual socio-demographic and clinical characteristics.

Specific country socio-economic indices could partially shed light on these differences. As hypothesized, higher economic wealth (GDP), better human development (HDI) and lower national unemployment were associated with better employment rates and lower absenteeism among RA patients. Paradoxically, the direction of associations changed when at-work productivity, or presenteeism, was the outcome: higher economic wealth and human development and lower unemployment were associated with more presenteeism. When grouping countries by world region, the USA and the three Asian countries included (Japan, Taiwan and Korea) had the highest employment, lowest absenteeism but, again, the highest presenteeism.

International differences in work status among RA patients have been previously reported. Dadoniene et al assumed better employment in case of higher economic prosperity, and Mau et al supposed better employment in case of lower national rates of economic unemployment. ${ }^{3,4}$ Our findings provided evidence both mechanisms might indeed play a role. The HDI, accounting for educational level and life expectancy in addition to GDP was at least as good and perhaps even a slightly better indicator of employment perspectives. On the other hand, we failed to show an influence of expenditures on social protection. We need to realize SPE reflects comprises expenditures for all kind of social hazards. It would be interesting to have a national 
indicator of the level of income substitution for sick leave or work disability to understand how this influences worker outcomes.

The QUEST-RA study already revealed differences in employment across a large number of countries, ${ }^{6}$ but did not report on the independent magnitude of the effect of GDP. In addition to 1.5-fold higher odds of patients from low (compared to high) GDP countries to have no employment, we also showed that females and patients with low education were less likely to be employed. Of interest, higher age and more comorbidities, had a stronger effect on not being employed in high GDP countries. As in QUEST RA, we saw a clear trend that in low income countries, patients continue to work with poorer health state compared to high income countries, although the interaction was not significant. Notwithstanding, these findings suggest health restrictions ( $\mathrm{HAQ}$, comorbidities) are better acknowledged by the social security system in wealthier countries. Alternatively, increasing job demands and pressure for productivity in wealthier countries make it harder to sustain worker participation at same level of disease severity in the current economic climate. International qualitative research might provide more insight which of both explanations contains truth.

Our study is the first to explore the role of country of residence on sick leave and presenteeism. While overall absenteeism followed the same pattern as employment, a paradox was seen with higher rates of presenteeism wealthier countries: likely, patients in high income countries experience more pressure towards efficiency and productivity. This seems to confirm the above suggestion that people in high income countries experience high work pressure.

Several limitations have to be addressed. Firstly, the national samples might not be representative for RA patients in participating countries, especially when sample sizes were small. If participation bias would be different in low compared to high income countries, likely lower educated and unemployed patients would have no access to healthcare in low income countries and our data even underestimate the countryeffect. Secondly, our study has a cross-sectional design, thus hindering causal inferences. With regard to exposure to country characteristics, it is of note this factor is present before the outcome. Thirdly, for the classification of countries following different socio-economic indices the cut-off was chosen arbitrarily, based on the variable's distribution. For some variables (GDP and HDI) international classifications exist but the choice of thresholds was not necessarily relevant for work outcomes. Fourthly, addressing indicators of labor force participation like 'employment status' or unemployment rate' misclassification bias may occur due to differences in national definitions or terminology. However, in this study data on the outcome 'employment' are generated by the WPAI question 'Are you currently working for pay?'. This question is likely to provide a valid and liable classification for employment. Moreover, the country index 'unemployment-rate' is based on data provided by the international Labor Organization who only include sufficiently comparable rates of labor force participation in their database. ${ }^{24}$ 
Fifthly, in absence of data on levels of compensation, we considered SPE as a remote proxy for income substitution in case of work restrictions due to illness. It must be noted that the personal insurance for work disability may be a potential confounder for which we were not able to adjust. Our study contributes to the understanding of differences in work outcome between countries. In comparative international research such differences should be taken into account as outcomes of interventions aiming to improve health or work ability cannot simply be transferred between countries. Moreover, healthcare providers aiming to improve work outcomes in RA-patients should account for national socio-economic system characteristics.

\section{Conclusions}

In conclusion, adverse work outcome in patients with rheumatoid arthritis is not only associated with clinical status and individual socio- demographic characteristics but also with the country of residence and country specific features such as economic wealth, human development or geographical region. Comparison of work outcome across countries should account for system level contextual factors. 


\section{References}

1. de Croon EM, Sluiter JK, Nijssen TF, Dijkmans BA, Lankhorst GJ, Frings-Dresen MH. Predictive factors of work disability in rheumatoid arthritis: a systematic literature review. Annals of the rheumatic diseases. 2004;63(11):1362-7.

2. Lenssinck MLB, Burdorf A, Boonen A, Gignac MA, Hazes JMW, Luime JJ. Consequences of inflammatory arthritis for workplace productivity loss and sick leave: a systematic review. Annals of the Rheumatic Diseases. 2013;72(4):493-505.

3. Dadoniene J, Uhlig T, Stropuviene S, Venalis A, Boonen A, Kvien TK. Disease activity and health status in rheumatoid arthritis: a case-control comparison between Norway and Lithuania. Annals of the rheumatic diseases. 2003;62(3):231-5.

4. Mau W, Listing J, Huscher D, Zeidler H, Zink A. Employment across chronic inflammatory rheumatic diseases and comparison with the general population. The Journal of rheumatology. 2005;32(4):721-8.

5. Chung CP, Sokka T, Arbogast PG, Pincus T. Work disability in early rheumatoid arthritis: higher rates but better clinical status in Finland compared with the US. Annals of the rheumatic diseases. 2006;65(12):1653-7.

6. Sokka T, Kautiainen H, Pincus T, Verstappen SMM, Aggarwal A, Alten R, et al. Work disability remains a major problem in rheumatoid arthritis in the 2000s: data from 32 countries in the QUEST-RA Study. Arthritis research \& therapy. 2010;12(2).

7. Stolwijk C, Castillo-Ortiz JD, Gignac M, Luime J, Boonen A. Importance of Contextual Factors When Measuring Work Outcome in Ankylosing Spondylitis: A Systematic Review by the OMERACT Worker Productivity Group. Arthritis care \& research. 2015;67(9):1316-27.

8. Dougados M, Soubrier M, Antunez A, Balint P, Balsa A, Buch MH, et al. Prevalence of comorbidities in rheumatoid arthritis and evaluation of their monitoring: results of an international, cross-sectional study (COMORA). Annals of the rheumatic diseases. 2014;73(1):62-8.

9. Lambert J, Hansen BB, Arnould B, Grataloup G, Guillemin I, Hojbjerre L, et al. Linguistic validation into 20 languages and content validity of the rheumatoid arthritis-specific Work Productivity and Activity Impairment questionnaire. The patient. 2014;7(2):171-6.

10. Zhang W, Bansback N, Boonen A, Young A, Singh A, Anis AH. Validity of the work productivity and activity impairment questionnaire--general health version in patients with rheumatoid arthritis. Arthritis research \& therapy. 2010;12(5):R177.

11. Reilly MC, Zbrozek AS, Dukes EM. The validity and reproducibility of a work productivity and activity impairment instrument. PharmacoEconomics. 1993;4(5):353-65.

12. WHO. Obesity: preventing and managing the global epidemic. Report of a WHO Consultation. WHO Technical Report Series 894. In: World Health Organization, ed. Geneva; 2000.

13. WHO. Physical status: the use and interpretation of anthropometry. Report of a WHO Expert Committee. WHO Technical Report Series 854. In: World Health Organization, ed. Geneva; 1995.

14. Uhlig T, Haavardsholm EA, Kvien TK. Comparison of the Health Assessment Questionnaire (HAQ) and the modified HAQ (MHAQ) in patients with rheumatoid arthritis. Rheumatology. 2006;45(4):454-8.

15. Bruce B, Fries JF. The Stanford Health Assessment Questionnaire: A review of its history, issues, progress, and documentation. Journal of Rheumatology. 2003;30(1):167-78.

16. Prevoo MLL, Vanthof MA, Kuper HH, Vanleeuwen MA, Vandeputte LBA, Vanriel PLCM. Modified Disease-Activity Scores That Include 28-Joint Counts - Development and Validation in a Prospective Longitudinal-Study of Patients with Rheumatoid-Arthritis. Arthritis and rheumatism. 1995;38(1):44-8.

17. England BR, Sayles H, Mikuls TR, Johnson DS, Michaud K. Validation of the Rheumatic Disease Comorbidity Index. Arthritis care \& research. 2014.

18. Wolfe F, Michaud K, Li T, Katz RS. Chronic conditions and health problems in rheumatic diseases: comparisons with rheumatoid arthritis, noninflammatory rheumatic disorders, systemic lupus erythematosus, and fibromyalgia. The Journal of rheumatology. 2010;37(2):305-15.

19. IMF. World Economic Outlook Database (http://www.imf.org/external/pubs/ft/weo/2011/02/weodata/index.aspx). 2011. 
20. Organization IL. Trends Econometric Models, http://www.ilo.org/global/research/globalreports/globalemployment-trends/2014/WCMS_233936/lang--en/index.htm. October, 2013.

21. PROGRAMME UND. Human Development Index and its components. 2013.

22. Organization IL. World Social Protection Report 2014/15-Building economic recovery, inclusive development and social justice. 2014.

23. StataCorp. Stata Statistical Software: Release 12. College Station, TX: StataCorp LP. 2011.

24. Kapsos S. World and regional trends in labour force participation: Methodologies and key results Economic and Labour Market Papers International Labour Office 2007;Employment Trends Unit, Economic and Labour Market Analysis Departmen(1). 


\section{Supplemental tables}

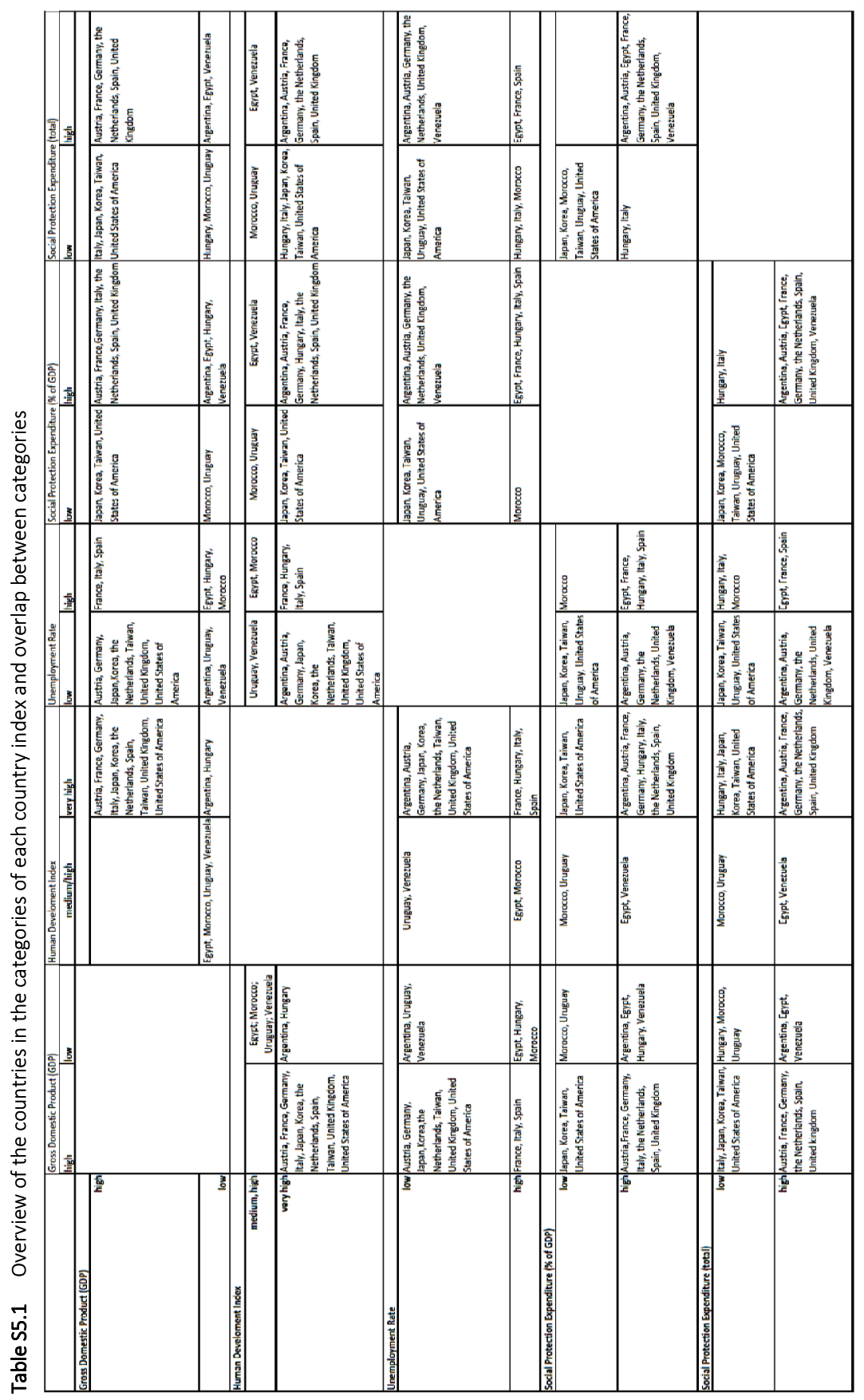




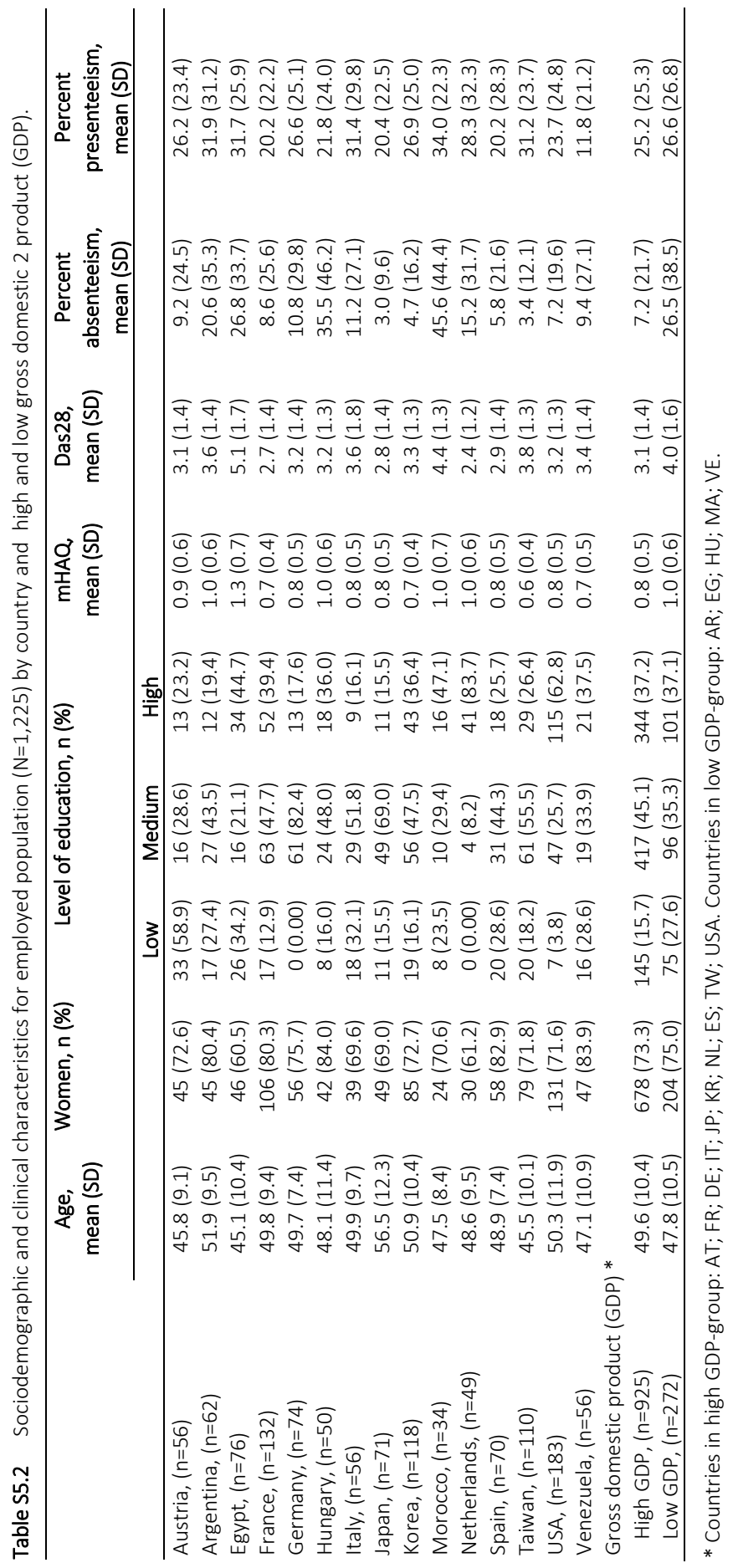




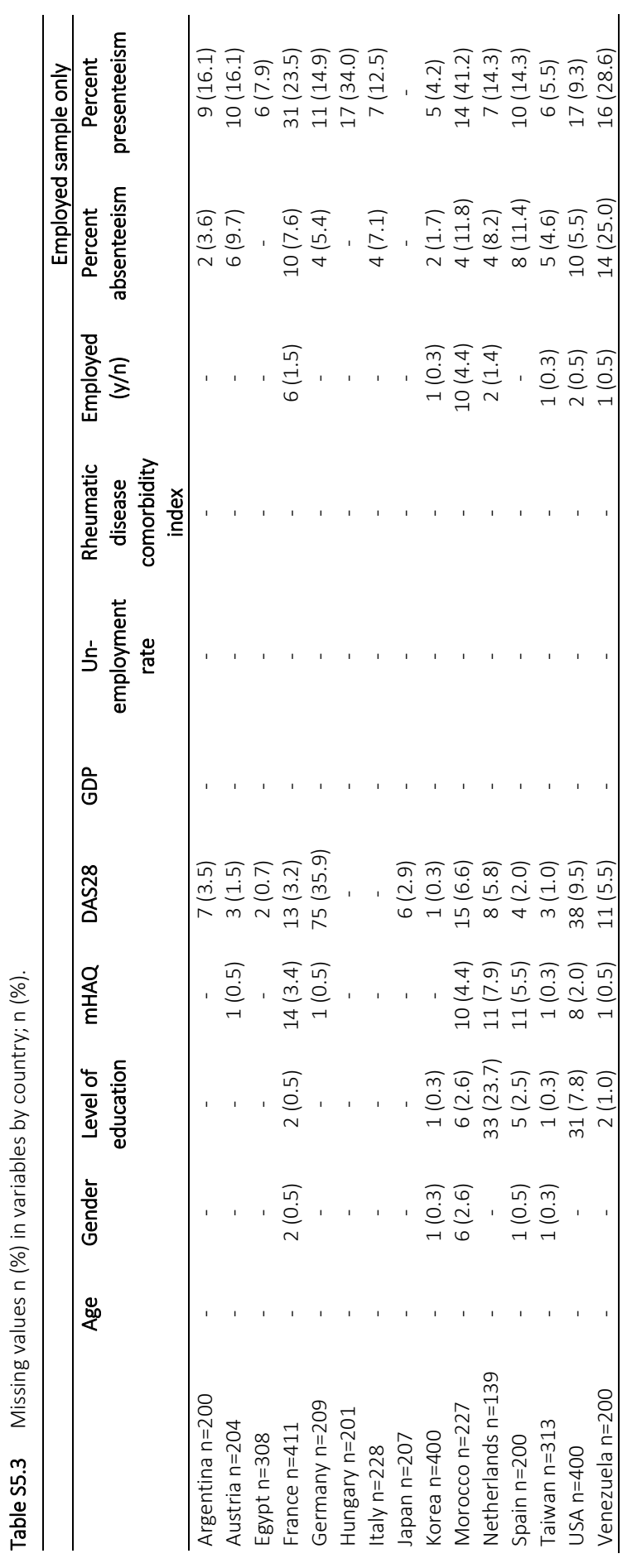




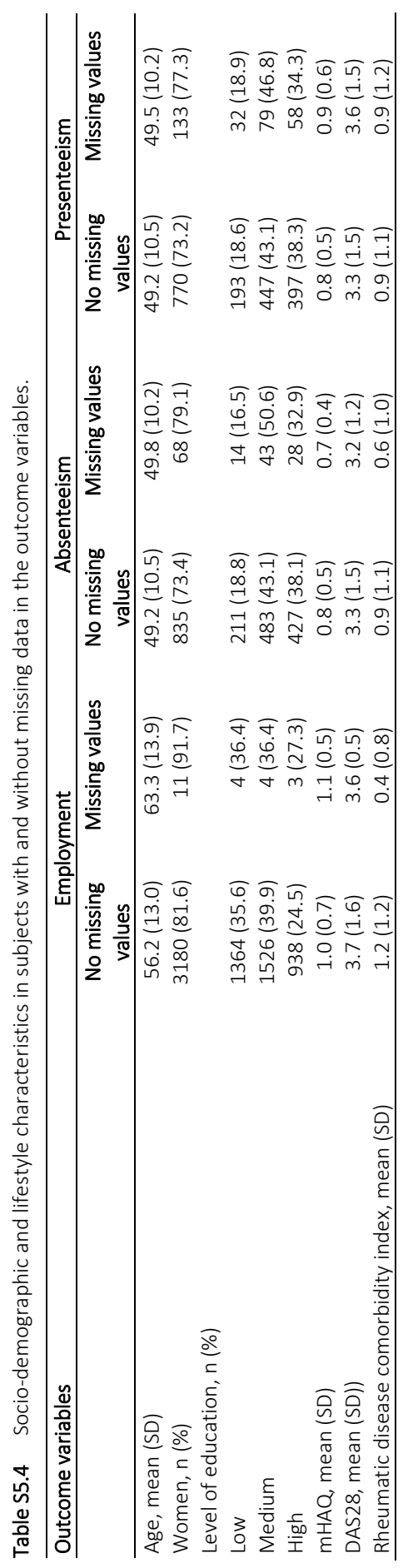




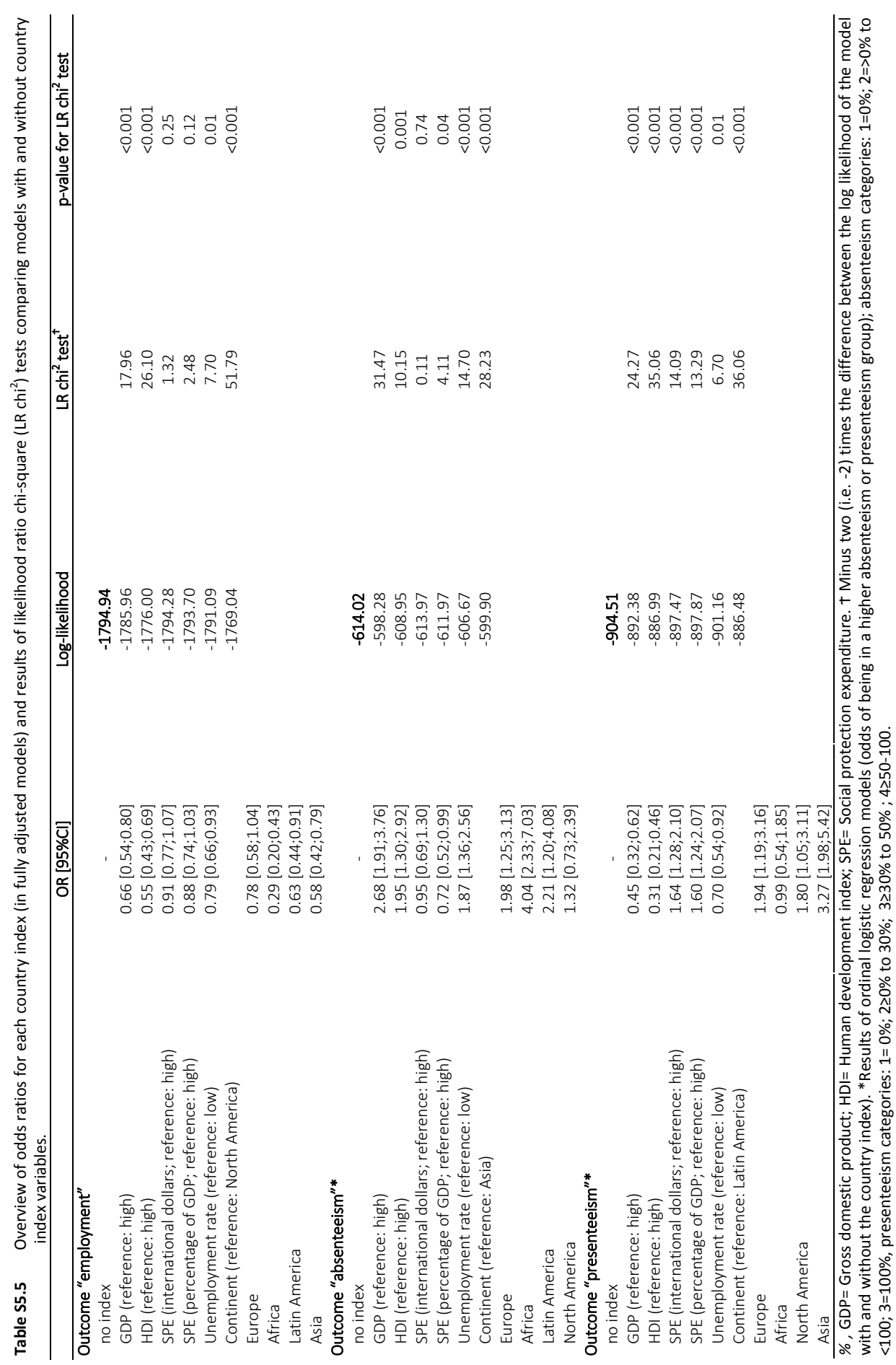





\section{Chapter 6}

Content validity of global measures for at-work productivity in patients with rheumatic diseases: an international qualitative study

Antje van der Zee-Neuen, Sarah Leggett, Annelies Boonen, Dorcas Beaton, Mihai Bojinca, Ailsa Bosworth, Sabrina Dadoun, Bruno Fautrel, Sofia Hagel, Catherine Hofstetter, Diane Lacaille, Denise Linton, Carina Mihai, Ingemar F. Petersson, Pam Roger, Carlo Scire', Suzanne MM Verstappen 


\section{Abstract}

\section{Objectives}

To identify from a patient's perspective, difficulties and differences in the comprehension of five global presenteeism measures in patients with inflammatory arthritis and OA across seven countries.

\section{Methods}

Seventy patients with a diagnosis of inflammatory arthritis or OA in paid employment were recruited from seven countries across Europe and Canada. Patients were randomly allocated to be cognitively debriefed on 3/5 global measures [Work Productivity Scale -Rheumatoid Arthritis, Work Productivity and Activity Impairment Questionnaire (WPAI), Work Ability Index, Quality and Quantity questionnaire, and WHO Health and Work Performance Questionnaire (HPQ)], with the WPAI debriefed in all patients as a standard measure of comparison between countries and patients. NVivo was used to code the data into four themes: construct and anchor, time recall, reference frame, and attribution.

\section{Results}

Discrepancies were found in the interpretation of the word performance (HPQ) between countries, with Romania and Sweden relating performance to sports rather than work. Seventy percent of patients considered that a 7-day recall (WPAI) can accurately represent how their disease affects work productivity. The compared to normal reference (Quality and Quantity questionnaire) was reportedly too ambiguous, and the comparison with colleagues (HPQ), made many feel uncomfortable. Overall, $29 \%$ of patients said the WPAI was the most relevant to them, making it the most favoured measure.

\section{Conclusion}

Overall, patients across countries agree that the construct of work productivity in the last 7 days can accurately reflect the impact of disease while at work. Some current constructs to assess atwork productivity are not interchangeable between languages. 


\section{Introduction}

At-work productivity loss, that is, presenteeism, is increasingly recognized as an important outcome in patients with inflammatory arthritis and OA. ${ }^{1,2}$ Presenteeism refers to the situation in which persons attend work while being ill, and can reflect either difficulties or restrictions in productivity that may possibly result in productivity loss. In general, people may transition between presenteeism and absenteeism, ${ }^{3}$ and factors determining transitions vary between individual patients depending on contextual factors (both personal and environmental) and health status. Although presenteeism can be considered an adverse outcome that requires interventions to reduce at-work productivity loss, presenteeism can also be an acceptable consequence of efforts to retain work participation of people with a (chronic) disease, when the alternative would be prolonged sick leave and the risk of work disability. While presenteeism is an important outcome from an employer's perspective, presenteeism is also a relevant outcome from the worker's perspective because restrictions in ability and productivity at work may reduce job satisfaction, morale and self-esteem. ${ }^{4}$ It is therefore important to gain a better insight into presenteeism from a patient's perspective, especially if we want to measure presenteeism in clinical studies and in clinical practice. Several self-reported measures of presenteeism are available to assess presenteeism from the patient's perspective, but results vary depending on the measure used. 5,6 Some of these are multi-item measures, whereas others capture productivity in one or two global items. ${ }^{7}$ The former offer advantages in terms of specifying the scope, while global measures are less explicit about the content but are beneficial with regard to feasibility in large clinical trials, observational studies, and clinical practice because of their ease of administration. ${ }^{8}$

Within the available global measures of presenteeism, most of the variation exists along four essential attributes of the measure; construct, recall period, reference frame, and attribution. First, several terms or concepts are used to describe the overall construct presenteeism, such as productivity and ability, and this may generate varying interpretations by patients and may vary across languages/cultures. For measures to be applied cross-culturally, the underlying construct measured by an instrument should be uniform across cultures, and the wording used to describe this construct should be adapted to the language/culture. Next, large variations in recall periods used in global measures of presenteeism exist (e.g. today and one/two years ${ }^{2,9}$ ). Overall, it is recommended that patient-reported outcomes use a recall period that corresponds to the characteristics of the condition of interest, the construct addressed and the intended use. ${ }^{10}$ Another important factor is the framing of the estimation of productivity (i.e. a standard for comparing one's productivity). While references can facilitate questionnaire completion, ${ }^{11}$ specific references may not be applicable to all respondents (e.g. comparison with colleagues). Similarly, attribution of productivity to 
a disease and its consequences is a cognitively taxing job, as it requires recognition of the cause of reduced productivity, and deciding whether symptoms are related to the disease (e.g. fatigue) and whether to take into consideration the consequences of treatments. ${ }^{12}$ Last but not least, the answer scale and meaning of the anchors can cause variation in results of scores.

The main objective of this international study was to understand the conceptual interpretation of five preselected global measures of presenteeism from the perspective of working individuals with inflammatory arthritis and OA, namely, the Work Productivity and Activity Impairment questionnaire (WPAI), the Work Productivity Scale - RA (WPS-RA), the Work Ability Index (WAI), the Quality and Quantity questionnaire (QQ) and the WHO Health and Work Performance Questionnaire (HPQ). Cognitive debriefing, a qualitative method often used to explore respondents' interpretations of questionnaire items, ${ }^{13,14}$ is a suitable approach to gain such insight, and was utilized in this study.

\section{Methods}

\section{Selection of global measures}

Based on meetings with and surveys of patients and experts (see supplementary data, section on pre-selection of global measures, available at Rheumatology Online), five global measures were chosen to be evaluated in this large international study, including: the WPAI, ${ }^{15}$ the WPS-RA, ${ }^{16}$ the WAI, ${ }^{17}$ the $\mathrm{QQ}^{2}$ and the $\mathrm{HPQ} .{ }^{9}$

\section{Participants}

The current study is part of a larger research project with an overall aim of recommending a reliable and valid patient-reported outcome for presenteeism to be used in clinical trials and clinical practice. The research programme consists of two phases: the first includes the current (cultural) content validity study and a test-retest reliability analysis of five pre-selected global measures, ${ }^{18}$ and the second phase will investigate further construct validity and interpretability (variability over time, clinically important difference and acceptable state) of the selected measures. Participants were recruited from outpatient rheumatology and/or orthopaedic clinics in seven countries: UK, the Netherlands, France, Italy, Sweden, Romania and Canada. Patients with a diagnosis of inflammatory arthritis (including RA, PsA and AS) or OA of the peripheral joints, aged 18 years or above, in full- or part-time paid employment, and able to communicate in the language of the participating country were eligible. Based on earlier studies implementing cognitive debriefing interviews, ${ }^{19-21}$ we estimated that 10 participants per country would be sufficient to explore cultural/language differences 
in the interpretation of the measures' content. Purposive sampling aimed to obtain a balanced distribution of age, gender, manual/non-manual jobs and disease type. Ethical approval was obtained in each country according to national guidelines, and informed written consent was obtained.

\section{At-work productivity global measures}

All five global measures in this study (Table 6.1) use an 11-point (from 0 to 10) visual analogue scale (VAS) for scoring (see supplementary data, section on at-work productivity global measures, available at Rheumatology Online). The WPAI, WPS-RA, WAI and HPQ presenteeism items were extracted from the complete questionnaires with permission from the developers.

Validated existing translations of the global measures were used where available. For languages where no translations were available, forward and backward translations were performed by an approved medical translating company (PharmaQuest Ltd) and further validated through interviews with five patient volunteers in each participating country.

Table 6.1 Characteristics of the five global presenteeism measures.

\begin{tabular}{|c|c|c|c|c|c|}
\hline $\begin{array}{l}\text { Global } \\
\text { measure }\end{array}$ & Construct & Recall period & $\begin{array}{l}\text { Reference } \\
\text { frame (if any) }\end{array}$ & Attribution & Anchors \\
\hline WPAI $1^{15}$ & $\begin{array}{l}\text { Productivity } \\
\text { (additional phrasing: } \\
\text { accomplished, kind } \\
\text { of work, carefully as } \\
\text { usual amount of } \\
\text { work) }\end{array}$ & 7 days & $\mathrm{N} / \mathrm{A}$ & $\begin{array}{l}\text { Disease } \\
\text { specific (RA, } \\
\text { PsA, AS, OA) }\end{array}$ & $\begin{array}{l}\text { Condition had no effect on } \\
\text { my work (0) - condition } \\
\text { completely prevented me } \\
\text { from working (10). }\end{array}$ \\
\hline WPS-RA $^{16}$ & $\begin{array}{l}\text { Productivity } \\
\text { \& interference }\end{array}$ & Last month & $\mathrm{N} / \mathrm{A}$ & Arthritis & $\begin{array}{l}\text { No interference }(0) \text { - } \\
\text { Complete interference } \\
(10)\end{array}$ \\
\hline WAI $^{26}$ & Work ability & Current & $\begin{array}{l}\text { Work ability } \\
\text { at its best }\end{array}$ & $\mathrm{N} / \mathrm{A}$ & $\begin{array}{l}\text { Completely unable to } \\
\text { work }(0)-\text { Work ability at } \\
\text { its best }(10)\end{array}$ \\
\hline$Q Q^{2}$ & Quality and quantity & Today & $\begin{array}{l}\text { Compared to } \\
\text { normal }\end{array}$ & N/A & $\begin{array}{l}\text { Practically nothing (0) - } \\
\text { Normal quantity (10) \& } \\
\text { Very poor quality (0) -very } \\
\text { good quality (10) }\end{array}$ \\
\hline $\mathrm{HPQ}^{27}$ & Performance & $\begin{array}{l}\text { One/two } \\
\text { years } \\
\text { (question B) } \\
\text { \& } 4 \text { weeks } \\
\text { (question C) }\end{array}$ & $\begin{array}{l}\text { Colleagues } \\
\text { performance } \\
\text { (question A) }\end{array}$ & $\mathrm{N} / \mathrm{A}$ & $\begin{array}{l}\text { Worst performance }(0) \text { - } \\
\text { Top performance }(10)\end{array}$ \\
\hline
\end{tabular}

WPAI: Productivity and Activity Impairment Questionnaire; WPS-RA: Work Productivity Scale - RA; WAI: Work Ability Index; QQ: Quality and Quantity questionnaire; HPQ: World Health Organization Health and Work Performance Questionnaire. 


\section{Cognitive debriefing interviews}

Patients were invited to take part in a cognitive debriefing interview lasting on average 45-60 min. Participating researchers/rheumatologists in each country were instructed on how to perform the interview (see supplementary data, section on cognitive debriefing training, available at Rheumatology Online). Data on demographics, clinical and occupational characteristics (job type; manual or non-manual ${ }^{22}$ ), and general wellbeing (VAS) were collected and sent securely to the central site in the UK for analysis. Participants were briefed on the study, which involved a practice run of the think out loud methodology used in cognitive debriefing. ${ }^{23}$ In each country, three out of the five global measures were randomly allocated to each participant, with the WPAI used as a standard measure of comparison across countries. The debriefing interviews were semi-structured and began with participants reading the first global measure out loud and providing feedback on the measure (i.e. general understanding). Participants were next questioned specifically on the construct measured in the question and on the anchors, the recall period, reference frames and attribution (see supplementary data, section on cognitive debriefing example questions and probes, available at Rheumatology Online). Following this, the participants provided general opinions and responded to probes on the constructs of the two additional measures allocated to them. Finally, participants were shown all five global measures and were asked which one was the most important measure to them and why. All interviews were audio recorded and transcribed verbatim. All transcripts were translated into English (by PharmaQuest Ltd) using forward translation, and reviewed by the interviewer in each country.

\section{Data analysis}

Descriptive statistics were used to summarize the sample characteristics. Deductive thematic analyses using the predefined themes for all attributes [construct, reference frames, recall period and attribution (Figure 6.1)] were applied to the data using the qualitative analysis software, NVivo 10. The data in each of the themes allowed for comparisons across countries. A semi-quantitative approach was used when reporting on the recall period accuracy and representation, reference frame and the measure of preference. 


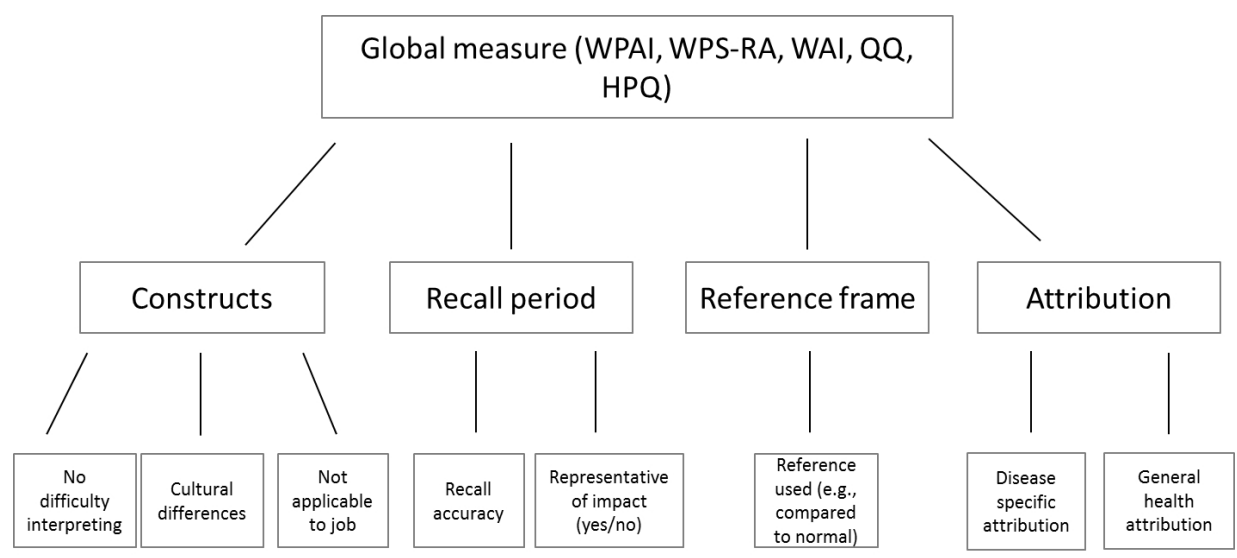

Figure 6.1 Predetermined hierarchy of themes developed to organize responses from the cognitive debriefing interviews for analysis.

\section{Results}

The mean age of the study population was 46 years (SD 10.7) and the mean symptom duration was 13.5 years (SD 10.1). Forty-nine participants (70\%) had a non-manual job and the majority of the participants were working full-time (Table 6.2).

Table 6.2 Characteristics of the study sample.

\begin{tabular}{lc}
\hline & Total population ( \\
& $\mathrm{n}=70)$ \\
\hline Age, mean (SD) & $45.6(10.7)$ \\
Female, $\mathrm{n}(\%)$ & $40(57.1)$ \\
Symptom duration in years, mean (SD) & $13.5(10.1)$ \\
General well-being (VAS 0-100m), mean (SD) \{0=very well, 100=very poorly\} & $32.0(24.6)$ \\
Diagnosis: & \\
Rheumatoid arthritis & $23(32.9)$ \\
Ankylosing spondylitis & $19(27.1)$ \\
Psoriatic arthritis & $13(18.6)$ \\
Osteoarthritis & $8(11.4)$ \\
Other inflammatory disease & $7(10.0)$ \\
Occupational information: & \\
Working full time, $\mathrm{n}$ (\%) & $54(77.1)$ \\
Hours worked per week, mean (SD) [range] & $36.9(10.1)[10-70]$ \\
Non-manual occupation, $\mathrm{n}(\%)$ & $49(70)$ \\
\hline
\end{tabular}

Other inflammatory diseases include undifferentiated arthritis and undifferentiated connective tissue disease. N - Number; SD - Standard deviation; VAS - Visual analogue scale. 


\section{Cognitive debriefing per attribute}

\section{Construct and anchor}

Generally, the construct used in the main stem of the question generated interpretations similar to one another across countries (Table 6.3), although issues with cultural applicability, job applicability and difficulty understanding some of the terminology were evident for some of the measures. The term productivity used in the WPAI and WPS-RA was interpreted in a similar way across countries. For example, one patient's interpretation of productivity related to their ability to perform their work tasks; this was a common interpretation across countries. Some participants struggled to relate the construct to their job due to a lack of producing products, for example, one patient stated that as there was nothing at the end of their work, there was no productivity in their job.

However, the use of the terms accomplished, kind of work, carefully, as usual and amount of work in the detailed instructions in the WPAI helped to clarify the concept, and the WPAI was consistently understood across countries (Table 6.3). The use of the word interference used in the stem and anchor of the WPS-RA caused difficulties for Romanian participants, reflecting a lack of clarity for this term in their language. One patient reported that they did not understand what the term interference meant and recommended it be removed from the question.

Participants from other countries did not express difficulties, and words synonymous with the meaning of interference, such as influence, were commonly used when describing their interpretation. Interpretations of work ability (WAI) adhered to a notion of being capable of performing work, and were interpreted similarly across countries. Differences in the interpretation of performance (HPQ) were evident, particularly for the Romanian and, to a lesser extent, Swedish participants in comparison with other countries. These participants expressed difficulty in scoring their work performance, because the corresponding term in their language normally relates to competing in sports as opposed to work. The use of the word performance therefore reportedly caused some confusion in the Romanian and Swedish participants.

The quality and quantity construct in the $\mathrm{QQ}$ were understood similarly across countries. Quantity was interpreted as relating to an amount of work, and quality was understood with phrases such as how well commonly being used to describe their interpretation. Quantity was reported as being difficult to apply to certain jobs in which there were daily variations in the quantity of work performed. 
For three of the global measures (WAI, HPQ and QQ), the anchor repeats the construct used in the stem (respectively ability, performance and quality or quantity), whereas the WPAI uses a new construct (work) and the WPS-RA only quantifies the anchors in terms of level of interference. Participants appeared to have a good understanding of the statements at each end of the scales, with anchors reflecting good work productivity (e.g. WAI - work ability at its best) generally being interpreted as being able to work without any impact from their rheumatic disease. For the $\mathrm{QQ}$, some patients stated that they worked more than the normal quantity. The worst end of the scale (e.g. WPAI - condition completely prevented me from working) was often interpreted as a complete inability to perform or even attend work due to their disease. However, many struggled with this interpretation because they could not relate to being in that situation (e.g. completely unable to work). The opposite direction of the VAS in the WPAI and WPS-RA (10=bad outcome) compared with the remaining measures (e.g. HPQ; 10=good outcome) caused confusion for some participants. A preconception that a score of 10 signifies a better outcome caused many to give a score opposite to what they intended. This was only noticed through probing the participants on their interpretation of the scales.

Recall

The recall periods of the WPAI (7 days), WPS-RA (1 month) and HPQ part C (4 weeks) were found to be of sufficient length to appropriately represent how the participants' diseases affected their work (Figures 6.2 and 6.3). In addition, the three time frames were short enough for people to feel they could accurately remember their work productivity. These findings were consistent across countries. The today recall (QQ) was frequently reported to be too short, because many participants had not yet been to work on the day of the interview, and the current recall in the WAI was commonly reported as being too ambiguous, with interpretations spanning 1 day to 4 years. Participants frequently expressed concern that the past year or two recall in the HPQ part B was too long to be accurately remembered.

\section{Reference frame}

Three global measures included a reference, that is, the QQ, WAI and the HPQ. The compared with normal reference (QQ) was reportedly too ambiguous, with many participants questioning what defines normal; this was a finding consistent across countries. The reference to work ability at its best in the WAI was frequently interpreted as referring to prior to the onset of their disease (what they had done at a time when they were healthy). A reference to the performance of most workers in the $\mathrm{HPQ}$ made some participants feel uncomfortable and was not applicable in cases of self-employed individuals. For example, one patient reported that the question made 
them feel uncomfortable, because judging others in terms of their work was not something they liked to do.

Participants were also asked what reference they used when answering the question in case no clear reference was provided. While a number of different responses were provided, participants most commonly reported comparing their at-work productivity with their productivity before the onset of their disease. Although the requirement of rating colleagues' work performance in the HPQ made some feel uncomfortable, $24 \%$ of participants reported using other colleagues as a reference when scoring their own work.

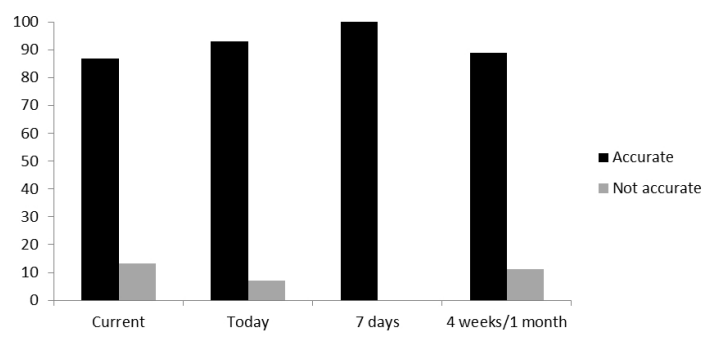

Figure 6.2 Percentage of perceived accuracy in recall for the periods in each of the global measures.

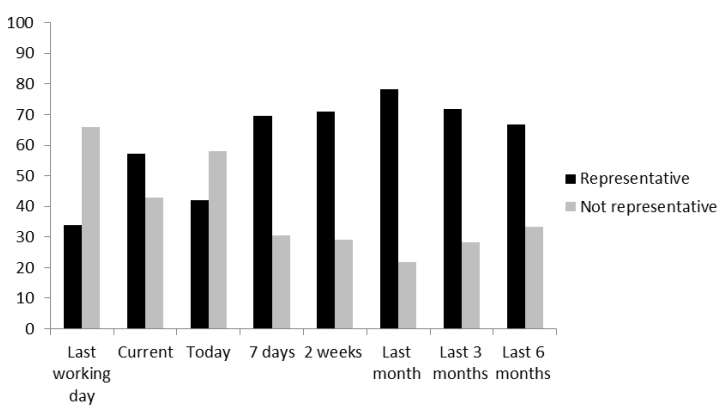

Figure 6.3 Recall periods believed to be representative of how condition impacts at-work productivity (\%).

\section{Attribution}

Most participants spontaneously related the judgement of their at-work productivity to their rheumatic disease, even when the question did not specifically refer to arthritis in the question (e.g. WAI). Most participants indicated they would answer the question in the same manner regardless of whether it referred to their specific disease, their general health or made no attribution to health. However, most participants admitted to answering in the context of their disease because they assumed that was what the researchers wanted to explore. One patient reported uncertainty because the question 
was quite general, but stated that as arthritis was obviously what the study was about, they did take their condition into account.

\section{Patient-preferred measure}

Sixty-five participants were asked what their favourite measure was (five participants were mistakenly not asked). The WPAI was the preferred patient measure, with 19/65 votes (29\%). The 7-day recall period and the elaborate nature of the stem-question were mentioned as main reasons for their preference. The least-favoured measure was the WAI, with eight votes (12\%), which may have been due to the issues regarding the ambiguous recall period and the lack of attribution. Three participants (5\%) stated they did not have a preference.

\section{Discussion}

This study is the first to investigate patients' understanding and interpretation of five global measures of presenteeism across six languages and seven countries, using a cognitive debriefing technique. The new insights gained from this research into crosscultural differences in the meaning of constructs and in patient's opinions about recall and reference framing will have important implications for researchers when selecting optimal patient-reported measures of presenteeism in people with rheumatic diseases. The WPAI most consistently received positive comments about the construct and recall period across individuals and countries, and was ultimately voted the preferred measure from the participants' perspective. Although the term productivity was less clear for a handful of participants who did not produce tangible products in their job, the clear and elaborate explanation added to the stem of the main WPAl question, seemed to clarify what the term productivity meant across jobs. Further, the recall of 7 days (used in the WPAI) was reported by all participants as an adequate length of time for recall accuracy, with the majority indicating they felt it was representative of how their disease affects their productivity. This is in line with the suggested recall of 7 days for presenteeism in the literature, ${ }^{24}$ and therefore we can recommend that it be used in presenteeism measures.

The WPS-RA, the WAI and the QQ also performed well, although weaknesses were identified with each one. While the measures fell short in one or two domains, they were praised for strengths in others. Concerns were raised by Romanian participants about the WPS-RA because they were unsure of the meaning of the term interference. Ambiguity was an issue for some participants with respect to the current recall period in the WAl, and the compared with normal reference in the QQ. Where ambiguous terms could lead to multiple interpretations, participants in our study suggested the use of additional instructions to provide further clarification. 
The reverse scaling of the WPAI and the WPS-RA ( $0=$ good outcome, 10=bad outcome) in comparison with the other global measures caused confusion in a few cases, with patients only realising they had misunderstood the order of the scales when asked about the anchors in more detail. The ordering of VASs varies for different instruments, with many scales using a high score to indicate a good outcome, and others, such as adult pain scales, using a high score to represent a bad outcome. ${ }^{25}$ The misinterpretations associated with such inconsistencies could be rectified through a universal ordering of scales, or where this is not feasible, more thorough instructions.

The HPQ performed poorly compared with other global measures due to cross-cultural difficulties in understanding the construct of performance, participants' dislike of comparing themselves with colleagues, and the recall period of one - two years in one of the three questions. While some participants also reported issues with other measures, these issues were not as substantial or as consistent across participants as they were for the HPQ.

Some limitations of our study deserve comments. Challenges were encountered when evaluating the issue of attribution of the productivity loss to arthritis vs. other health conditions. This was a limitation of our study design. Because all participants were recruited from rheumatology departments, participants correctly assumed the research was conducted in the context of rheumatic diseases. This was problematic for measures in which no reference to a specific health condition was made, because we cannot generalize from our study how patients would attribute their work productivity loss if the questionnaire was administered outside of a rheumatology clinical context. Finally, a mistake in one of the anchors in the QQ meant that very good quality was anchored instead of normal quality (used in the original questionnaire for six of the seven countries). However, this did not affect the results because the concept of normal quality was still addressed in the question, and there was no interference with the main themes of interest (i.e. construct, recall, etc.). Future research needs to concentrate on cross-cultural comparisons with healthy controls, as well as on patients with chronic diseases or injuries, because these comparisons were not addressed in our study.

\section{Conclusion}

Based on the results of our cognitive debriefing study, we recommend that the WPAI, WPS-RA, WAI and QQ could be used by researchers and clinicians interested in using a global measure of presenteeism in people with IA and OA, and conclude that the WPAI was the instrument preferred by participants (see supplementary data, section on selection of global measures to carry forward for further analysis, available at Rheumatology Online). 


\section{References}

1. Kessler RC, Maclean JR, Petukhova $M$ et al. The effects of rheumatoid arthritis on labor force participation, work performance, and healthcare costs in two workplace samples. J Occup Environ Med 2008;50:88-98.

2. Brouwer WB, Koopmanschap MA, Rutten FF. Productivity losses without absence: measurement validation and empirical evidence. Health Policy 1999;48:13-27.

3. Tang K, Escorpizo R, Beaton DE et al. Measuring the impact of arthritis on worker productivity: perspectives, methodologic issues, and contextual factors. J Rheumatol 2011;38:1776-90.

4. Black C. Dame Carol Black's review of the health of Britain's working age population: working for a healthier tomorrow. London: TSO, 2008, 125.

5. Escorpizo R, Bombardier C, Boonen A et al. Worker productivity outcome measures in arthritis. J Rheumatol 2007;34:1372-80.

6. Beaton DE, Tang K, Gignac MA et al. Reliability, validity, and responsiveness of five at-work productivity measures in patients with rheumatoid arthritis or osteoarthritis. Arthritis Care Res 2010;62:28-37.

7. Tang K, Boonen A, Verstappen SM et al. Worker productivity outcome measures: OMERACT filter evidence and agenda for future research. J Rheumatol 2014;41:165-76.

8. Jenkinson C. Measuring health and medical outcomes. London: UCL Press, 1994.

9. Kessler RC, Barber C, Beck A, et al. The World Health Organization Health and Work Performance Questionnaire (HPQ). J Occup Environ Med 2003;45:156-74.

10. Norquist JM, Girman C, Fehnel S, DeMuro-Mercon C, Santanello N. Choice of recall period for patientreported outcome (PRO) measures: criteria for consideration. Qual Life Res 2012;21:1013-20.

11. Check J, Schutt RK. Survey research. Research methods in education. London: SAGE Publications, 2012, 159-85.

12. Marx RG, Hogg-Johnson S, Hudak P et al. A comparison of patients' responses about their disability with and without attribution to their affected area. J Clin Epidemiol 2001;54:580-6.

13. Coons SJ, Gwaltney CJ, Hays RD et al. Recommendations on evidence needed to support measurement equivalence between electronic and paperbased patient-reported outcome (PRO) measures: ISPOR ePRO Good Research Practices Task Force report. Value Health 2009;12:419-29.

14. Collins D. Pretesting survey instruments: an overview of cognitive methods. Qual Life Res 2003;12: 229-38.

15. Reilly MC, Zbrozek AS, Dukes EM. The validity and reproducibility of a work productivity and activity impairment instrument. Pharmacoeconomics 1993;4:353-65.

16. Osterhaus JT, Purcaru O, Richard L. Discriminant validity, responsiveness and reliability of the rheumatoid arthritis_specific Work Productivity Survey (WPS-RA). Arthritis Res Ther 2009;11:R73.

17. Tuomi K, Ilmarinen J, Jahkola A, Katajarinne L, Tulkki A. Work ability index. Helsinki: Finnish Institute of Occupational Health, 1998, 30.

18. Leggett S, van der Zee-Neuen A, Boonen A et al. Test_retest reliability and correlations of five global measures addressing at-work productivity loss in patients with rheumatic diseases. J Rheumatol 2015 (in press) doi: 10.3899/jrheum.141605

19. Pusic AL, Klassen AF, Scott AM et al. Development of a new patient-reported outcome measure for breast surgery: the BREAST-Q. Plast Reconstr Surg 2009;124:345-53.

20. Price VE, Klaassen RJ, Bolton-Maggs PH et al. Measuring disease-specific quality of life in rare populations: a practical approach to cross-cultural translation. Health Qual Life Outcomes 2009;7:92.

21. Brod M, Hammer M, Christensen T, Lessard S, Bushnell DM. Understanding and assessing the impact of treatment in diabetes: the Treatment-Related Impact Measures for Diabetes and Devices (TRIMDiabetes and TRIM-Diabetes Device). Health Qual Life Outcomes 2009;7:83.

22. Great Britain. Office of Population Censuses and Surveys. Employment Department Group, Great Britain. Office of Population Censuses and Surveys. Standard occupational classification. London: HMSO, 1990, ix, $281 \mathrm{pp}$. 
23. Willis GB. Cognitive Interviewing: A “How To" Guide. Reducing Survey Error through Research on the Cognitive and Decision Processes in Surveys. 1999.

http://www.hkr.se/pagefiles/35002/gordonwillis.pdf (10 August 2014, date last accessed).

24. U.S. Department of Health and Human Services Food and Drug Administration. Guidance for Industry Patient-Reported Outcome Measures: Use in Medical Product Development to Support Labeling Claims. 2009. http://www.fda.gov/downloads/Drugs/. . ./Guidances/UCM193282.pdf (11 August 2014, date last accessed).

25. Jensen MP, Karoly $\mathrm{P}$, Braver $\mathrm{S}$. The measurement of clinical pain intensity: a comparison of six methods. Pain 1986;27:117-26. 


\section{Chapter 7}

Test-retest reliability and correlations of 5 global measures addressing at-work productivity loss in patients with rheumatic diseases

Sarah Leggett, Antje van der Zee-Neuen, Annelies Boonen, Dorcas Beaton, Mihai Bojinca, Ailsa Bosworth, Sabrina Dadoun, Bruno Fautrel, Sofia Hagel, Catherine Hofstetter, Diane Lacaille, Denise Linton, Carina Mihai, Ingemar F. Petersson,

Pam Rogers, Jamie Sergeant, Carlo Scire, Suzanne Verstappen

J Rheumatol. 2016;43(2):433-439 


\section{Abstract}

\section{Objectives}

Several global measures to assess at-work productivity loss or presenteeism in patients with rheumatic diseases have been proposed, but the comparative validity is hampered by the lack of data on test-retest reliability and comparative concurrent and construct validity. Our objective was to test-retest 5 global measures of presenteeism and to compare the association between these scales and health-related well-being.

\section{Methods}

Sixty-five participants with inflammatory arthritis or osteoarthritis in paid employment were recruited from 7 countries (UK, Canada, Netherlands, France, Sweden, Romania, and Italy). At baseline and 2 weeks later, 5 global measures of presenteeism were evaluated: the Work Productivity Scale-Rheumatoid Arthritis (WPS-RA), Work Productivity and Activity Impairment Questionnaire (WPAI), Work Ability Index (WAI), Quality and Quantity questionnaire (QQ), and the WHO Health and Performance Questionnaire (HPQ). Agreement between the 2 timepoints was assessed using single-measure intraclass correlations (ICC) and correlated between each other and with visual analog scale general well-being scores at followup by Spearman correlation.

\section{Results}

ICC between measures ranged from fair (HPQ 0.59) to excellent (WPS-RA 0.78). Spearman correlations between measures were moderate (Qquality vs WAI, $r=0.51$ ) to strong (WPS-RA vs WPAl, $r=0.88$ ). Correlations between measures and general well-being were low to moderate, ranging from $-0.44 \leq r \leq 0.66$.

\section{Conclusion}

Test-retest results of 4 out of 5 global measures were good, and the correlations between these were moderate. The latter probably reflect differences in the concepts, recall periods, and references used in the measures, which implies that some measures are probably not interchangeable. 


\section{Introduction}

Inflammatory arthritis (IA) and osteoarthritis (OA) are chronic diseases known to affect many aspects of an individual's life including social, psychological, financial, and occupational consequences. ${ }^{1-3}$ Many workers with rheumatic disorders such as rheumatoid arthritis (RA), psoriatic arthritis (PsA), ankylosing spondylitis (AS), and OA may experience restrictions participating in the workforce, potentially leading to sick days from work and early work cessation. ${ }^{4}$ Rates of work disability in rheumatic patients are well documented, varying from $16 \%$ to $39 \%$ in patients with PsA in association with longer disease duration; ${ }^{5} 67 \%$ after an average disease duration of 15 years in patients with $\mathrm{RA}^{6}{ }^{6}$ and somewhat lower rates in patients with AS varying from $3 \%$ to $50 \%$ after 18 and 45 years' disease duration, respectively. ${ }^{7}$ Work disability literature for $\mathrm{OA}$ is limited, although it suggests much lower rates compared to inflammatory arthritis. ${ }^{8}$ However, with advances in disease management for rheumatic diseases in the last decade, individuals with rheumatic diseases may be able to remain in employment. ${ }^{9}$ This can be related to both earlier diagnosis and earlier and more effective pharmacologic treatment, suggesting that measures of productivity could be included as routine outcome measures in clinical trials and in observational studies. ${ }^{10-13}$ Nonetheless, for those who remain in employment, sickness absence and at-work productivity loss may be experienced. At-work productivity loss, also known as presenteeism, comprises the level of difficulty experienced at work due to health conditions and the amount of productivity lost to such difficulties. Measuring presenteeism is relevant for patients as it reflects the difficulties and challenges patients experience in order to function at their work. A change in worker productivity for an individual can jeopardize the outcomes considered important for most workers, such as self-esteem and family esteem, social inclusion and participation, and material standards of living. ${ }^{2}$ The importance of presenteeism as part of work-related outcomes is becoming increasingly recognized as a disease-related outcome, and subsequently, attention is shifting to presenteeism as a potential predictor of work disability, offering the opportunity to identify and support people at risk for becoming work-disabled. Thus, presenteeism measurements have become an integral part of identifying the overall effect of rheumatic disorders on work and also on worker productivity both in trials and in clinical followup.

Different measures are available to evaluate presenteeism, including global measures and multi-item measures. ${ }^{14}$ Global measures record a general perception of presenteeism using 1 or 2 single items, while multi-item measures use a number of questions, with a focus on one or multiple aspects of presenteeism [e.g., time management, physical demands, mental interpersonal and output demands - The Work Limitations Questionnaire (WLQ- $\left.25^{15}\right)$ ]. Global measures are particularly attractive as they are more feasible in large clinical studies with interests in many outcome domains. 
Despite increasing research on the clinimetric properties of these global measures for at-work productivity, several questions remain. ${ }^{14}$ First, no data on test-retest reliability are available for the measures in an arthritis population, and comparative construct and concurrent validity is scarce. ${ }^{16,17}$ Second, data on comparative validity are limited but needed when aiming to recommend a global measure for use in a rheumatic working population. Finally, whether the global measures are applicable to differing occupational classes is an important but unanswered question.

Our aim was to investigate test-rest reliability of 5 global measures in patients with IA and OA including the Work Productivity Scale-Rheumatoid Arthritis (WPS-RA), Work Productivity and Activity Impairment Questionnaire (WPAI), Work Ability Index (WAI), Quality and Quantity questionnaire (QQ), and the WHO Health and Performance Questionnaire (HPQ); and to compare the association between these measures with each other and with general well-being to determine whether the data between the scales are interchangeable. The 5 global measures at the center of investigation were chosen after a survey among researchers, patients, and clinicians with expertise in the field of worker productivity.

\section{Materials and methods}

\section{Study population}

Individuals with a physician diagnosis of IA (including RA, PSA, and AS) or OA were recruited for study via 1 outpatient rheumatology or orthopedic clinic from 7 participating countries (United Kingdom, Canada, The Netherlands, France, Sweden, Romania, and Italy). Patients had to be age $\geq 18$ years, in paid full or part-time employment, and able to communicate verbally and in writing in the language of the participating country. The reliability data collected in this study were part of a larger study that applied cognitive debriefing to investigate the content validity of the measures, the results of which will be presented in a different report. Recruitment aimed at 10 participants per country, with an equal distribution of age, sex, manual/nonmanual jobs, and disease type. All patients provided written informed consent. Ethical approval was obtained from each participating center according to national ethical guidelines.

\section{Data collection}

The following 5 global measures were selected after a survey among researchers, rheumatologists, and patients: ${ }^{14}$ WPAI, ${ }^{18}$ WPS-RA, ${ }^{19} \mathrm{WAI}^{20}{ }^{20} \mathrm{QQ},{ }^{21}$ and the HPQ. ${ }^{22}$ All 5 global measures in this study use an 11-point visual analog scale (VAS) for scoring presenteeism. Characteristics of the global measures can be found in Table 7.1. The 
WPAI, WPS-RA, WAI, and HPQ presenteeism items were extracted from the large absenteeism and presenteeism questionnaires with permission from the developers. The HPQ can be summed to provide 2 scores: a ratio of presenteeism in comparison to co-workers, or a standalone single-item measure. ${ }^{23}$ For this study, the single-item measure was used (question $\mathrm{C}$ of the $3 \mathrm{HPQ}$ questions presented to study patients).

Table 7.1 Characteristics of the five global presenteeism measures

\begin{tabular}{|c|c|c|c|c|c|}
\hline $\begin{array}{l}\text { Global } \\
\text { measure }\end{array}$ & Construct & Recall period & $\begin{array}{l}\text { Reference } \\
\text { frame (if } \\
\text { any) }\end{array}$ & Attribution & Anchors \\
\hline $\mathrm{WPAI}^{16}$ & $\begin{array}{l}\text { Productivity } \\
\text { (additional phrasing: } \\
\text { accomplished, kind } \\
\text { of work, carefully as } \\
\text { usual amount of } \\
\text { work) }\end{array}$ & 7 days & $\mathrm{N} / \mathrm{A}$ & $\begin{array}{l}\text { Disease } \\
\text { specific (RA, } \\
\text { PsA, AS, OA) }\end{array}$ & $\begin{array}{l}\text { Condition had no effect on } \\
\text { my work (0) - condition } \\
\text { completely prevented me } \\
\text { from working (10). }\end{array}$ \\
\hline WPS-RA $^{17}$ & $\begin{array}{l}\text { Productivity } \\
\text { \& interference }\end{array}$ & Last month & $\mathrm{N} / \mathrm{A}$ & Arthritis & $\begin{array}{l}\text { No interference }(0) \text { - } \\
\text { Complete interference (10) }\end{array}$ \\
\hline $\mathrm{WAI}^{18}$ & Work ability & Current & $\begin{array}{l}\text { Work ability } \\
\text { at its best }\end{array}$ & N/A & $\begin{array}{l}\text { Completely unable to work } \\
\text { (0) - Work ability at its best } \\
\text { (10) }\end{array}$ \\
\hline $\mathrm{QQ}^{19}$ & Quality and quantity & Today & $\begin{array}{l}\text { Compared to } \\
\text { normal }\end{array}$ & $\mathrm{N} / \mathrm{A}$ & $\begin{array}{l}\text { Practically nothing (0) - } \\
\text { Normal quantity (10) \& Very } \\
\text { poor quality (0) - very good } \\
\text { quality (10) }\end{array}$ \\
\hline$H P Q^{20}$ & Performance & $\begin{array}{l}\text { One/two } \\
\text { years } \\
\text { (question B) } \\
\& 4 \text { weeks } \\
\text { (question C) }\end{array}$ & $\begin{array}{l}\text { Colleagues } \\
\text { performance } \\
\text { (question A) }\end{array}$ & N/A & $\begin{array}{l}\text { Worst performance }(0) \text { - Top } \\
\text { performance (10) }\end{array}$ \\
\hline
\end{tabular}

WPAI: Productivity and Activity Impairment Questionnaire; WPS-RA: Work Productivity Scale - Rheumatoid Arthritis; WAI: Work Ability Index; QQ: Quality and Quantity questionnaire; HPQ: World Health Organization Health and Work Performance Questionnaire.

If available, translated global measures were used in each country, otherwise the measures were translated into the corresponding language of the participating country by a company specializing in translations in medicine (PharmaQuest Ltd.). Translations were conducted using cognitive debriefing interviews with 5 patient volunteers with rheumatic diseases for each language of interest, ${ }^{24}$ and utilized a forward and backward translation methodology.

Participants completed the set of global measures at 2 timepoints: at baseline and 2 weeks thereafter. An interval of 2 weeks has been recommended for use in testretest reliability analyses, ${ }^{25}$ and we believed 2 weeks would reflect little or no change in work productivity. Participants were sent hard copies of the baseline questionnaires by post 2 weeks before they were scheduled to attend the hospital/research center for 
the cognitive interview study. Participants completed the baseline questionnaires at home, which were then returned to each participating center in a prepaid envelope. The 2-week questionnaire along with reminders were sent to participants to ensure the timepoints were separated by a 2 -week interval. Participants were instructed to complete the 2-week questionnaires at home prior to the interview. The global measures were presented in a booklet to participants, with instructions for each of the individual measures. Before the start of the cognitive interview, demographic (age, sex, highest level of education), clinical (diagnosis, symptom duration, date of diagnosis), and occupational (job description, demands, incentives for working) information was collected. Occupations were categorized into manual and nonmanual occupations according to the UK Standard Occupational Classification. ${ }^{26}$ Finally, patients were asked about their general well-being using a VAS ranging from 0 (very well) to 100 (very poorly).

\section{Statistical analysis}

Descriptive statistics were used to summarize subjects'demographic, clinical, and occupational characteristics. For the total study population, test-retest reliability data for each of the 5 global measures at baseline and 2-week followup were generated using single-measure intraclass correlations (ICC), applying a 2-way random-effects model based on a repeated-measure ANOVA (ICC 2,1). ${ }^{27}$ Missing values were accounted for automatically in the ICC analysis using listwise deletion. ICC values are in general interpreted as: $>0.75=$ excellent for group level analyses,

$0.40-0.75=$ fair to good, and $<0.40=$ poor. ${ }^{28}$ Bland-Altman plots were created to identify error across the range of score scales for each of the 5 measures. Bland-Altman plots were considered appropriate as they allow systematic differences over the range of possible values to be detected that would otherwise be difficult to detect using simple point clouds. In a sensitivity analysis, ICC were computed to determine the reliability of the measures within the groups classified as having manual and nonmanual jobs.

Spearman correlations were also used to compare the level of correlation among global measures of presenteeism, and between the measures with VAS general wellbeing. SPSS 20 was used to generate the ICC and Spearman correlations; STATA 13 was used for descriptive analysis and to create the Bland and Altman plots.

\section{Results}

Although 70 ( $n=10$ per country) were recruited for study, data for 5 participants were excluded from analysis because of likely misinterpretation of the direction of the scales, with the WPAI and WPS-RA ranging from good to worse and other measures ranging from worse to good. This misinterpretation became apparent during the 
cognitive interviews and was confirmed using scatterplots between the different global measures. Further, fewer observations were recorded for the QQ $(n=62)$ and the HPQ $(n=64)$. The total study population (useable data) therefore comprised 65 patients with RA, PsA, AS, OA, or other, e.g., connective tissue disorder. The median age was 45 years [interquartile range (IQR) 37-52], 55\% were female, and the median disease duration was 13 years (IQR 6-19). The majority of participants had RA (32\%) (Table 7.2), and 71\% had a nonmanual occupation. In general, participants had mild to moderate impact of disease based on the general well-being scale. The median score at baseline was 3 for the WPAI (IQR 1-6; higher score = worse score), 3 for the WPS-RA (IQR 2-6; higher score = worse score), 7 for the WAI (IQR 5-9; higher score = best score), 72 for the total QQ (IQR 49-100; higher score = best score; QQ questions 1 and 2 multiplied to give a range of 0-100), and a median of 7 for HPQ question C (IQR 6-8; higher score = best score).

Table 7.2 Demographic and clinical characteristics ( $n=65)$.

\begin{tabular}{lc}
\hline & Value \\
\hline Age & $45(37-52)$ \\
median (IQR) & $46(11)$ \\
mean, (SD) & $36(55)$ \\
Female gender, $\mathrm{n}(\%)$ & \\
Symptom duration in years & $13(6-19)$ \\
median (IQR) & $13(10)$ \\
mean, (SD) & \\
VAS well-being & $28(13-53)$ \\
median (IQR) & $34(25)$ \\
mean, (SD) & $21(32 \%)$ \\
Diagnosis & $20(31 \%)$ \\
Rheumatoid arthritis & $11(17 \%)$ \\
Ankylosing spondylitis & $8(12 \%)$ \\
Psoriatic arthritis & $5(8 \%)$ \\
Osteoarthritis & \\
Other inflammatory disease & \\
\hline
\end{tabular}

Other inflammatory diseases include undifferentiated arthritis and undifferentiated connective tissue disease. N: Number; IQR: Interquartile range; SD: Standard deviation; VAS: Visual analogue scale.

\section{Test-retest reliability}

ICC for all 5 global measures at first and second assessment are shown in Table 7.3. Overall, the ICC in the total sample ranged from 0.59 (95\% Cl 0.40-0.73; HPQ question C) to 0.78 (95\% Cl 0.65-0.86; WPS-RA), which indicates fair to excellent agreement between test-retest scores at baseline and 2-week followup at group level $(p<0.001$ for all tests). Bland-Altman plots illustrate the differences between the 2 timepoints (baseline and 2 weeks) and the mean scores at baseline and 2 weeks, demonstrating the degree of variation for all 5 global measures for the total sample (See 
Supplementary Figure S7.1, available online at jrheum.org). The 95\% limits of agreement vary between each of the measures, but in general, the variation of the difference around the mean for most was moderate. For each measure, a few differences outside or close to the limit lines are present, demonstrating minimal levels of disagreement between the 2 timepoints (See panels, Supplementary Figure S7.1, available online at jrheum.org).

Table 7.3 Intraclass correlations for assessment at 2 time points (baseline and 2 weeks) of the five global measures for the total sample.

\begin{tabular}{lll}
\hline Global measure & $\mathrm{N}$ & ICC \\
\hline WPAI & 65 & $0.74^{*}$ \\
WPA-RA & 65 & $0.78^{*}$ \\
WAI & 65 & $0.75^{*}$ \\
$Q_{\text {Quantity }}$ & 63 & $0.69^{*}$ \\
$Q_{\text {Quality }}$ & 62 & $0.73^{*}$ \\
$Q_{\text {Total }}$ & 62 & $0.76^{*}$ \\
HPQ-question C & 64 & $0.59^{*}$ \\
\hline
\end{tabular}

WPAI: $0=$ rheumatoid arthritis had no effect on my work, $10=$ rheumatoid arthritis completely prevented me from working; WPS-RA: $0=$ no interference, $10=$ complete interference; WAI: $0=$ completely unable to work, $10=$ work ability at its best; $\mathrm{QQ}$ : $0=$ practically nothing/very poor quality, 10=normal quantity/normal quality; $\mathrm{HPQ}$ question $\mathrm{C}$ : $0=$ =worst performance, $10=$ top performance. $\mathrm{N}$ : Number. ICC: Intraclass correlations. * $p<0.001$

ICC in both the nonmanual working group $(n=46)$ and the manual working group $(n=19)$ showed good to excellent agreement, with ICC ranging from 0.67 (95\% Cl 0.47-0.80; $\mathrm{HPQ}$ question C) to $0.83\left(95 \% \mathrm{Cl} 0.71-0.90 ; \mathrm{Q}_{\text {quality }}\right)$ in the nonmanual group of participants, and poor to excellent agreement rate, with a range of $0.39(95 \% \mathrm{Cl}-0.08$ to 0.70 ; $\mathrm{HPQ}$ question $\mathrm{C})$ to $0.76(95 \% \mathrm{Cl} 0.47-0.90$; WPS-RA) in the manual group (Table 7.4).

Table 7.4 Intraclass correlations for the assessments over time of the five global measures for the nonmanual and manual working groups.

\begin{tabular}{lcccc}
\hline Global measure & \multicolumn{2}{c}{ Non-manual job } & \multicolumn{2}{c}{ Manual job } \\
\cline { 2 - 5 } & $\mathrm{N}$ & $\mathrm{ICC}$ & $\mathrm{N}$ & $\mathrm{ICC}$ \\
\hline WPAI & 46 & $0.77^{*}$ & 19 & $0.68^{*}$ \\
WPS-RA & 46 & $0.78^{*}$ & 19 & $0.76^{*}$ \\
WAI & 46 & $0.77^{*}$ & 19 & $0.67^{*}$ \\
QQuantity & 45 & $0.75^{*}$ & 18 & $0.53^{* *}$ \\
QQuality $_{\text {QQ }}$ & 44 & $0.83^{*}$ & 19 & $0.59^{* *}$ \\
HPQ- question C & 44 & $0.81^{*}$ & 18 & $0.65^{*}$ \\
\hline
\end{tabular}

N: Number; ICC: Intraclass correlation coefficients. ${ }^{*} \mathrm{p} \leq 0.001 ;{ }^{* *} \mathrm{p}<0.01$. 


\section{Construct validity}

Spearman rank correlations between the 5 global measures yielded values ranging from strong (WPAl and WPS-RA, $r=0.88)$ to moderate $\left(Q_{\text {quality }}\right.$ vs. WAl, $\left.r=0.51\right)$. Assuming that these measures should assess the same construct, namely presenteeism, then ICC are justified. These ranged from fair [-0.46 (95\% Cl -0.64 to -0.25) for WPAl and $\mathrm{Q}_{\text {quantity; }}$ negative values as a result of opposing anchors on scales] to excellent [0.85 (95\% Cl 0.76 to 0.90) for WPAI and WPS-RA]. Correlations between each of the individual measures and VAS general well-being were low to moderate, ranging from $r=-0.44$ (QQ total) to $r=-0.66$ (WPS-RA) ( $p<0.001$ for all tests; Table 7.5).

Table 7.5 Spearman correlations between five at-work productivity loss measures and VAS general wellbeing.

\begin{tabular}{|c|c|c|c|c|c|c|c|}
\hline & WPAI & WPS-RA & WAI & $Q_{\text {Quantity }}$ & $Q_{\text {Quality }}$ & $\mathrm{QQ}_{\text {Total }}$ & $\mathrm{HPQ}$ - question $\mathrm{C}$ \\
\hline WPAI & - & & & & & & \\
\hline WPS-RA & 0.88 & - & & & & & \\
\hline WAI & -0.69 & -0.73 & - & & & & \\
\hline QQuantity & -0.60 & -0.67 & 0.65 & - & & & \\
\hline Quality & -0.57 & -0.65 & 0.51 & 0.81 & - & & \\
\hline $\mathrm{QQ}_{\text {Total }}$ & -0.63 & -0.68 & 0.56 & 0.94 & 0.91 & - & \\
\hline $\mathrm{HPQ}$ - question C & -0.67 & -0.74 & 0.66 & 0.61 & 0.55 & 0.61 & \\
\hline VAS well-being & 0.58 & 0.66 & -0.61 & -0.45 & -0.46 & -0.44 & -0.53 \\
\hline
\end{tabular}

VAS: Visual analogue scale; WPAI: $0=$ rheumatoid arthritis had no effect on my work, $10=$ rheumatoid arthritis completely prevented me from working; WPS-RA: $0=$ no interference, $10=$ complete interference; WAl: $0=$ completely unable to work, $10=$ work ability at its best; $\mathrm{QQ}$ : $0=$ practically nothing/very poor quality, 10=normal quantity/normal quality; $\mathrm{HPQ}$ question C: $0=$ worst performance, $10=$ top performance. Negative correlations are present when the comparison is made between two global measures with opposing visual analogue scales (e.g., WPAI vs. QQ). P values all $<0.001$.

\section{Discussion}

The results showed that 4 out of the 5 measures, the WPS-RA, WAI, QQ, and WPAI (considered acceptable as only marginally short at 0.74 ), met or exceeded the 0.75 threshold of acceptability for agreement between a baseline and 2-week interval, an interval we felt would reflect a stable situation with little or no change in work productivity. The correlations between the global measures suggested mostly moderate construct validity. Low to moderate convergent validity between the measures and general well-being was evident. Although the ICC of the 5 global measures have not previously been compared, individually our results are congruent to the limited reliability evidence used within different chronic conditions such as irritable bowel syndrome ${ }^{29}$ and Crohn's disease, ${ }^{30}$ while the data from the other global measures serve to build upon the sparse evidence base. 
The discrepancy between ICC in the manual and nonmanual participant groups was an interesting finding. Consistently higher agreement for the nonmanual subgroup was evident, with the most extreme difference lying within the QQ quality question (nonmanual 0.83; manual 0.59). This may be partly determined by a variance in physical exertion in manual work over time compared to sedentary work, as reflected in inconsistent scoring over the 2 timepoints. Manual work is known to be a risk factor for presenteeism in musculoskeletal disorders, ${ }^{31-33}$ highlighting a contextualized relationship between rheumatic diseases and work productivity. Although this would normally account for differences in the magnitude of work ability, in this study it also seemed to suggest some instability in scores (lower reliability) in jobs with more fluctuating demands. As such, it may be worthwhile to account for intensity of job demands in future analysis.

Correlations between the 5 global measures in our study were moderate. This is similar to the literature in which previous findings demonstrate moderate correlations between at-work productivity outcome measures [e.g., WALS and the Endicott Work Productivity Scale $(r=0.55)$ and WALS and the WLQ-25 index $(r=0.61)] .{ }^{9}$ Although each measure at its core measures presenteeism, different concepts are included "ability" (WAI), as well as different timeframes, for example, "today" (QQ), "7 days" (WPAI), and "one month" (WPS-RA). However, the strong association between the WPAI and the WPS-RA ( $r=0.88$ ) suggests congruence between the 2 measures, potentially with regard to their conceptual foci, as both measures utilize the term "productivity."

The low to moderate results of the VAS general well-being and global measure correlations imply that productivity loss may be only partly captured by general health issues, suggesting that other factors, including contextual factors, may contribute to productivity loss. Recent research into contextual factors of work disability and absenteeism supports this notion, showing that factors such as family support towards work, work modifications, and physical job demands influence both work disability and absenteeism; ${ }^{34-36}$ the same factors may also apply to presenteeism.

There were a few limitations to our study. The reversal of the VAS for the WPAI and WPS-RA accounted for the loss of 5 patients in the analysis, as a misinterpretation of the direction of the anchors on the scales was apparent. The opposing scores on the remaining measures indicated a clear intention to score similar scores on the measures with reversed VAS. The collection of general well-being VAS only at the 2-week timepoint is a limitation. However, an interval of 2 weeks for test-retest investigations is often thought to be appropriate as there is little risk for recall bias and clinical change. ${ }^{25,37}$ Further, it is possible that an element of social desirability bias may have influenced the results; however, participants were reassured of data confidentiality to eliminate any uncertainty of employers seeing participants' responses, which we hope minimizes the possibility of social desirability bias. As well, although the questionnaires were rigorously translated using an approved translation company, some differences in 
translation may contribute to the moderate results; we expect the effect of this to be minimal due to procedures used during translation.

Test-retest reliability of the 5 global measures of presenteeism was mostly good, with 4 of the 5 measures meeting or exceeding the threshold of acceptable reliability. The WPS-RA performed best in the test-retest reliability analysis, and with the WPAI in the comparison between measures, suggesting interchangeability between available data using the 2 methods. Whether the remaining measures can be considered interchangeable is tentative. The findings suggest that different instruments in different diseases and discourses should perhaps be used. Based on our findings, the $\mathrm{HPQ}$ would not be recommended for use as a global measure of presenteeism in rheumatic working populations. The extent to which other measures provide different information likely depends on predictive ability with regard to absence and work disability. Additional work is warranted to support psychometric evidence of the 5 global measures, paying particular attention to potential contextual factors, such as manual and nonmanual occupations, that may influence study results. 


\section{References}

1. Waddell G, Burton AK. Is work good for your health and well-being? Norwich: The Stationery Office; 2006.

2 Black C. Working for a healthier tomorrow: Work and health in Britain. Norwich: The Stationery Office; 2008.

3. Bevan S, Quadrello T, McGee R, Mahdon M, Vavrovsky A, Barham L. Fit for work? Musculoskeletal disorders in the European workforce. London: The Work Foundation; 2009.

4. Dunlop DD, Manheim LM, Yelin EH, Song J, Chang RW. The costs of arthritis. Arthritis Rheum 2003;49:101-13.

5. Tillett W, de-Vries C, McHugh NJ. Work disability in psoriatic arthritis: A systematic review. Rheumatology 2012;51:275-83.

6. Verstappen SM, Bijlsma JW, Verkleij H, Buskens E, Blaauw AA, ter Borg EJ, et al. Overview of work disability in rheumatoid arthritis patients as observed in cross-sectional and longitudinal surveys. Arthritis Rheum 2004;51:488-97.

7. Boonen $A$, de Vet $H$, van der Heijde $D$, van der Linden S. Work status and its determinants among patients with ankylosing spondylitis. A systematic literature review. J Rheumatol 2001;28:1056-62.

8. Gabriel SE, Crowson CS, Campion ME, O'Fallon WM. Indirect and nonmedical costs among people with rheumatoid arthritis and osteoarthritis compared with nonarthritic controls. J Rheumatol 1997;24: 43-8.

9. Beaton DE, Tang K, Gignac MA, Lacaille D, Badley EM, Anis AH, et al. Reliability, validity, and responsiveness of five at-work productivity measures in patients with rheumatoid arthritis or osteoarthritis. Arthritis Care Res 2010;62:28-37.

10. Ziegler S, Huscher D, Karberg K, Krause A, Wassenberg S, Zink A. Trends in treatment and outcomes of rheumatoid arthritis in Germany 1997-2007: Results from the National Database of the German Collaborative Arthritis Centres. Ann Rheum Dis 2010;69:1803-8.

11. Neovius M, Simard JF, Klareskog L, Askling J. Sick leave and disability pension before and after initiation of antirheumatic therapies in clinical practice. Ann Rheum Dis 2011;70:1407-14.

12. Olofsson T, Englund M, Saxne T, Joud A, Jacobsson LT, Geborek P, et al. Decrease in sick leave among patients with rheumatoid arthritis in the first 12 months after start of treatment with tumour necrosis factor antagonists: A population-based controlled cohort study. Ann Rheum Dis 2010;69:2131-6.

13. Kristensen LE, Englund M, Neovius M, Askling J, Jacobsson LT, Petersson IF. Long-term work disability in patients with psoriatic arthritis treated with anti-tumour necrosis factor: A population-based regional Swedish cohort study. Ann Rheum Dis 2013;72:1675-9.

14. Tang K, Boonen A, Verstappen SM, Escorpizo R, Luime JJ, Lacaille D, et al. Worker productivity outcome measures: OMERACT filter evidence and agenda for future research. J Rheumatol 2014;41:165-76.

15. Lerner D, Amick BCl, Rogers WH, Malspeis S, Bungay K, Cynn D. The Work Limitations Questionnaire. Med Care 2001;39:72-85.

16. Zhang W, Bansback N, Boonen A, Young A, Singh A, Anis AH. Validity of the Work Productivity and Activity Impairment Questionnaire - General health version in patients with rheumatoid arthritis. Arthritis Res Ther 2010;12:R177.

17. Lambert J, Hansen BB, Arnould B, Grataloup G, Guillemin I, Hojbjerre L, et al. Linguistic validation into 20 languages and content validity of the rheumatoid arthritis-specific Work Productivity and Activity Impairment Questionnaire. Patient 2014;7:171-6.

18. Reilly MC, Zbrozek AS, Dukes EM. The validity and reproducibility of a work productivity and activity impairment instrument. Pharmacoeconomics 1993;4:353-65.

19. Osterhaus JT, Purcaru O, Richard L. Discriminant validity, responsiveness and reliability of the rheumatoid arthritis-specific Work Productivity Survey (WPS-RA). Arthritis Res Ther 2009;11:R73.

20. Tuomi K, Ilmarinen J, Jahkola A, Katajarinne L, Tulkki A. Work ability index. 2nd ed. Helsinki: Finnish Institute of Occupational Health; 1998.

21. Brouwer WB, Koopmanschap MA, Rutten FF. Productivity losses without absence: Measurement validation and empirical evidence. Health Policy 1999;48:13-27. 
22. Kessler RC, Barber C, Beck A, Berglund P, Cleary PD, McKenas D, et al. The World Health Organization Health and Work Performance Questionnaire (HPQ). J Occup Environ Med 2003;45:156-74.

23. Kessler RC, Petukhova M, Mclnnes K. HPQ Short Form (absenteeism and presenteeism questions and scoring rules). [Internet. Accessed October 21, 2015.] Available from: http://www.hcp.med.harvard.edu/hpq/ftpdir/absenteeism\%20presenteeism\%20scoring\%20050107.p df

24. Beaton DE, Bombardier C, Guillemin F, Ferraz MB. Guidelines for the process of cross-cultural adaptation of self-report measures. Spine (Phila Pa 1976) 2000;25:3186-91.

25. Marx RG, Menezes A, Horovitz L, Jones EC, Warren RF. A comparison of two time intervals for testretest reliability of health status instruments. J Clin Epidemiol 2003;56:730-5.

26. Office for National Statistics. Standard occupational classification 2000. Volume 1. Structure and description of unit groups. London: The Stationery Office; 1990.

27. Shrout PE, Fleiss JL. Intraclass correlations: Uses in assessing rater reliability. Psychol Bull 1979;86: 420-8.

28. Fleiss JL. Reliability of measurement. The design and analysis of clinical experiments. New York, Chichester: Wiley; 1986:1-32.

29. Bushnell DM, Reilly MC, Galani C, Martin ML, Ricci JF, Patrick DL, et al. Validation of electronic data capture of the Irritable Bowel Syndrome-Quality of Life Measure, the Work Productivity and Activity Impairment Questionnaire for Irritable Bowel Syndrome and the EuroQol. Value Health 2006;9:98-105.

30. Vergara M, Montserrat A, Casellas F, Villoria A, Suarez D, Maudsley M, et al. A new validation of the Spanish Work Productivity and Activity Impairment Questionnaire-Crohn's disease version. Value Health 2011;14:859-61.

31. Agaliotis M, Fransen M, Bridgett L, Nairn L, Votrubec M, Jan S, et al. Risk factors associated with reduced work productivity among people with chronic knee pain. Osteoarthritis Cartilage 2013;21:1160-9.

32. Ng YG, Tamrin SB, Yik WM, Yusoff IS, Mori I. The prevalence of musculoskeletal disorder and association with productivity loss: A preliminary study among labour intensive manual harvesting activities in oil palm plantation. Ind Health 2014;52:78-85.

33. Geuskens GA, Hazes JM, Barendregt PJ, Burdorf A. Predictors of sick leave and reduced productivity at work among persons with early inflammatory joint conditions. Scand J Work Environ Health 2008;34:420-9.

34. Lacaille D, Sheps S, Spinelli JJ, Chalmers A, Esdaile JM. Identification of modifiable work-related factors that influence the risk of work disability in rheumatoid arthritis. Arthritis Rheum 2004;51:843-52.

35. Allaire SH, Anderson JJ, Meenan RF. Reducing work disability associated with rheumatoid arthritis: Identification of additional risk factors and persons likely to benefit from intervention. Arthritis Care Res 1996;9:349-57.

36. Boonen A, Boone C, Albert A, Mielants H. Understanding limitations in at-work productivity in patients with active ankylosing spondylitis: The role of work-related contextual factors. I Rheumatol 2015;42:93-100.

37. Streiner DL, Norman GR. Health measurement scales: A practical guide to their development and use. 4th ed. Oxford: Oxford University Press; 2008. 



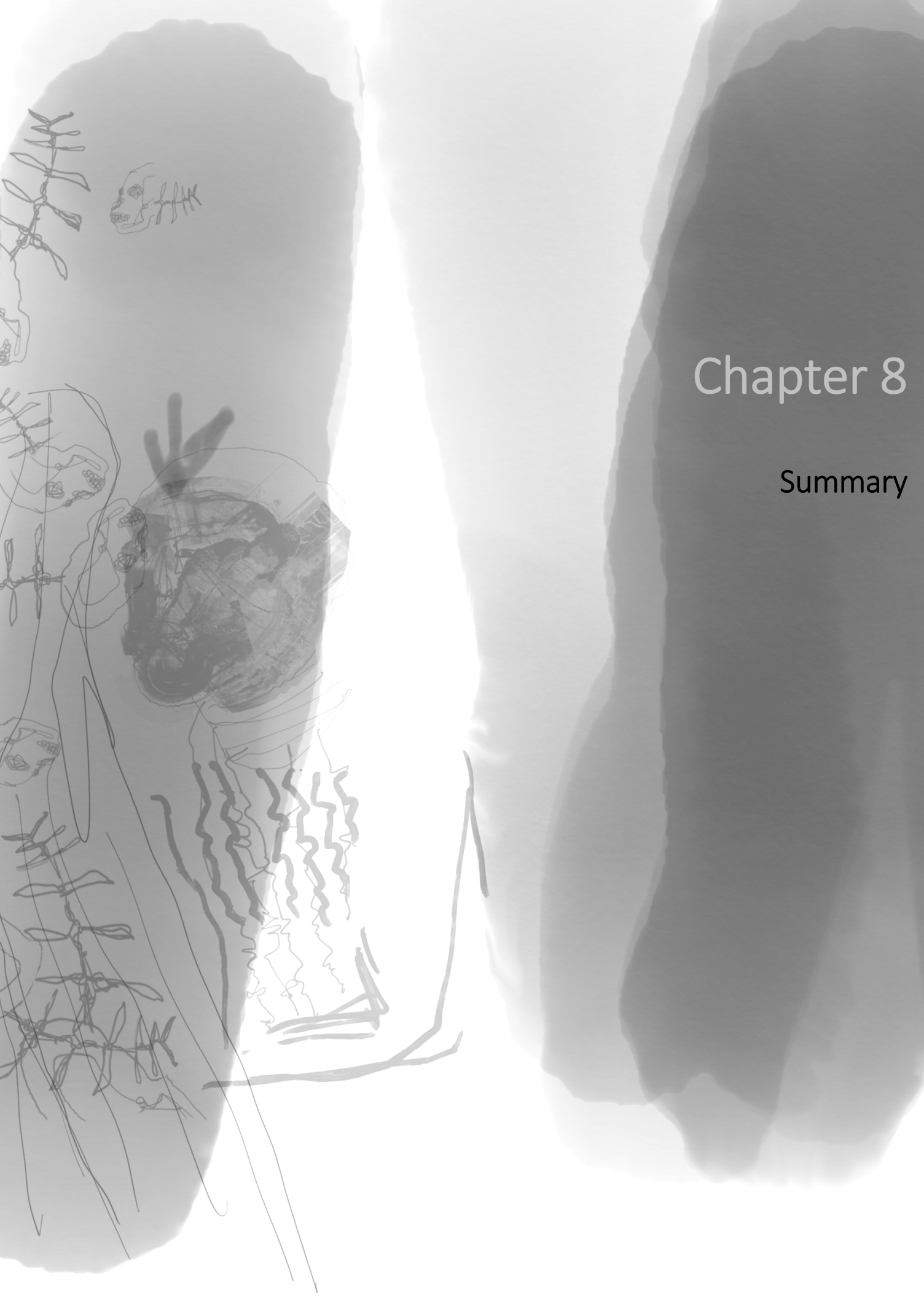





\section{Summary}

In this chapter we summarize the studies addressed in chapters two to seven.

Part I Health and work outcomes of musculoskeletal diseases in the context multimorbidity

In chapter 2 we studied data from 8904 subjects that participated in a nationwide Dutch household survey and showed that $19 \%$ of all subjects had more than 1 disease, 20\% had MSKD and 56\% of those with multimorbidity had MSKD. Compared to other chronic disease, MSKD had the strongest impact on physical health as determined by the 12-item Short Form Survey (SF12) (B -8.37 [95\%Cl -8.84; -7.89]) and the second strongest impact (after cancer) on healthcare costs (Exp (B) $2.27[95 \% \mathrm{Cl} 2.08 ; 2.51])$. Of all chronic diseases only mental diseases had a relevant impact on mental health (SF 12 mental component score) (B -12.98 [95 \% Cl -13.74; -12.22]). In addition, we found a linear decrease in physical and mental health and a steep increase in healthcare costs when the number of diseases increased. In persons with multimorbidity including a MSKD, physical health was significantly lower (-10.5 points) and healthcare costs were higher (3.5-fold compared to 2.5-fold increase) than in persons with multimorbidity without MSKD. With regard to healthcare costs, this was only significant when comparing the combination of MSKD and mental disease to all other combinations of two diseases. When mental health was the outcome, no influence of the presence or absence of MSKD in multimorbidity was observed. This study provides data that can be worthwhile when discussing needs of healthcare systems when caring for patients with multimorbidity.

In chapter 3 we restricted the population of the above mentioned study to persons in the working age range (18-65 years) who had paid work, were work disabled (WD), unemployed (UE) or depending on a living allowanced (LA) which resulted in a sample of 5396 persons. Overall, $17 \%$ of subjects had MSKD, 14\% of the subjects had more than 1 disease, and $61 \%$ of persons with multimorbidity had MSKD. We showed that all chronic diseases were associated with WD and LA and the majority of diseases also with the likelihood of incurring sick leave in the 12 months prior to survey completion. The risk of adverse work outcome was systematically highest for persons with mental diseases: the odds were 10.54 [7.69; 14.44] when WD was the outcome; 5.60 [2.77; 11.34] when LA was the outcome; 3.03 [1.91; 4.80] when UE was the outcome and 3.24 [2.33; 4.52] when sick leave was the outcome. The odds for MSKD were lower than for mental disease, but still substantially increased when compared to persons without an MSKD (WD: 2.06 [1.56; 2.71]; LA: 2.15 [1.18; 3.91]; UE: 1.35 [0.94; 1.96]; sick leave: 2.29 [1.92; 2.73]). When further exploring the impact of multimorbidity, each increase in the number of diseases was associated with a strong increase in the odds of all adverse work outcomes. When studying association between patterns of 
multimorbidity and work outcome, the presence of a MSKD tended to amplify the risk of adverse work outcome. This trend was most pronounced for sick leave where the odds for multimorbidity including an MSKD (OR 4.04 [95\% Cl 3.07; 5.34]) were significantly higher than for multimorbidity without MSKD (OR $2.40[95 \% \mathrm{Cl} 1.78$; 3.24]). Our results emphasize the need to develop common strategies among all chronic diseases to improve work outcome in daily clinical care.

\section{Part II Early intervention to improve work outcome of patients with musculoskeletal diseases}

In chapter 4 we evaluated the effects and costs of an integrated intensive 4-weeks multidisciplinary program ("Rehabilitation and Reintegration in patients with Rheumatic disease (3R-program)) with a wellness component. We were interested to know (1) whether it had beneficial effects on days absent from work and time until work resumption when compared to usual care, (2) whether program costs would be worth the gain in working days and (3) to what extent the program would reduce resource utilization and improve health in those participating. Data from a large Dutch occupational health service database, that registers real life work-outcomes of persons with sick leave due to musculoskeletal complaints, could be used as the usual care comparator. Those following the 3R-program resumed their work on average 17 days earlier, resulting in an average reduction of $€ 4223$ in related productivity costs compared with the group that had received usual care. Moreover, after the 4-weeks program, the hazard ratio of work resumption in the program-group was significantly higher than in the usual care group [HR 1.60 (95\% Cl 1.22-2.11)]. However, program costs were substantial and mounted to $€ 6,172$ per patient with some $26 \%$ of the costs (€ 1600) attributable to hotel costs. This resulted in the amount of $€ 356$ per avoided sick leave day. However, in addition to working days gained, healthcare costs were $€ 775$ lower in the 6 months following the program compared to the 6 months prior to the program.

Moreover, significant health improvements were found with an average EQ-5D utility of $0.57( \pm 0.26)$ in the beginning of the program and $0.70( \pm 0.22) 6$ months thereafter $(p<0.01)$. For the mean VAS score this was $56.1( \pm 15.1)$ and $69.4( \pm 13.6)$ respectively $(p<0.01)$. Our study provides insight into the costs and benefits of a holistic return to work program and provides data that can be worthwhile when discussing optimization of healthcare.

Part III Influence of country of residence on work outcomes and validity of presenteeism measures in patients with rheumatoid arthritis

In chapter 5 we investigated the contribution of country of residence and several country characteristics including gross domestic product (GDP), human development 
index (HDI), unemployment rate, social protection expenditures (SPE) or world region to employment status, absenteeism and presenteeism in a large international sample consisting of 3920 rheumatoid arthritis patients from 17 countries. Multinational data on patients' demographic background, disease characteristics and work outcome were available from the COMORA study.

We found large country differences for all work outcomes independent of sociodemographic and clinical characteristics. Taking the country with the best work outcome as a reference, patients in Morocco had lowest odds to be employed (OR 0.2; [95\% Cl 0.1;0.3] vs. USA) and highest odds of absenteeism (OR 12.6 [4.5;35.9] vs. Japan), while presenteeism was highest in Taiwan (OR 13.8[5.9;32.0] vs. Venezuela). Higher economic wealth (GDP) was associated with better employment rates (OR 0.66 [95\% $\mathrm{Cl} 0.54 ; 0.80]$ ) compared to low GDP and lower absenteeism (OR 2.68 [95\%Cl 1.91;3.76]). Similarly, better HDI and lower national unemployment were associated with better employment and lower absenteeism. Paradoxically, the direction of associations changed when presenteeism was the outcome: higher economic wealth and human development and lower unemployment were associated with more presenteeism. When grouping countries by world region, countries in Africa, Latin America, Asia and Europe had lower odds of employment compared to North America. Countries in Europe, Africa and Latin America had significantly higher odds of absenteeism than countries in Asia. Countries in Europe, Asia and North America had significantly higher odds of being in a higher presenteeism group compared to Latin America. Our results suggest that international research in patients with RA should account for country differences. Results should be presented at least on the level of geographical area. Moreover, healthcare for RA-patients should be in accordance with national needs, which may require re-evaluation of international evidence on effective work-interventions in the national context.

In chapter 6 we explored the conceptual interpretation of five preselected global (single item) measures of presenteeism from the perspective of working individuals with inflammatory arthritis (IA) and osteoarthritis (OA), namely, the presenteeism item in the Work Productivity and Activity Impairment Questionnaire (WPAI), the Work Productivity Scale - Rheumatoid Arthritis (WPS-RA), the Work Ability Index (WAI), Quality and Quantity questionnaire (QQ), and the WHO Health and Performance Questionnaire (HPQ). Ten participants per country were recruited from outpatient rheumatology or orthopedic clinics in seven countries: UK, the Netherlands, France, Italy, Sweden, Romania and Canada. Deductive, thematic analyses were based on predefined themes for all attributes of the global measures, namely construct, reference framing, recall period and disease attribution. We found that the overall interpretation of the construct was similar across countries. An exception was the use of the term 'interference' in the stem and anchor of the WPS-RA which was not well understood by participants from Romania. Moreover, in comparison with other 
countries, the interpretation of the term 'performance', to describe he construct of interest in the same questionnaire was different for Romanian and Swedish participants who indicated that performance was rather related to competing (for example in sports) than to working. Difficulties that were not directly attributable to country of residence were encountered with the recall period 'current' in the WAI and the 'compared with normal' reference in the QQ. Although the WPAI was ultimately selected as the best instrument by $29 \%$ of the participants, the reverse scaling of the WPAI and WPS-RA compared to other instruments (i.e. $0=$ good outcome, $10=\mathrm{bad}$ outcome) caused confusion. The HPQ scored poorly as participants regularly disliked comparing themselves with colleagues and due to the long recall period of one-two years in one of the three questions. Our study shows that the validity of tools to measure presenteeism depends on patient perceptions as well as on cultural and linguistic habits.

In chapter 7 we further investigated the comparative validity of the presenteeism measures introduced in chapter 6 in terms of test-retest reliability and correlations between measures and general well-being, as such comparative data were not available yet. We showed that the WPS-RA, WAI, QQ, and WPAI had an acceptable agreement for the comparison of baseline and follow-up scores after 2 weeks $(I C C>0.74)$. The lowest agreement was found for the HPQ $(I C C=0.59)$. Correlations between the different measures were mostly moderate with the exception of the comparison of WPS-RA and WPAI (Spearman's $r=0.88$ ), and correlations between the measures and general health related well-being were low to moderate $(r=-0.44$ (QQ) to $r=-0.66$ (WPS-RA)). The findings suggest that different instruments in different diseases and discourses should likely be used. 



\section{General discussion}

In this thesis we address several gaps in knowledge of a number of contextual factors in relation to work participation in patients with musculoskeletal diseases (MSKD). Firstly, we were interested to compare the impact of MSKD on health and work outcomes compared with other chronic diseases and to understand how the presence of MSKD in the context of multimorbidity affects these outcomes. Secondly, we focus on the role of the treatment context, more specifically on an early multi-component program, in enhancing work resumption. In a last part, we address the relevance of economic and cultural context of the country of residence as predictor for adverse work outcome.

Our main findings are

- All major chronic diseases (i.e. MSKD, migraine, diabetes, cardiovascular (CVD), cancer, respiratory, skin, mental and gastro-intestinal diseases) are associated with adverse health and work outcomes and high healthcare costs. However, MSKD have a comparably larger impact on physical health and (together with mental diseases) also on sick leave. Moreover, presence of MSKD in the context of multimorbidity tends to amplify the adverse association of multimorbidity with physical health, healthcare costs and sick leave.

- A multidisciplinary treatment program with spa-elements in persons with recent sick leave due to MSKD has beneficial effects on work resumption. Participants resume their work on average 17 days sooner than persons who receive usual care. In addition, improvement in health and reduction in healthcare consumption is observed.

- $\quad$ Lower economic wealth and less human development of countries are associated with worse employment, higher absenteeism but paradoxically with lower presenteeism of persons with rheumatoid arthritis (RA).

- $\quad$ Linguistic and cultural differences related to country of residence are associated with differences in the comprehension of 2 of 5 single global measures of presenteeism in patients with MSKD. The Work Productivity Scale - Rheumatoid Arthritis and the Work Performance Questionnaire are less suitable for use in multinational studies.

In this chapter we will discuss the findings of the studies from which the above mentioned conclusions are drawn.

Despite growing attention for chronic disease and multimorbidity and increasing research into its impact on functioning and health outcome, ${ }^{1-7}$ it seems there is a delay in the adjustment of clinical care to the needs of these patients. To date, healthcare systems are still organized following a disease-oriented approach. Yet, there are great opportunities with regard to improvement of care for persons with one or more 
chronic diseases. This thesis shows all chronic diseases and even stronger multimorbidity are associated with adverse work outcome, comprising work disability, unemployment, dependence on living allowances as well as sick leave. This offers opportunities for a common approach for prevention, as risk factors for adverse work outcome are largely generic across diseases. Current knowledge on prevention of adverse work outcome remains fragmented, as it is often disease specific. When efforts across diseases would be joined, innovative interventions to support or enhance worker participation could be more efficient. A first step could be the introduction of a generic screening tool to detect restrictions in work participation in clinical encounters, combined with a referral tool when problems are identified. In screening, the role of multimorbidity should receive attention as a possible risk factor. It is therefore important to know that the presence of MSKD and possibly mental diseases may even amplify the risk for adverse work outcome in those with multimorbidity.

Interdisciplinary collaboration can play an essential role when aiming at optimizing work participation in persons with (multiple) chronic diseases. In multidisciplinary programs, various components involved in work participation are being addressed directed at physical and mental demands in relation to individual workplace requirements and work-life balance. The 3R-program is an example of such an approach aiming to prevent long-term absence or work disability in persons with MSKD. Specific for $3 R$ is the recognition of the need to reduce stress as a prerequisite for work participation in nowadays stressful times in terms of physical relaxation but also in terms of coping with limitations, work-related stressors and challenges in worklife balance. Although the 3R-program has been evaluated in MSKD, the components of the program seem to be relevant for work participation in all persons with chronic diseases. For example, physiotherapy components are mainly focused on improvement of overall physical functioning and condition. As such it might potentially be generalizable to other diseases. On this line it should be emphasized that the positive results of the $3 R$ - program were similar for degenerative, inflammatory and nonspecific musculoskeletal complaints. This notwithstanding, further research is needed to be able to draw conclusions on whether this intervention would be equally effective in patients with other chronic diseases and which exact components of the program are most effective from a patient or professional perspective.

While the $3 R$ program recognizes the need to intervene early, ${ }^{8,9}$ the question can be raised whether the 4-weeks $3 R$ intervention program already early in the course of sick leave, should be the first step in supporting work participation of persons with chronic disease. It should be reminded $3 R$ has high costs and patients are absent from work for a period of 4 weeks. Alternatively, a stepwise approach in offering the interventions that differ in content and intensity has to be considered. Eligibility for participation in the holistic program would thereby be reserved for persons with multiple risk factors for adverse work outcome. 
When gathering evidence on work retention or reintegration programs, several methodological challenges are encountered. Ideally such evidence on efficacy of interventions is gathered along RCTs. Yet, participation in RCTs is voluntary and often characterized by in- and exclusion criteria. This will result in selection bias, which will influence results and limit generalizability on the other hand. Moreover, blinding of participants and researchers in this type of interventions is difficult. In addition, the relevant effects of programs on sick leave and work disability are happening in the long-term future, which requires long term follow up that is often not feasible in RCTs. Pragmatic trials offer only a partial solution, as they will still suffer from selection bias, difficulty in defining 'usual care' and the time frame. A solution for this gap in evidence may be found in the introduction of cohorts of persons with chronic diseases. Cohorts of employed persons exist but the challenges of persons that work despite an illness cannot be sufficiently addressed in such cohorts.

The inclusion of work related outcomes in cohorts of patients with chronic diseases, is rare and should be encouraged. ${ }^{10}$ This would require inclusion of a core set of work outcomes, but also core contextual factors (at the workplace or individual) and workrelated interventions in addition to health related outcomes and interventions. Such cohorts will not only help to understand which health variables or contextual factors have adverse impact om work outcome, but will also identify which work-related factors might negatively influence the course of the chronic disease itself. Large databases analyzed in a Bayesian approach might help to develop risk calculators for adverse work outcomes on the one hand, but also identify specific factors that seem amenable to modification.

Another challenge in relation to generalizability of the 3R-program concerns its potential application in other countries than the Netherlands. Feasibility of this program is largely dependent (a) on the ability of the healthcare system to identify patients with early sick leave and (b) on reimbursement for work interventions. The latter can theoretically come from employers, insurance companies or government. In this line, it is relevant to consider the influence of country of residence as well as economic and cultural factors related to country of residence on work participation. In our international study we showed large differences in work participation across countries and systems even when correcting for disease severity. Therefore return-towork programs are by definition not generalizable and can only be seen as such if they are studied in multinational studies that account for country of residence or system related factors. Our research suggests that GDP and HDI are suitable for the classification of countries in such studies. Although the exact mechanism of action of components involved in GDP (and thereby HDI) and thus what we exactly measure with GDP remains a black box, they highlight the limitations in transferability of study results on work outcomes from different countries and the relevance of adequate system regulations. 
A particularly interesting finding of our study on the impact of country and system level factors on work outcome was the paradox of worse employment, higher absenteeism but lower presenteeism in countries with lower economic wealth and human development. This paradox may potentially be related to high work pressure in highincome countries but also to cultural differences in the interpretation of the studyquestion. However, the interpretation of the WPAI, which was used for the data collection, seems stable across countries. A more likely explanation for the presenteeism paradox is that absenteeism in lower income countries still needs more attention, while in high-income countries specific attention should be given to presenteeism. When addressing the issue of presenteeism, minimizing work pressure in persons with chronic diseases is of outmost importance, particularly since presenteeism has previously been identified as predictor for absenteeism. ${ }^{11}$

\section{Conclusion}

This thesis concentrated on work participation as a relevant outcome when caring for patients with musculoskeletal diseases. We revealed the fundamental role of personal (co-existing disease) or environmental (reintegration program, country of residence) context in relation to work outcome. As the acknowledgement of this impact is growing, future challenges include a redesigned system in which contextual needs related to participation are equally relevant as needs of disease related symptoms. Although we showed that variation in work participation is to a large extent driven by country level cultural and economic factors, we also pointed out the need for a more efficient healthcare system with a holistic and problem oriented approach and with particular attention for work participation. The concrete steps necessary for this transition need attention and further exploration. 


\section{References}

1. Fortin $\mathrm{M}$, et al. Multimorbidity and quality of life in primary care: a systematic review. Health Qual life outcomes. 2004;2:51.

2. Fortin $\mathrm{M}$, et al. Relationship between multimorbidity and health-related quality of life of patients in primary care. Qual Life Res. 2006;15(1):83-91.

3. Loza $E$, et al. Multimorbidity: prevalence, effect on quality of life and daily functioning, and variation of this effect when one condition is a rheumatic disease. Semin Arthritis Rheum. 2009;38(4):312-9.

4. Alonso J, et al. Health-related quality of life associated with chronic conditions in eight countries: results from the International Quality of Life Assessment (IQOLA) Project. Qual Life Res. 2004;13(2): 283-98.

5. Hubertsson J, et al. Sick leave patterns in common musculoskeletal disorders--a study of doctor prescribed sick leave. BMC Musculoskeletal Disord. 2014;15:176.

6. Woolf AD, Pfleger B. Burden of major musculoskeletal conditions. Bulletin of the World Health Organization. 2003;81(9):646-56.

7. Kessler RC, et al. The effects of chronic medical conditions on work loss and work cutback. J Occup Environ Med. 2001;43(3):218-25.

8. Raad SE. Betere zorg voor werkenden. Den Haag: SER, 2014.

9. Verzekeringsgeneeskunde, N.V.V., NVGG richtlijn "Reumatoïde Artritis en participatie in arbeid" 2015.

10. Escorpizo R, et al. Worker productivity outcome measures in arthritis. J Rheumatol. 2007;34(6): 1372-80.

11. Taloyan $\mathrm{M}$, et al. Sickness presenteeism predicts suboptimal self-rated health and sickness absence: a nationally representative study of the Swedish working population. PLoS One. 2012;7(9):e44721. 




\section{Nederlandse samenvatting}

Werk is van belang voor de maatschappij en de samenleving. Enerzijds is er het economisch perspectief waarbij (deels noodzakelijke) goederen en diensten geproduceerd worden, waaruit het individu en de maatschappij inkomen genereren, en waardoor vervolgens consumptie, investeringen of aanbieden van (publieke) diensten mogelijk worden. Anderzijds is er ook het sociale en culturele perspectief wanneer het gaat om zingeving, kennisoverdracht, sociale ontwikkeling en vooruitgang. Arbeidsparticipatie draagt bij aan fysieke en mentale gezondheid van het individu, zorgt voor financiële autonomie, sociale interactie en persoonlijke ontwikkeling. Echter, een chronische ziekte kan relevante invloed hebben op de participatie van het individu in het arbeidsproces. Deze invloed wordt niet alleen bepaald door de biologische aspecten van de ziekte maar ook door zogenaamde contextuele factoren. Deze contextuele factoren zijn omgevingsfactoren (zoals de aard van het werk, de balans tussen werk en privé of de organisatie van de gezondheidszorg of het sociale zekerheidssysteem) maar ook persoonlijke factoren (zoals het opleidingsniveau, de manier van omgaan met stress of de aanwezigheid van één of meerdere andere aandoeningen). Contextuele factoren kunnen een positieve of negatieve invloed hebben op de arbeidsparticipatie van het individu. Zo kan een slechte sfeer op de werkplek bijdragen aan een vermindering van een al beperkt werkvermogen terwijl een prettige werksfeer het werkvermogen juist kan verbeteren. Ook de beschikbaarheid en hoogte van inkomensuitkeringen bij verzuim of arbeidsongeschiktheid kunnen invloed hebben op de uiteindelijk individuele beslissing van het chronisch ziek individu om uiteindelijk al dan niet te verzuimen of een arbeidsongeschiktheid te accepteren dan wel uit te stellen.

De meeste musculoskeletale aandoeningen (MSA) zijn chronische ziekten. Maar liefst 20\% van de Nederlandse en Europese bevolking heeft een chronische MSA. Door het veelvuldig voorkomen en de belangrijke impact op met lichamelijk functioneren, zijn MSA in veel Westerse landen de belangrijkste reden zijn voor uitkeringen omwille van arbeidsongeschiktheid en ziekteverzuim. Gezien de relevantie van arbeidsparticipatie als deel van 'gezondheid', is er in het verleden al veel onderzoek gedaan bij MSA naar factoren die geassocieerd zijn met nadelige arbeidsuitkomsten of factoren die dit kunnen voorspellen. Hierbij lag de focus vaak op biomedische factoren maar recenter ook op contextuele factoren. Diverse aspecten van contextuele factoren blijven onderbelicht, deels omdat het vrij nieuwe uitdagingen betreffen in onze samenleving. In dit proefschrift werd daarom specifiek aandacht besteed aan enkele contextuele factoren die tot op heden nog onderbelicht waren. Ten eerste waren wij benieuwd of MSA in vergelijking met andere chronische aandoeningen een grotere impact hebben op gezondheids- en werkuitkomsten. Door de veroudering van de samenleving, steeds vroegere diagnosestelling en het optreden van leefstijl-gerelateerde aandoeningen op 
jongere leeftijd is de waarschijnlijkheid groot dat steeds meer mensen één chronische aandoening hebben maar ook een toenemende kans om aan meerdere aandoeningen tegelijkertijd te lijden (multimorbiditeit). Derhalve werd in dit proefschrift ook onderzocht hoe de aanwezigheid van MSA in multimorbiditeit deze uitkomsten beïnvloedt. Ten tweede concentreerden we ons op de rol van een multi-component behandelprogramma met een bio-psycho-sociale benadering, dat snel bij het optreden van verzuim vroeg wordt ingezet met als doel om de werkhervatting te verbeteren. De tegenwoordig gebruikte benadering van patiënten met ziekteverzuim bestaat namelijk vaak uit losse medische of paramedische maatregelen die slechts zelden gecombineerd worden. Tevens wordt vaak het belang van psychosociale aspecten onderschat. Tenslotte richtten wij ons op de relevantie van de economische en culturele context gerelateerd aan het land waar men woont als voorspeller voor nadelige werkuitkomsten. Dit is enerzijds relevant omdat samengevatte, internationale onderzoeksresultaten mogelijk geen betekenisvolle informatie bevatten voor verschillende landen en anderzijds ook omdat de vertaling van onderzoeksresultaten met betrekking tot werkuitkomsten geen rekening houdt met variabelen die karakteristiek zijn voor verschillende landen.

Deel I Gezondheids- en werkuitkomsten van MSA in de context van multimorbiditeit

De meeste studies in de gezondheidszorg concentreren zich op de rol van één centraal staande chronische aandoening bij het onderzoeken van gezondheids- en werkuitkomsten terwijl nog maar weinig bekend is over de invloed van multimorbiditeit en de rol van MSA in de context van multimorbiditeit. Het is aannemelijk dat personen die meer dan één aandoening hebben ook een groter risico op slechte gezondheid en verminderde arbeidsparticipatie hebben. In hoofdstuk 2 bestudeerden wij de gegevens van 8904 personen die deel hadden genomen aan de "Nationale peiling van het bewegingsapparaat 2010" van de Nederlandse Organisatie voor toegepast-natuurwetenschappelijk onderzoek (TNO) op vraag van het Nederlands Reumafonds. Twintig procent van alle deelnemers had een MSA, en 19\% van alle deelnemers had meer dan één aandoening, waarvan ruim de helft (56\%) een MSA als één van de aandoeningen had.

Met behulp van statistische modellen onderzochten wij de impact van de 7 belangrijkste chronische aandoeningen; MSA, psychische aandoeningen, diabetes, kanker, aandoeningen van het darmstelsel, migraine, hartaandoeningen, aandoeningen van de ademwegen en huidaandoeningen op de fysieke en mentale gezondheid gemeten met de 12-item Short Form Survey (SF12), een generiek meetinstrument voor levenskwaliteit. Onze statistische modellen gaven aan met hoeveel punten (B) (op een schaal van 0 tot 100) de score voor fysieke en mentale gezondheid daalde bij aanwezigheid van een van de chronische aandoeningen en de bijbehorende 
betrouwbaarheidsintervallen $(95 \% \mathrm{BI})$ hoe betrouwbaar dit resultaat was. Met een ander model werd de factor $(\operatorname{Exp}(B))$ berekend waarmee in zorgkosten (en bijbehorende betrouwbaarheidsintervallen) toenemen bij de aanwezigheid van een van de chronische ziektes berekend ten opzichte van de kosten voor personen zonder chronische aandoening.

Van de chronische aandoeningen hadden MSA de sterkste impact op fysieke gezondheid. Op de SF12 zorgde dit voor een daling van 8 punten (B -8.37 [95\%BI -8.84; -7.89]). Tevens hadden MSA (na kanker) de grootste impact op zorgkosten die 2 maal hoger waren dan de kosten voor een persoon zonder MSA (Exp (B) 2.27 [95\% BI 2.08; 2.51]). Van alle onderzochte aandoeningen hadden alleen psychische aandoeningen een significante impact op mentale gezondheid. We constateerden ook een lineaire daling in fysieke en mentale gezondheid en een sterke stijging van zorgkosten bij een toenemend aantal aandoeningen. Bij personen met multimorbiditeit waarbij een van de aandoeningen een MSA was, was er sprake van een significant lagere fysieke gezondheid en hogere zorgkosten dan bij personen met multimorbiditeit zonder MSA. Voor de zorgkosten was dit verschil enkel significant bij de vergelijking van de combinatie van MSA met mentale aandoeningen met alle andere combinaties van 2 aandoeningen. Voor de invloed van multimorbiditeit op mentale gezondheid was de aan- of afwezigheid van MSA irrelevant. De resultaten van onze studie geven aanleiding tot discussie over de behoeftes van zorgsystemen in de zorg voor patiënten met multimorbiditeit.

In hoofdstuk 3 beperkten we de populatie uit hoofdstuk 2 tot personen in de werkzame leeftijd (18-65 jaar) die ofwel betaald werk hadden, arbeidsongeschikt waren, werkloos waren of afhankelijk waren van een bijstandsuitkering. In deze steekproef had $17 \%$ een MSA, 14\% had meer dan één aandoening en $61 \%$ van de personen met multimorbiditeit had een MSA. Met onze modellen berekenden wij voor elke chronische ziekte hoe groot de kans (OR en bijbehorende 95\% BI) op ongunstige werkuitkomsten was. Voor de uitkomsten arbeidsongeschiktheid, werkloosheid en afhankelijkheid van een bijstandsuitkering werd deze kans berekend in vergelijking met de uitkomst betaald werk. Voor de uitkomst ziekteverzuim werd de kans berekend ten opzichte van het niet optreden van ziekteverzuim. We toonden aan dat alle chronische aandoeningen verband hielden met het vaker vóórkomen van arbeidsongeschiktheid en afhankelijkheid van een bijstandsuitkering en de meerderheid van aandoeningen ook met de kans op ziekteverzuim gedurende de 12 maanden voorafgaande aan het invullen van de vragenlijst.

Voor personen met mentale aandoeningen was het risico op ongunstige werkuitkomsten stelselmatig het hoogst, namelijk in vergelijking met mensen zonder mentale aandoening 10 keer hoger voor arbeidsongeschiktheid (OR [95\% BI]: 10.54 [7.69; 14.44]), 5 keer hoger voor de afhankelijkheid van een bijstandsuitkering (5.60 [2.77; 11.34]), 3 keer hoger voor werkloosheid 3.03 [1.91; 4.80] en ook 3 keer hoger voor ziekteverzuim $(3.24[2.33 ; 4.52])$. Voor mensen met MSA was het risico op 
arbeidsongeschiktheid, afhankelijkheid van een bijstandsuitkering en ziekteverzuim meer dan twee keer hoger dan voor mensen zonder MSA (arbeidsongeschiktheid: 2.06 [1.56; 2.71]; bijstandsuitkering: 2.15 [1.18; 3.91] en ziekteverzuim: 2.29 [1.92; 2.73]). Dit gold niet voor werkloosheid $(1.35$ [0.94; 1.96]).

Een toenemend aantal aandoeningen was gerelateerd aan een sterke toename van het risico op ongunstige werkuitkomsten. Tevens bleek de aanwezigheid van een MSA een versterkend effect te hebben op de impact van multimorbiditeit op deze uitkomsten. Deze trend bleek het sterkst aanwezig te zijn bij de associatie van multimorbiditeit met ziekteverzuim (kans voor multimorbiditeit met MSA 4.04 [95\% BI 3.07; 5.34] ten opzichte van 2.40 [95\% BI 1.78; 3.24] voor multimorbiditeit zonder MSA).

Eerder was de invloed van verschillende chronische ziektes op arbeidsuitkomsten nooit vergeleken en werd ook weinig aandacht geschonken aan de invloed van het aantal aandoeningen dan wel aanwezigheid van specifieke co-morbiditeiten. Onze resultaten onderstrepen de noodzaak om werkuitkomsten bij chronisch zieke werknemers te verbeteren door middel van gezamenlijke strategieën in de dagelijkse klinische zorg.

Deel II Vroege interventie ter verbetering van werkuitkomsten bij patiënten met MSA

In hoofdstuk 4 evalueerden wij de effecten en kosten van een 4 weken durend intensief multidisciplinair behandelprogramma dat bestond uit diverse componenten inclusief een kuur-component ("Revalidatie en Rëintegratie voor patiënten met reumatische aandoeningen" (3R-programma)). We onderzochten (1) of het programma in vergelijking met de gebruikelijke zorg voordelige effecten had op de werkhervatting en de duur van het ziekteverzuim, (2) in hoeverre de programmakosten de winst in niet verzuimde werkdagen waard waren en (3) in welke mate het programma het zorggebruik van deelnemers zou verminderen en hun gezondheid zou verbeteren. Ter vergelijking met de programma-groep konden wij over een databestand van een grote Nederlandse Arbodienst beschikken waarin werkuitkomsten van werknemers met MSA geregistreerd werden. Personen die deelnamen aan het 3R-programma hervatten hun werk gemiddeld 17 dagen eerder wat in een gemiddelde vermindering van €4223 in productiviteitskosten resulteerde vergeleken met de groep die gebruikelijke zorg ontving. Verder was in de 3R-groep ook de kans op werkhervatting na het 4 weken durende programma significant hoger dan voor de groep met gebruikelijke zorg (hazard ratio (HR) 1.60 [95\% $\mathrm{BI} 1.22-2.11]$ ). De kosten van het 3R-programma waren echter substantieel en liepen op tot $€ 6,172$ per patiënt per cyclus van 4 weken waarbij maar liefst $26 \%$ van dit bedrag te wijten waren aan de hotelkosten. Zo kan dan uiteindelijk berekend worden dat de behandelkosten €356 zijn per verzuimdag die kan worden voorkomen. Noemenswaardig is dat de kosten door zorggebruik in de 6 maanden na het programma $€ 775$ lager waren dan in de 6 maanden voorafgaande aan het programma. Ook werden significante gezondheidsverbeteringen gemeten met 
een gemiddelde EuroQol 5 Dimension (EQ-5D) utiliteit van $0.57( \pm 0.26)$ aan het begin van het programma en $0.70( \pm 0.22) 6$ maanden na het programma $(p<0.01)$. De gemiddelde EuroQol Visual Analogue Scale (VAS) score op deze tijdstippen was respectievelijk 56.1 ( \pm 15.1 ) en $69.4( \pm 13.6)$ ( $p<0.01)$.

Onze studie geeft inzicht in de kosten en baten van een holistisch werkhervattingsprogramma voor werknemers met MSA. De resultaten kunnen relevant zijn in de discussie over de optimalisatie van de gezondheidszorg.

Deel III Invloed van economische en culturele context gerelateerd aan het land waar men woont op werkuitkomsten en validiteit van meetinstrumenten voor presenteeïsme bij patiënten met reumatoïde artritis

In hoofdstuk 5 onderzochten wij de bijdrage van het land waar men woont en van diverse land- karakteristieken (waaronder het bruto nationaal product (BNP), een index voor menselijke ontwikkeling (Human Development Index=HDI), werkloosheidspercentages, uitgaves voor sociale zekerheid of geografische ligging) aan werk-status, ziekteverzuim en presenteeïsme (productievermindering op het werk) bij patiënten met reumatoïde artritis (RA)). Hiervoor gebruikten wij data van een studie bij 3920 patiënten uit 17 landen wereldwijd die deel hadden genomen aan de COMOrbidities in Rheumatoid Arthritis international study (COMORA)-studie en van wie informatie bekend was over demografie, ziekte-karakteristieken en werk uitkomsten. Tussen de verschillende landen vonden wij grote verschillen in werkuitkomsten, en deze konden niet toegeschreven worden aan verschillen in demografische en klinische karakteristieken. In vergelijking met de Verenigde Staten, het land met hoogste tewerkstelling in een betaalde baan, hadden patiënten met RA in Marokko de laagste kans op betaald werk (OR 0.2; [95\%B। 0.1;0.3] en in vergelijking met Japan (het land met het minste ziekteverzuim) de grootse kans op ziekteverzuim (OR 12.6 [95\%BI 4.5;35.9]). De kans op presenteeïsme was het hoogst in Taiwan (OR 13.8[95\%BI 5.9;32.0] vergeleken met Venezuela waar presenteeïsme het laagst was).

Wanneer we de invloed van land probeerden ter verklaren, zagen we dat een hoger BNP gerelateerd was aan een hogere kans op betaald werk (OR 0.66 [95\%BI 0.54;0.80]) en minder kans op ziekteverzuim (OR 2.68 [95\%BI 1.91;3.76]). Ook een betere HDI en lagere nationale werkloosheid waren geassocieerd aan hogere kansen op betaald werk en een lagere kans op ziekteverzuim. De richting van de associatie veranderde echter op paradoxale wijze toen presenteeïsme de uitkomst was: een hoger BNP en HDI waren gerelateerd aan meer presenteeïsme. Na het groeperen van landen aan de hand van hun geografische ligging toonden wij dat patiënten in landen in Afrika, Latijns Amerika, Azië en Europa minder kans hadden op betaald werk dan patiënten in Noord Amerika. Patiënten in Europa, Afrika en Latijns Amerika hadden een significant hogere kans op ziekteverzuim dan patiënten in Aziatische landen. Landen in Europa, Azië en Noord Amerika hadden significant meer kans op presenteeïsme dan patiënten in Latijns Amerikaanse landen. 
We onderzochten ook hoe goed factoren die kenmerken van het land weergeven, de variatie in de verschillende werkuitkomsten verklaarden. Hoewel de aard van de gebruikte modellen enkel een indirecte vergelijking toeliet leken modellen met de HDI de uitkomsten "betaald werk" en 'presenteeïsme" het beste te verklaren, terwijl "ziekteverzuim" het beste verklaard leek te worden door modellen met het BNP. Onze resultaten suggereren vooral dat internationaal onderzoek naar werkuitkomsten bij patiënten met RA rekening moet houden met land-specifieke verschillen. Resultaten zouden idealiter minimaal op het niveau van het geografische gebied gepresenteerd worden. Verder is het van belang dat arbeidsgerelateerde zorg of hervormingen van zorg voor patiënten met RA in overeenstemming zijn met de nationale structuren en behoeftes. Het laatste vergt mogelijk de herbeoordeling van internationaal bewijs voor effectieve werk-interventies in een nationale context.

In hoofdstuk 6 exploreerden wij de conceptuele interpretatie van 5 voorgeselecteerde, door de patiënt zelf ingevulde 'globale' (bestaande uit een enkele vraag) meetinstrumenten voor presenteeïsme bij werkende personen met inflammatoire of degeneratieve reumatische aandoeningen in verschillende landen. De gegevens uit het voorgaande onderzoek suggereren immers dat we meer aandacht moeten geven aan internationale vergelijkingen in de gezondheidszorg, en dat dit ook inhoudt dat we kijken naar de vragenlijsten waarmee we de impact van werk op werkvermogen beoordelen. De geselecteerde instrumenten die gescoord moesten worden op een schaal van 0 tot 10 waren: de Work Productivity and Activity Impairment Questionnaire (WPAI), de Work Productivity Scale - Rheumatoid Arthritis (WPS-RA), de Work Ability Index (WAI), de Quality \& Quantity vragenlijst (QQ) en de WHO Health \& Performance Questionnaire (HPQ). In elk deelnemend land, te weten Groot-Brittannië, Nederland, Frankrijk, Italië, Zweden, Roemenië en Canada, werden 10 deelnemers geworven op de polikliniek Reumatologie. Deductieve, thematische analyses werden uitgevoerd die gebaseerd waren op vooraf vastgestelde thema's voor alle attributen van de globale meetinstrumenten, namelijk het construct, de genoemde referenties, de herinnerperiode en de verwijzing naar de ziekte (Tabel 1).

We vonden dat de interpretatie van het bevraagde construct in de verschillende landen over het algemeen vergelijkbaar was. Een uitzondering vormde het gebruik van het woord "interference", in het Nederlands vertaalt naar "belemmering" van de WPS-RA, welke door deelnemers uit Roemenië niet goed werd begrepen. Verder interpreteerden deelnemers uit Roemenië en Zweden het woord "performance" (in het Nederlands "prestatie(s)") anders dan deelnemers uit andere landen. Zij gaven aan dat deze term eerder gerelateerd was aan competitie (zoals bij voorbeeld bij het sporten) dan aan werken. Moeilijkheden die niet direct toe te schrijven waren aan het land van herkomst werden ondervonden bij de herinnerperiode "current" (in het Nederlands "huidige") van de WAI en de "compared to normal" (in het Nederlands "vergeleken met een normale werkdag") referentie van de QQ. Hoewel de WPAI uiteindelijk door $29 \%$ van de deelnemers geselecteerd werd als instrument dat het best 
de impact van de ziekte op arbeidsvermogen weerspiegeld, zorgde de omgekeerde scoring ( $0=$ positief; $10=$ negatief) in vergelijking met de andere meetinstrumenten voor verwarring. De HPQ werd laag beoordeeld omdat deelnemers herhaaldelijk aangaven het onprettig te vinden om zichzelf te vergelijken met hun collegae en omdat de herinnerperiode van 1-2 jaar als te lang ervaren werd.

Onze studie toonde dat de validiteit van meetinstrumenten die productiviteitsvermindering op het werk meten deels afhankelijk is van de culturele en linguïstische gewoontes van patiënten.

Tabel 1 Construct, herinnerperiode, referenties en verwijzing naar ziekte per meetinstrument.

\begin{tabular}{|c|c|c|c|c|}
\hline Meetinstrument & Construct & Herinnerperiode & Referenties & $\begin{array}{l}\text { Verwijzing naar } \\
\text { ziekte }\end{array}$ \\
\hline WPAI & $\begin{array}{l}\text { Productiviteit } \\
\text { (additionele termen: } \\
\text { bereikte, soort werk, zo } \\
\text { zorgvuldig als } \\
\text { gewoonlijk, } \\
\text { hoeveelheid werk) }\end{array}$ & 7 dagen & n.v.t. & $\begin{array}{l}\text { ziektespecifiek } \\
\text { (reumatoïde artritis, } \\
\text { artritis psoriatica, } \\
\text { ziekte van } \\
\text { Bechterew, artrose) }\end{array}$ \\
\hline$Q Q$ & kwaliteit \& kwantiteit & vandaag & $\begin{array}{l}\text { ten opzichte van } \\
\text { normaal }\end{array}$ & n.v.t. \\
\hline $\mathrm{HPQ}$ & prestaties & $\begin{array}{l}1 \text { of } 2 \text { jaar (vraag B), } 4 \\
\text { weken (vraag C) }\end{array}$ & $\begin{array}{l}\text { De prestatie van } \\
\text { collega's (vraag A) }\end{array}$ & n.v.t. \\
\hline WAI & werkvermogen & op dit moment & $\begin{array}{l}\text { werkvermogen in } \\
\text { beste periode }\end{array}$ & n.v.t. \\
\hline WPS-RA & $\begin{array}{l}\text { productiviteit \& } \\
\text { belemmering }\end{array}$ & afgelopen maand & n.v.t. & artritis \\
\hline
\end{tabular}

Work Productivity and Activity Impairment Questionnaire (WPAI), Work Productivity Scale - Rheumatoid Arthritis (WPS-RA), Work Ability Index (WAI), Quality \& Quantity vragenlijst (QQ), WHO Health \& Performance Questionnaire (HPQ)

In hoofdstuk 7 onderzochten wij de vergelijkende validiteit van de meetinstrumenten uit hoofdstuk 6 . Wij vergeleken de test-hertest betrouwbaarheid en onderzochten de correlaties (samenhang) tussen de scores van de verschillende meetinstrumenten en tussen de scores en het algehele welbevinden van de deelnemers. De test-hertest betrouwbaarheid is een kenmerk van de kwaliteit van een meetinstrument. Hierbij worden de metingen van 2 momenten met elkaar vergeleken. Een hogere mate aan overeenkomst tussen de scores van de verschillende meetmomenten geeft een hogere mate van betrouwbaarheid weer. We lieten zien dat de scores die deelnemers hadden aangegeven bij de WPS-RA, WAI, QQ en WPAl tijdens het eerste meetmoment (baseline) op acceptabele wijze overeen kwamen met de scores 2 weken later (intraclass correlation coefficient (ICC) >0.74). De laagste overeenkomst werd gevonden bij de HPQ (ICC=0.59), die vraagt naar algehele 'prestaties' gedurende de afgelopen 4 weken (28 dagen). De correlaties tussen de verschillende meet- 
instrumenten waren meestal matig met uitzondering van de vergelijking van de WPSRA met de WPAI (Spearman's Rho r=0.88). Deze correlatie is waarschijnlijk sterker omdat beide instrumenten vragen naar "productiviteit" ook al is de herinnerperiode bij de WPAI 7 dagen en bij de WPS-RA 1 maand. Correlaties tussen de meetinstrumenten en het algehele welbevinden waren laag tot matig ( $r=-0.44(Q Q)$ to $r=-0.66$ (WPS-RA)). Onze resultaten suggereren dat de HPQ minder valide is en dat de WPS-RA en WPAI grotendeels uitwisselbaar zijn. De herinnerperiode kan dan bepalend zijn voor de keuze voor een van de twee instrumenten. Het is echter ook niet onbelangrijk om hierbij de voorkeur van de patiënt mee te nemen die, zoals getoond in hoofdstuk 6, uitgaat naar de WPAI. In deze studie was het door het geringe aantal patiënten niet mogelijk om het onderscheid in validiteit tussen landen te bestuderen. $\mathrm{Er}$ is echter reeds en vervolgstudie gestart die een groter aantal patiënten uit verschillende landen omvat.

In hoofdstuk 8 en 9 zijn de bevindingen uit dit proefschrift samengevat en bediscussieerd.

De toename in het aantal mensen met méér dan één chronische aandoening (multimorbiditeit) vraagt aandacht voor de specifieke impact van multimorbiditeit op gezondheid, en de inrichting van gezondheidszorg en sociale zekerheidssystemen. Op dit ogenblik is de klinische zorg nog niet aangepast aan de behoeftes van patiënten met meerdere chronische aandoeningen. Gezondheidsopleidingen en systemen zijn nog steeds georganiseerd volgens een benadering die één ziekte centraal stelt. Er zijn veel kansen voor de verbetering van de zorg voor patiënten met een of meer chronische aandoeningen. Dit proefschrift toont aan dat alle chronische aandoeningen, maar veel meer nog multimorbiditeit, geassocieerd zijn met negatieve werk-uitkomsten zoals arbeidsongeschiktheid, werkloosheid, afhankelijkheid van uitkeringen en ziekteverzuim. Dit geeft de mogelijkheid voor een gemeenschappelijke aanpak voor arbeidsgerichtte zorg, mede gezien eerder onderzoek aantoont dat risico factoren voor negatieve werkuitkomsten voor de verschillende aandoeningen grotendeels generiek zijn. De huidige kennis met betrekking tot preventie van negatieve werkuitkomsten blijft onvolledig gezien de focus vaak op een specifieke ziekte ligt en de meer generieke functionele problemen van deze ziektes onvoldoende aandacht krijgen. Bovendien maakten we duidelijk dat elke extra aandoening de kans op moeilijkheden in het arbeidsproces sterk verhoogd. De efficiëntie van innovatieve interventies die zich richten op het verbeteren van arbeidsparticipatie zou vergroot kunnen worden door ziekte overschrijdende aandacht, gericht op problemen en restricties. Een eerste stap zou hierbij de introductie van een screening-tool zijn, ontworpen om beperkingen in arbeidsparticipatie aan het licht te brengen gedurende de reguliere, klinische spreekuren. Dit instrument zou tevens aangevuld moeten worden door een tool voor type advies of verwijzing gebaseerd op de specifieke belemmeringen die het screeningstool oppikt. Bij deze screening moet multimorbiditeit de nodige aandacht krijgen als mogelijke risicofactor. Hierbij is het eveneens belangrijk om te weten dat de aanwezigheid van MSA en eventueel ook van mentale aandoeningen tot een toename 
van het risico op negatieve werkuitkomsten kan leiden bij personen met meer dan een aandoening. De inzet van zulke screenings- en verwijstools binnen de zorg voor patiënten met chronische aandoeningen vergt dat gezondheidsprofessionals ook leren klinisch te redeneren rondom arbeid als een gezondheid gerelateerde uitkomst.

Een nieuwe behandelmogelijkheid die in dit proefschrift geëvalueerd werd is het vroeg aanbieden van een multidisciplinair behandelprogramma met een ontspanningscomponent en focus op arbeid bij mensen met MSA. Het programma richt zich op de fysieke en mentale eisen in relatie tot de draagkracht van het individu en de thuissituatie. Een uniek kenmerk van het 3R-programma is de erkenning dat ook stressreductie door fysieke ontspanning en door het leren van coping-strategieën voor beperkingen, werkgerelateerde stress factoren en de uitdagingen van de werk-privé balans een bijdrage kan leveren aan arbeidsparticipatie. Door het ontwerp van de studie is het echter niet mogelijk om te achterhalen welke componenten bijgedragen hebben aan de gevonden gunstige effecten. Hoewel het $3 R$ programma geëvalueerd werd voor MSA lijken de componenten van het programma relevant voor arbeidsparticipatie van personen met diverse chronische aandoeningen. Fysiotherapie is bijvoorbeeld vooral gericht op het verbeteren van het fysieke functioneren en de algehele conditie en is daarom in principe ook geschikt voor andere aandoeningen. In deze context is het feit dat de positieve resultaten van het 3R-programma onafhankelijk waren van het type MSA noemenswaardig. Desondanks is verder onderzoek noodzakelijk om te achterhalen of deze interventie even effectief zou zijn bij patiënten met andere chronische aandoeningen.

De positieve effecten van het 3R-programma waren mogelijk deels toe te schrijven aan het vroege ingrijpen in het proces van ziekteverzuim. Het is echter de vraag of een 4-weeks, hoog-intensief-programma onmiddellijk aangeboden moet worden aan personen die slechts enkele dagen verzuimen, zeker gezien de hoge kosten van het programma en de 4 weken durende afwezigheid op het werk. De bovengenoemde screening van personen met (risico op) negatieve werkuitkomsten kan ook helpen bij een genuanceerde selectie van deelnemers waarbij op basis van individuele risicofactoren een eenvoudige dan wel complexere intensievere begeleiding aangeboden wordt. Dit kan zeer waarschijnlijk de kosteneffectiviteit verbeteren en zal vooral kosten besparen voor het totale budget dat nodig zou zijn om op grote schaal intensieve begeleiding aan te bieden. Tot slot is het bovendien zeer aannemelijk dat bij grotere volumes van dit type zorg ook de prijs van de behandeling gunstiger zal worden.

De toepasbaarheid van het 3R-programma in andere landen dan Nederland is potentieel uitdagend gezien de uitvoerbaarheid van het programma grotendeels afhankelijk is van a) de mogelijkheid van zorgsystemen om patiënten vroeg in de periode van ziekteverzuim waar te nemen en b) de beschikbaarheid van financiële middelen voor abeidsinterventies. Financiële middelen kunnen theoretisch beschikbaar gesteld worden door werkgevers, verzekeraars of overheden. Hierbij moet echter ook 
gedacht worden aan de impact van het land van verblijf en daaraan gerelateerde culturele en economische factoren op arbeidsparticipatie. In ons internationaal onderzoek toonden wij grote verschillen in arbeidsparticipatie bij patiënten met RA tussen landen en systemen, en dit was onafhankelijk van de ernst van de ziekte. Daarom zijn observationele en interventionele studies naar arbeidsparticipatie in principe niet generaliseerbaar en kunnen enkel als dusdanig worden beschouwd als zij zijn onderzocht in de context van multinationale studies die rekening houden met het land van verblijf of systeem specifieke factoren. Onze resultaten suggereren dat BNP of HDI geschikt zouden zijn voor de classificatie van landen in dergelijke studies. De exacte werkingsmechanismen van de componenten van BNP en dus ook HDI blijven onduidelijk. Het zijn grove maten die onvoldoende inzicht geven in de oorzaak van de verschillen in werkuitkomsten tussen landen. Desondanks verduidelijken ze de beperkingen in de overdraagbaarheid van studieresultaten van werkgerelateerde studies uit verschillende landen evenals het belang van adequate reglementen vanuit het systeem.

Een bijzonder interessante uitkomst van onze studie betreffende de impact van land en systeem factoren op werk uitkomsten was de paradox dat personen in landen met een lager BNP en HDI wel minder kans hadden om betaald te werken en meer kans hadden op ziekteverzuim echter een lagere kans hadden op productiviteitsvermindering op het werk onafhankelijk van de ernst van de ziekte. Mogelijke verklaringen voor deze paradox is de hoge werkdruk in de "rijkere" landen maar ook culturele verschillen in de interpretatie van de studievraag. Belangrijk uitgangspunt is dat we ook aantoonden dat de WPAI, die gebruikt was voor de dataverzameling van arbeidsuitkomsten, goed en vergelijkbaar begrepen te worden in verschillende landen. Een waarschijnlijkere verklaring voor de paradox is daarom dat er in landen met een lager inkomen meer aandacht gegeven moet worden aan absenteïsme terwijl in landen met een hoger inkomen meer aandacht gegeven moet worden aan presenteeïsme. Bij de aanpak van presenteeïsme is het verminderen van de werkdruk van personen met chronische aandoeningen van uiterst groot belang, vooral gezien presenteeïsme reeds eerder geïdentificeerd werd als voorspellende factor voor verzuim.

\section{Conclusie}

Dit proefschrift concentreerde zich op arbeidsparticipatie als relevante uitkomstmaat bij de zorg voor patiënten met MSA. We toonden de fundamentele rol van de persoonlijke context (multimorbiditeit) en de omgevingscontext (re-integratie programma, land van verblijf) in relatie tot werkuitkomsten aan. Met de toenemende mate van erkenning voor deze rol is een van de toekomstige uitdagingen een herstructurering van het gezondheidszorgsysteem waarin de contextuele behoeftes in verband met participatie even belangrijk zijn als de behoeftes die voortkomen uit ziektegerelateerde symptomen. Hoewel wij toonden dat de variatie in arbeids- 
participatie voor een groot deel bepaald wordt door land-specifieke culturele en economische factoren, suggereren de gegevens ook dat er behoefte is aan een efficiënter gezondheidszorgsysteem met een holistische en probleemgestuurde aanpak en met bijzondere aandacht voor arbeidsparticipatie. De concrete stappen die nodig zijn voor deze transitie hebben aandacht nodig en behoeven verder onderzoek. 




\section{Valorisation addendum}

\section{Background and main findings}

Chronic diseases are associated with unfavorable health outcomes, high healthcare costs and adverse work outcomes. ${ }^{1,2}$ In the Netherlands, approximately $31 \%$ of the general population reports at least one chronic condition ${ }^{3}$ and this proportion is even rising due to an aging population, lifestyle-related diseases at a younger age, and earlier diagnoses. ${ }^{4,5}$ Therefore, the co-occurrence of chronic diseases, also referred to as multimorbidity, is increasing. The growing number of individuals with one or more chronic diseases is particularly concerning in the context of traditional job-markets. In addition to the limited number of available jobs, the pressure on the individual to work longer and more efficiently is higher than ever, threatening persons with chronic diseases who are already at increased risk of adverse work outcome, additionally.

This thesis emphasizes that the risk for adverse work outcome is independent of the type of disease. Yet, when accounting for the prevalence, the societal burden of musculoskeletal diseases (MSKD) and mental diseases is larger. More-over, comparable adverse work outcome across diseases is observed not only for sick leave and workdisability, but also for economic unemployment and being dependent of a living allowance. Further, while each additional comorbidity increases the risk for adverse health and work outcome, this impact is stronger when the additional disease is a MSKD. ${ }^{1,2}$ Importantly, a reduction of the duration of sick leave is seen when an intensive, multidisciplinary treatment program aimed at work resumption is followed by patients on recent sick leave due to MSKD when compared to usual care. ${ }^{6}$ Finally, we highlight that aggregated results on work outcomes from international studies cannot be transferred to individual countries. Indeed, country of residence, defining the wider economic and social security context of a person with a chronic disease, contributed relevantly to the work outcome of patients with MSKD. ${ }^{7}$ On the same line, translations of existing English single global questions on impairments in work ability at the job (presenteeism), results interpretational problems for some languages. ${ }^{8}$

\section{Contribution of this thesis to society}

This thesis adds evidence to a broader range of national and international initiatives on worker participation in MSKD but also holds relevant evidence for other diseases and medical specialists. In the Netherlands, the Dutch Society of Rheumatology (Nederlandse Vereniging voor Reumatologie; NVR) published a guideline 'Worker Participation and Rheumatoid Arthritis, ${ }^{9}$ which provides a reference frame of evidence to support work participation in patients with rheumatoid arthritis (RA). This guideline proposes to include (screening) questions about the current work ability of RA-patients at each medical encounter and to integrate this in the individual patient's treatment 
plan. During my thesis, I was involved in Taget@Work, a project within the Workgroup 'Economic aspects of Rheumatic Diseases' of the NVR aims to implement and add new evidence to the Dutch Guideline. Coordinated and supported by the "Centrum Werk Gezondheid", Target@Work contributes to the latter by providing tools for rheumatologists and nurse specialists how to retrieve information on work ability during the clinical encounter, how to select patients wih possible adverse work outcomes and how to integrate this knowledge in a treatment plan. Personally, I contributed to an E-learning program which contains several modules and is offered to rheumatologists together with a team session. However, even after training of rheumatology teams based on the E-learning followed by an interactive session, work ability was only addressed in $47 \%$ of working patients during the routine clinical encounter. ${ }^{10}$ Participating rheumatologists and specialist nurses revealed they consider work outcome an important treatment goal, but also identified barriers to the implementation of the screening tool, including time and limited skills, but also lacking evidence on (cost-) effectiveness of some situations related to the identification and management of work restrictions.

This thesis contributed to possible solutions. First, we identified several valid single item and patient self-reported global instruments that measures presenteeism (i.e. atwork productivity loss). Scoring is not time-consuming and can even be included as part of the preparations that patients are advised to undertake before coming to the clinic. The use of validated instruments in clinical practice as part of the electronic patient file allows not only to follow-up work ability of the individual patient but also the performance of the team about efforts to include work ability in the management plan. Next, as multimorbidity was shown to result in a steep increase in risk for sick leave and work disability its presence could act as an additional warning sign for long-term sick leave and future work disability. Finally, the multidisciplinary care treatment-program (RRR) evaluated in this thesis can be seen as a new treatment possibility for patients on recent sick leave. The evaluation of the costs and effects in a real life setting could provide additional insight into a better selection of patients that benefit most from such an intensive program. Cost might be substantially reduced when the intervention is offered only to a selected group of patients with more severe impairments in their work ability but also by offering the program in a less exclusive environment, resulting in lower prices for lodging and catering. An important issue that needs to be addressed is whether such interventions are part of medical care, and therefor paid by the health insurance OR the (financial) responsibility of the employer. In this context, it is also relevant to discuss whether such programs could be commercialized by private partners. While healthcare products are increasingly turned into businesses for profit, frameworks should be available to ensure care is provided to the intended (complex) populations, and monitoring of quality of care and health effects should be in place. Value and not volume should drive such initiatives. 
As this thesis showed that all chronic diseases are related to adverse work outcomes, there is a need for several medical disciplines to address work outcomes in daily care. The activities conducted in the field of rheumatology may serve as an example.

\section{Healthy work for persons with (and without) chronic disease}

We realize that physicians and nurses may experience a conflict of interest, when they doubt whether maintaining their work is in fact beneficial for patients. It is indeed questionable whether increase in work productivity should be a goal on its own. While 'work' might be therapeutic in some circumstances, 'sick leave;' is definitely required to enable the individual to get better from an episode of illness and regain strength. We should strive to maintain symbiotic work situations by keeping those persons at work that would otherwise face social isolation through sickness and who are likely to be able to contribute relevantly to society. While much evidence is available showing which disease characteristics and contextual factors have an adverse impact on productivity and labour force participation, there is almost no data indicating which work-related factors have an invigorating effect on disease severity. However, such factors require attention and matching the workers work load and work ability should be considered. The issue of 'suitable work' seems relevant and while it can be partly covered by the domains of medical research, availability of such jobs it not within reach of the healthcare system itself. Moreover, work-related factors that amplify the negative impact of disease on health, are likely also 'unhealthy' for workers without chronic disease. Creating universal healthy workplaces that allow persons with or without chronic disease to maintain optimal and enduring functioning and health throughout their working career should be the ultimate goal: collaboration of researchers, policy makers and companies is needed to achieve a better work-life balance and improve workplace facilities. Even without chronic disease, the balance between the right and the duty to participate in labor force, and possibilities to adopt new and more individualized ways of working require a discussion in a larger public setting. 


\section{References}

1. van der Zee-Neuen A, Putrik P, Ramiro S, Keszei A, de Bie R, Chorus A, et al. Impact of Chronic Diseases and Multimorbidity on Health and Health Care Costs: The Additional Role of Musculoskeletal Disorders. Arthritis Care Res 2016;68(12):1823-31.

2. van der Zee-Neuen A, Putrik P, Ramiro S, Keszei A, de Bie R, Chorus A, et al. Work outcome in persons with musculoskeletal diseases: comparison with other chronic diseases \& the role of musculoskeletal diseases in multimorbidity. BMC Musculoskelet Disord 2017;18(1):10.

3. Centraal Bureau voor de Statistiek DHH. Gezondheid aandoeningen beperkingen; persoonskenmerken. 2012

4. van den Akker M, Buntinx F, Metsemakers JF, Roos S, Knottnerus JA. Multimorbidity in general practice: prevalence, incidence, and determinants of co-occurring chronic and recurrent diseases. J Clin Epidemiol 1998;51(5):367-75.

5. Starfield B. Challenges to primary care from co- and multi-morbidity. Prim Health Care Res Dev. 2011;12(1):1-2.

6. van der Zee-Neuen A, van der Linden S, Keszei A, de Bie R, Wolter N, Rodenburg P, et al. Effects and costs of an intensive return to work program for patients with recent sick leave due to musculoskeletal disorders. evaluation report. Musculoskelet Disord 2017;18(1):10.

7. van der Zee-Neuen A, Putrik P, Ramiro S, Keszei A, Hmamouchi I, Dougados M, et al. Large country differences in work outcomes in patients with RA - an analysis in the multinational study COMORA. 2017.

8. Leggett S, van der Zee-Neuen A, Boonen A, Beaton D, Bojinca M, Bosworth A, et al. Content validity of global measures for at-work productivity in patients with rheumatic diseases: an international qualitative study. Rheumatology 2016;55(8):1364-73.

9. Verzekeringsgeneeskunde NVv. NVGG richtlijn "Reumatoïde Artritis en participatie in arbeid" 2015.

10. Baart TRP. Werk als behandeldoel- Eindmeting bij patiënten in de polikliniek van medische centraTarget@Work. 2015. 



\section{Dankwoord}

Dit proefschrift is niet het resultaat van de inspanningen van een enkeling maar van het werk en de steun van velen. ledereen die op wat voor manier dan ook heeft bijgedragen aan de totstandkoming van dit proefschrift en het bijzondere en leerzame traject wat hieraan voorafging wil ik hierbij van harte bedanken.

In het bijzonder wil ik de leden van mijn promotieteam, prof. dr. A.E.R.C.H. Boonen, prof. dr. J.M.J.P. van der Linden en prof. dr. R.A. de Bie bedanken.

De Duitse naam voor een vrouwelijke promotor is "Doktor-mutter". Deze term is zeer zeker van toepassing op jou, Annelies. Hoewel ik ontzettend veel van jou heb mogen leren was je beslist niet uitsluitend gericht op wetenschappelijke correctheid en een leerzame periode. Je wist mij te motiveren als ik het even zwaar had en had altijd veel lof als ik een groot of klein obstakel had overwonnen. Maar juist ook jouw betrokkenheid en interesse in mij als persoon, mijn gezin en hobbies maakte de tijd met jou plezierig.

De Amerikaanse schrijver en humorist Mark Twain zei ooit "The really great people make you feel that you, too, can become great". Sjef, toen ik begin 2011 bij u op sollicitatiegesprek mocht komen wist u mij meteen dit gevoel te geven en heeft u mij de kans gegeven om aan mijn eigen onderzoeks-reis te beginnen. Ik wil u hartelijk danken voor uw vertrouwen en onze leerzame gesprekken maar ook voor uw demonstratie stijgijzer-lopen gedurende een van onze gezamenlijke presentaties (:) Aan het begin van mijn promotietraject leek de wereld van het onderzoek mijlenver verwijderd van mijn bekende achtergrond in de fysiotherapie. Daar kwam verandering in toen jij als promotor bij ons onderzoeksteam kwam, Rob. Je wist met zo een gemak over sample-size berekeningen, statistische modellen en het schrijven van artikelen te praten dat ik begon te geloven dat het allemaal wel meeviel. Het was juist deze mindset die mij heeft geholpen om de dingen vanuit een ander perspectief te zien en nieuwe uitdagingen met plezier aan te pakken.

Het contact met mijn onderzoeksteam heb ik te danken aan Nico Wolter. Nico, jij hebt voor mij de deur geopend voor de grote uitdagingen en kansen die mijn promotietraject rijk was. Ook heb je voor talloze kansen om te netwerken gezorgd en wist je altijd een positief woord over mij te zeggen. Bedankt voor alles. Door jou heb ik ook contact gehad met alle partijen die betrokken waren bij het pilot-project van de stichting RRR. In het bijzonder wil ik Stefan Kleintjens, Mark Engelman, Lars Bogaert, Bert Corneth en Hans Coenen bedanken voor jullie hulp en de interessante en verrijkende gesprekken en overleggen. 
During my Phd-trajectory I had the pleasure of being part of the OMERACT workerproductivity group. Many thanks to all members of this group but especially to Suzanne Verstappen and Sarah Leggett with whom I collaborated closely. Suzanne, thank you for your help and support during the cognitive debriefing project but also for our informal conversations in Manchester when the days' work was done. Sarah, thank you for being you, really. It was such a pleasure to work with you. I feel like we were almost always on the same line without having to waste too many words on it. I wish you all the best for your future, for your work AND your private life.

Mijn dank gaat ook uit naar de coauteurs van de verschillende hoofdstukken van dit boek. In het bijzonder wil ik Polina Putrik, Sofia Ramiro en Andras Keszei bedanken voor hun intensieve betrokkenheid bij de totstandkoming van diverse hoofdstukken. Astrid Chorus wil ik bedanken voor haar bereidheid om de data van de Nationale Peiling Bewegingsapparaat 2010 met ons te delen maar ook voor haar bijdrage aan de gerelateerde artikelen. Special thanks to the members of the COMORA study who allowed us to make use of their data and who contributed to the improvement of the related manuscript.

Mijn tijd als promovenda werd in hoge mate positief beïnvloed door mijn collega promovendi op de afdeling reumatologie. Wat hebben wij veel geleerd van elkaar maar vooral, wat hebben we veel gelachen en ongein uitgehaald. Simon, Andrea, Carmen, Ivette, Lieke, José, Michiel, Mayke, Joost, Bart, Ellis en Casper. Door jullie werd mijn Phd-traject onvergetelijk, om niet te zeggen epic. :-

In het bijzonder wil ik uiteraard mijn twee roomies en paranimfen bedanken, Simon en Andrea.

Simon, toen ik jou voor het eerst tegenkwam op de gang op de UNS 50 en hoorde dat wij collega's waren wist ik dat het wel goed zou komen met mijn Phd. Na onze verhuizing na UNS 40- west werd het alleen maar beter en gezelliger. Bedankt voor jouw hulp bij teveel dingen om hier op te noemen. Bedankt ook voor de specialistenoverleggen, de HB-momenten en je luisterend oor wanneer dat nodig was. You're my brother from another mother! :) Andrea, je kwam pas later bij ons op de kamer zitten. Maar wat een geluk dat Simon jou wist te strikken. Bedankt voor alle toffe gesprekken over van alles, onze "trainings-momenten", je vaardigheid om dingen voor mij te relativeren en de Oostenrijkse buien. Bedankt ook voor je hulp bij de valorisatie en Nederlandse samenvatting van dit proefschrift. Ik ben blij en trots om jullie beiden tijdens de verdediging van mijn proefschrift naast mij te hebben staan.

Ook wil ik Joop Vugs bedanken, de kunstenaar die de omslag van dit boek heeft ontworpen. Joop, ik weet welke mentale en fysieke inspanningen het van jou heeft 
gevraagd om dit voor mij te doen. Ik ben je ontzettend dankbaar hiervoor en ben trots om jouw werk op mijn proefschrift vereeuwigd te zien.

Mijn lieve vrienden en familie wil ik bedanken voor de nodige afleiding en zo nu en dan ook het bieden van een nieuwe kijk op mijn onderzoeksresultaten.

„Man zündet auch nicht ein Licht an und setzt es unter einen Scheffel, sondern auf einen Leuchter; so leuchtet es allen, die im Hause sind. So lass Dein Licht leuchten vor den Leuten, damit sie Deine guten Werke sehen(Matthäus 5,14-16). "Liebe Mama und Papa. Mit diesem Taufspruch habt ihr schon damals euer Vertrauen in mich gezeigt. In all den Jahren habt ihr nie gezweifelt, dass ich das was ich will auch erreichen kann. Euer Stolz auf mich und das Glück das ihr mit mir teilt wann immer ich erfolgreich bin oder das Leben mir zulacht, war und ist immer ein großer Teil meines Antriebs. Dieses Buch ist geschrieben aus gerade diesem Antrieb und wäre da nicht das Fundament bestehend aus Liebe, Vertrauen und Zuversicht auf dem ich bauen darf und das mich seit meiner Geburt begleitet dann wäre es nie geschrieben. Danke, dass es euch gibt und dass ihr immer an mich glaubt!

Lieve Martijn, je bent mijn rots in de branding, je helpt mij letterlijk en figuurlijk de hoogste bergen te beklimmen. Zonder jouw steun en begrip gedurende de afgelopen jaren had ik dit proefschrift nooit kunnen afronden. Je vertrouwen in mij geeft me moed en laat mij ook in mijn eigen vaardigheden geloven. Ik ben er zo trots op om jou mijn man te mogen noemen. Martijn, bedankt dat je in mijn leven bent en dat jij, Finley onze dagen samen nog mooier maakt. 




\section{Curriculum Vitae}

Antje van der Zee-Neuen werd op 6 februari 1984 geboren in het Duitse Mönchengladbach. Na het behalen van haar diploma aan het Mathematisch Naturwissenschaftliches Gymnasium Mönchengladbach in 2003, verhuisde zij naar Heerlen voor de opleiding Fysiotherapie. Nadat zij deze in 2007 succesvol had afgerond verhuisde zij naar Zwitserland om als fysiotherapeute te werken bij Physioteam Zeni in Heerbrug en de praktijk Zach in Urnäsch. In 2008 begon zij aan de beroepsbegeleidende masterstudie Complimentary, Psychosocial and Integrated Health Sciences in het Oostenrijkse Graz welke zij in 2011 afrondde. In 2010 keerde Antje terug naar Nederland en werkte als supervisor van de afdeling Fysiotherapie bij Thermae2000 in Valkenburg. In 2011 begon zij aan haar promotietraject op de afdeling reumatologie van het Maastricht Universitair Medisch Centrum onder leiding van professor Annelies Boonen, professor Rob de Bie en professor Sjef van der Linden. Tijdens haar promotieonderzoek volgde zij tevens de masterstudie Public Health met de studierichting Epidemiologie. Ze behaalde het bijbehorende diploma in 2013. Ook werden diverse cursussen gevolgd om haar wetenschappelijke competenties verder te ontwikkelen. Haar onderzoeksresultaten werden op nationale en internationale congressen gepresenteerd. Haar wetenschappelijke inspanningen resulteerden in dit proefschrift. 




\section{List of publications}

Impact of chronic diseases and multimorbidity on health and healthcare costs: the additional role of musculoskeletal disorders ; Antje van der Zee-Neuen, Polina Putrik, Sofia Ramiro, Andras Keszei, Rob de Bie, Astrid Chorus, Annelies Boonen, Arthritis Care \& Research (Hoboken) 2016 Dec; 68(12):1823-31

Work outcome in persons with musculoskeletal diseases: comparison with other chronic diseases and the role of musculoskeletal diseases in multimorbidity; Antje van der Zee-Neuen, Polina Putrik, Sofia Ramiro, Andras Keszei, Rob de Bie, Astrid Chorus, Annelies Boonen, BMC musculoskeletal disorders 2017 Jan; 18 (1): 10

Content validity of global measures for at-work productivity in patients with rheumatic diseases: an international qualitative study; Antje van der Zee-Neuen, Sarah Leggett, Annelies Boonen, Dorcas Beaton, Mihai Bojinca, Ailsa Bosworth, Sabrina Dadoun, Bruno Fautrel, Sofia Hagel, Catherine Hofstetter, Diane Lacaille, Denise Linton, Carina Mihai, Ingemar F Petersson, Pam Rogers, Carlo Sciré, Suzanne MM Verstappen, Rheumatology (Oxford). 2016 Aug; 55(8): 1364-73'

Test-retest Reliability and Correlations of 5 Global Measures Addressing At-work Productivity Loss in Patients with Rheumatic Diseases; Sarah Leggett, Antje van der Zee-Neuen, Annelies Boonen, Dorcas E Beaton, Mihai Bojinca, Ailsa Bosworth, Sabrina Dadoun, Bruno Fautrel, Sofia Hagel, Catherine Hofstetter, Diane Lacaille, Denise Linton, Carina Mihai, Ingemar F Petersson, Pam Rogers, Jamie C Sergeant, Carlo Sciré, Suzanne M M Verstappen, J Rheumatol. 2016 Feb; 43(2): 433-9

Effects and costs of an intensive return to work program for patients with recent sick leave due to musculoskeletal disorders; Antje van der Zee-Neuen, Sjef van der Linden, Andras Keszei, Rob de Bie, Nico Wolter, Pieter Rodenburg, Annelies Boonen, submitted.

Large country differences in work outcomes in patients with RA - an analysis in the multinational study COMORA; Antje van der Zee-Neuen, Polina Putrik, Sofia Ramiro, Andras P. Keszei, Ihsane Hmamouchi, Maxime Dougados, Annelies Boonen, submitted 
